INEEL/EXT-2000-01147

September 2000

\title{
Direct Push Groundwater Circulation Wells for Remediation of BTEX and Volatile Organics
}

\author{
R. C. Borden \\ R. S. Cherry
}




\title{
Direct Push Groundwater Circulation Wells for Remediation of BTEX and Volatile Organics
}

\author{
Robert C. Borden (North Carolina State University) \\ Robert S. Cherry (INEEL)
}

Published September 2000

Idaho National Engineering and Environmental Laboratory Idaho Falls, Idaho 83415

Prepared for the

U.S. Department of Energy

National Petroleum Technology Office

Under DOE Idaho Operations Office

Contract DE-AC07-99ID13727 


\section{ABSTRACT}

Direct push groundwater circulation wells (DP-GCW) are a promising technology for remediation of groundwater contaminated with dissolved hydrocarbons and chlorinated solvents. In these wells, groundwater is withdrawn from the formation at the bottom of the well, aerated and vapor stripped and injected back into the formation at or above the water table. Previous field studies have shown that: (a) GCWs can circulate significant volumes of groundwater; and (b) GCWs can effectively remove volatile compounds and add oxygen.

In this work, we describe the development and field-testing of a system of DP-GCWs for remediation of volatile organics such as benzene, toluene, ethylbenzene, and toluene (BTEX). The GCWs were constructed with No. 20 slotted well screen $(2.4 \mathrm{~cm}$ ID) and natural sand pack extending from 1.5 to $8.2 \mathrm{~m}$ below grade. Air is introduced $\sim 7.5 \mathrm{~m}$ below grade via $0.6 \mathrm{~cm}$ tubing. Approximately $15 \%$ of the vertical length of the air supply tubing is wrapped in tangled mesh polypropylene geonet drainage fabric to provide surface area for biological growth and precipitation of oxidized iron. These materials were selected to allow rapid installation of the GCWs using $3.8 \mathrm{~cm}$ direct push Geoprobe ${ }^{\circledR}$ rods, greatly reducing well installation costs.

Laboratory testing of these sparged wells and computational fluid dynamics (CFD) modeling showed that these wells, although they used only about $1 \mathrm{~L} / \mathrm{min}$ of air, could circulate about $1 \mathrm{~L} / \mathrm{min}$ of water through the surrounding aquifer. This flow was sufficient to capture all of a flowing contaminant if the wells are sufficiently closely together, about 1 meter on center depending on the air flow rate supplied, in a line across the plume. The CFD work showed the details of this ability to capture, and also showed that unforeseen heterogeneities in the aquifer such as a gradient of permeability or a thin impermeable layer (such as a clay layer) did not prevent the system from working largely as intended.

The system was tested in a petroleum contaminated aquifer near Rocky Point, NC. The contaminant plume there is approximately $10 \mathrm{~m}$ deep, $50 \mathrm{~m}$ wide and contains up to $4 \mathrm{mg} / \mathrm{L}$ total BTEX and $75 \mathrm{mg} / \mathrm{L}$ dissolved iron. An extensive pilot test was first performed to estimate the zone of influence for a single well. At this site an air injection rate of $1.2 \mathrm{~L} / \mathrm{min}$ resulted in a water flow rate of 1 to $2 \mathrm{~L} / \mathrm{min}$ based on bromide dilution tests in the GCW. The GCW increased the dissolved oxygen concentration in the discharge water to between 6 and $8 \mathrm{mg} / \mathrm{L}$ and reduced contaminant concentrations to less than $20 \mu \mathrm{g} / \mathrm{L}$ total BTEX. Monitoring results from a 73 day pilot test were then used to define the zone of influence for a single DP-GCW and to design a full scale barrier system. 


\section{CONTENTS}

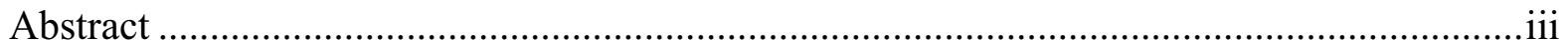

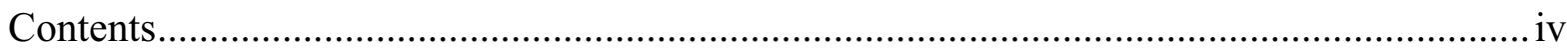

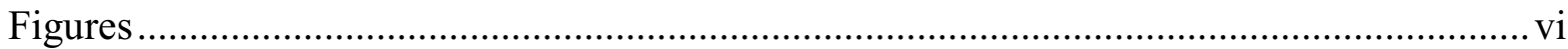

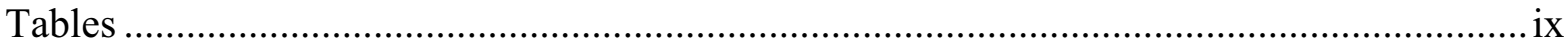

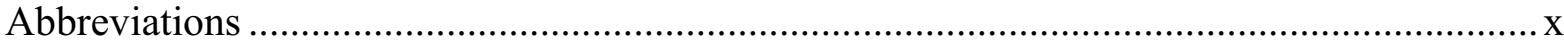

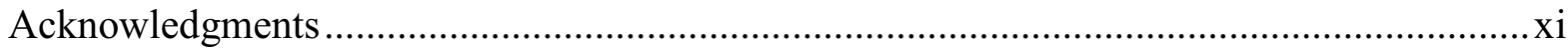

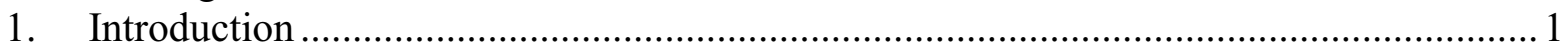

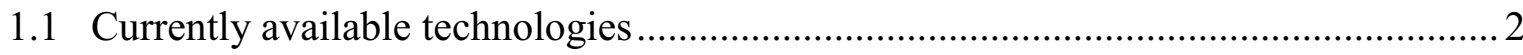

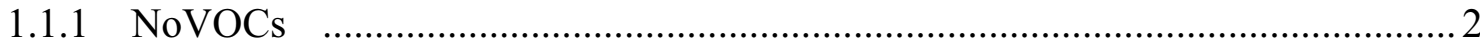

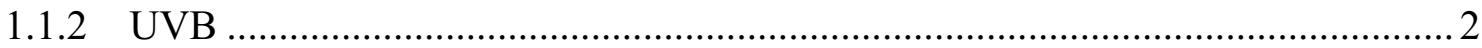



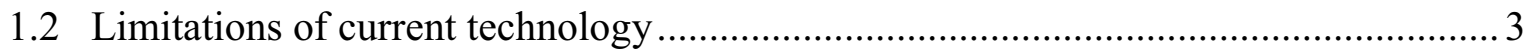



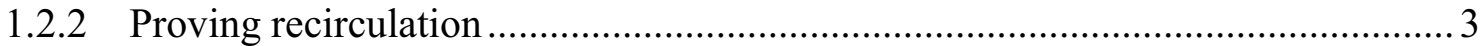

1.2.3 In-well processes .................................................................................... 3

1.3 New approach to the problem .......................................................................... 4

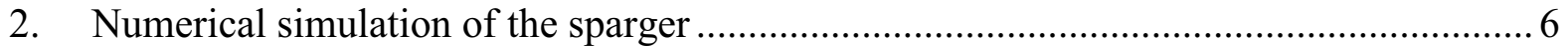





2.3 Isolated sparger in constant permeability soil ...................................................... 8

2.4 Isolated sparger in variable permeability soil ....................................................... 11

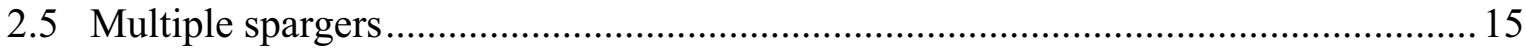



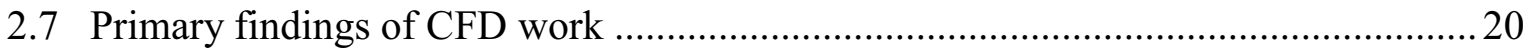

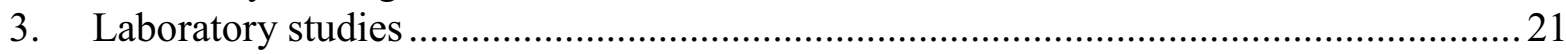

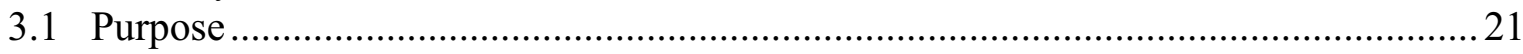

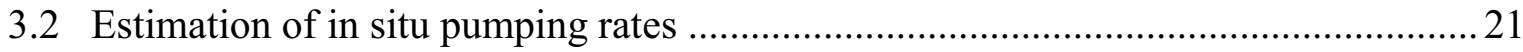

3.2.1 Water flowrate vs. headloss in a vertical circulation well................................. 21

3.2.2 Head produced by air lift pump (DP-GCW) ................................................ 22



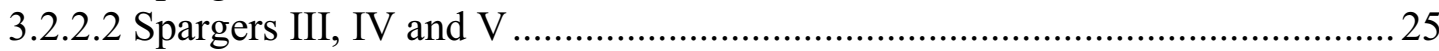

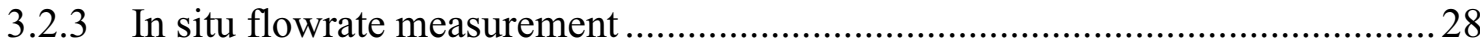

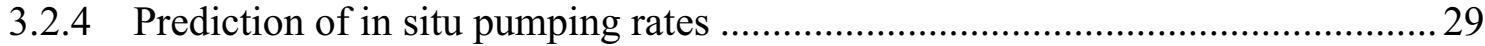



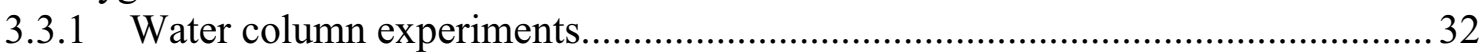

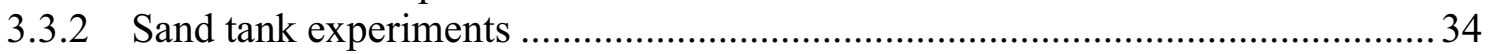

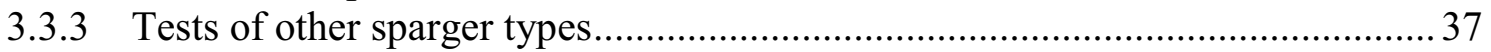

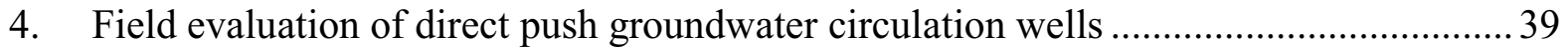



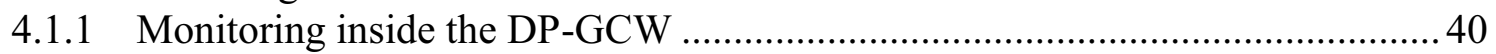

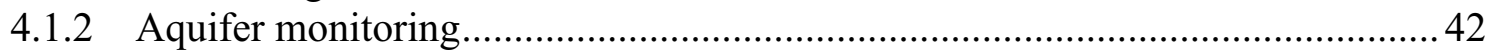

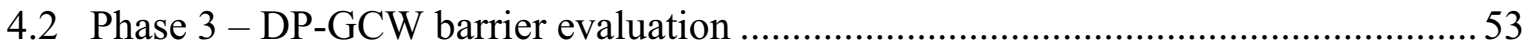

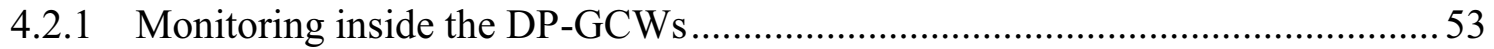

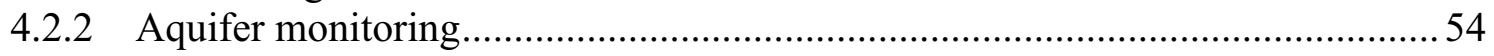




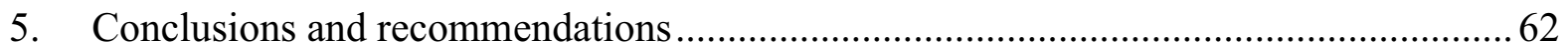

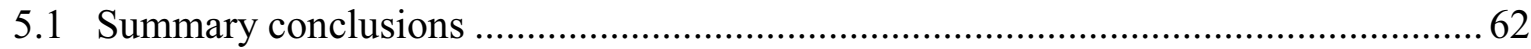

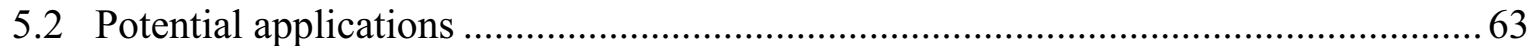

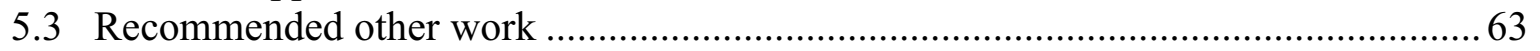

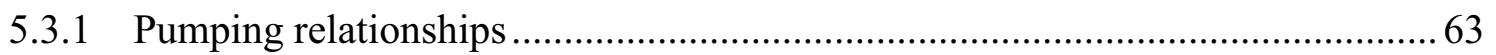

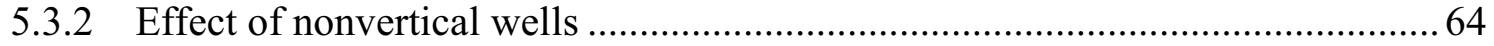

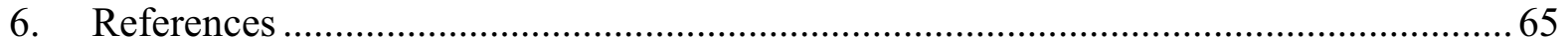




\section{FIGURES}

1.1 Typical in-well aeration application. 2

2.1 Schematic of the model for the sparger and surrounding soil showing the inflow and outflow planes of the aquifer, the water table, the bottom plane and the near and far planes of symmetry. The width of the computational domain is the distance halfway to the adjacent sparger for the case of multiple spargers.

2.2 Massless particle traces for four sets of particles inserted from the inflow plane showing how the particles are captured by the sparger for the constant permeability case. .......... 9

2.3 Massless particle traces for four sets of particles inserted into the outflow plane and moved backwards to show from where the particles came.

2.4 Capture window at the inlet of the computational domain, for the constant permeability case, showing which particles (equivalent to streamlines) will be captured by the sparger. Outflow area at the outlet of the computational domain shows which particles were captured by the sparger.

2.5 Distribution of vertical volumetric flow rate of liquid through the sparger for the constant permeability case.

2.6 Vertical distribution of horizontal permeability for the variable permeability study. The permeability in the vertical direction is locally half that for the horizontal direction..... 12

2.7 Vertical variation of the contaminated water flow for the variable permeability case used for the far field boundary conditions in the simulation.

2.8 Massless particle traces for five sets of particles inserted from the inflow plane showing how the particles are captured by the sparger for the variable permeability case.

2.9 Capture window at the inlet of the computational domain for the constant permeability case showing which particles will be captured by the sparger. Outflow area at the outlet of the computational domain shows which particles were captured by the sparger. ..... 14

2.10 Distribution of vertical volumetric flow rate of liquid through the sparger for the variable permeability case compared to the constant permeability case.

2.11 Capture windows for water at the inflow boundary plane that is eventually captured by the sparger. Shown are the half-spacing cases of $6,2,1,0.5$, and 0.45 meters. ............ 15

2.12 Capture window for the $0.45 \mathrm{~m}$ half-spacing at the inflow boundary and the window of outflow at the outflow boundary.

2.13 Distribution of vertical volumetric flow rate of contaminated water through the sparger for the half-spacing cases of $6,2,1,0.5$, and 0.45 meters.

2.14 Massless particles traces for five sets of particles inserted from the inflow plane showing how particles are captured by the sparger for the $0.45 \mathrm{~m}$ half spacing case...... 17

2.15 Capture window for the $0.45 \mathrm{~m}$ half-spacing at the inflow boundary and the window of outflow at the outflow boundary with halved aquifer flow velocity.

2.16 Massless particle traces for a set of particles inserted from the inflow plane at $17.5 \mathrm{~cm}$ from the near symmetry plane showing how the particles are captured and recirculated by the sparger for the $0.45 \mathrm{~m}$ half spacing case for the halved aquifer flow rate.

2.17 Massless particles traces for a set of particles inserted from the inflow plane for the impermeable layer case showing how the impermeable layer causes the sparger to behave as if it were two spargers.

3.1 Dimensionless flow rate as a function of dimensionless well radius......................... 22

3.2 Schematic of Sparger I 
3.3 Lift versus water flowrate produced by Sparger I for several different air flowrates..... 24

3.4 Lift versus water flowrate produced by Sparger II for several different air flowrates....25

3.5 Relative lift versus water flowrate produced by Sparger III for three different air

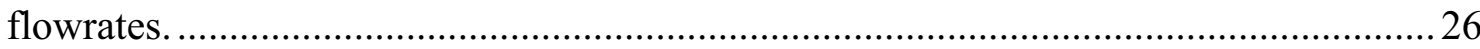

3.6 Relative lift versus water flowrate produced by Sparger IV for three different air



3.7 Relative lift versus water flowrate produced by Sparger V for three different air

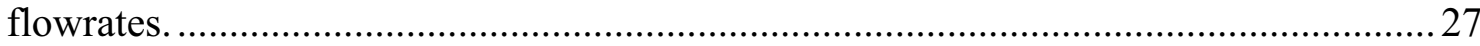

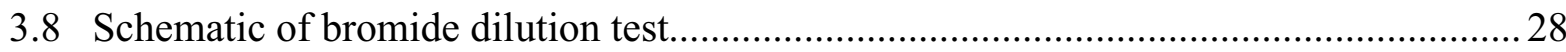

3.9 Comparison of predicted and observed in situ pumping rates for Sparger III. .................30

3.10 Comparison of predicted and observed in situ pumping rates for Sparger IV ................. 31

3.11 Comparison of predicted and observed in situ pumping rates for Sparger V. ..................31

3.12 Typical oxygenation rate data from water column tests .................................................32

3.13 Configuration of sampling tubes and sparger in the sand tank …................................. 35

3.14 DO response in sampling wells of Figure 3.13 at $25 \mathrm{~L} / \mathrm{min}$ air flow to Sparger I. .......... 36

3.15 Water level in sand tank along the face (H0-180) and width (H90-270) of Sparger I.... 37

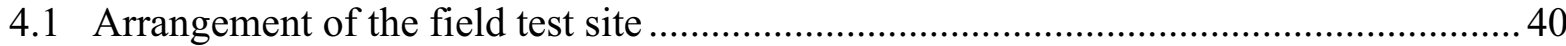

4.2 Variation in dissolved oxygen concentrations inside the DP-GCW during Phase 2 ...... 41

4.3 Variation in total BTEX concentrations inside the DP-GCW during Phase 2.................4 41

4.4 Total BTEX concentration at each sampling depth vs time for MLS-7 ..........................4 43

4.5 Total BTEX concentration in multilevel samplers at $7 \mathrm{ft} \mathrm{BGS} \mathrm{before} \mathrm{air} \mathrm{injection} \mathrm{(Oct.}$ 2) and after 73 days of air injection (Dec. 14) in a single DP-GCW (Phase 2) located at $\mathrm{x}=0 \mathrm{ft}, \mathrm{y}=15 \mathrm{ft}$.

4.6 Total BTEX concentration in multilevel samplers at $12 \mathrm{ft}$ BGS before air injection (Oct. 2) and after 73 days of air injection (Dec. 14) in a single DP-GCW (Phase 2) located at $\mathrm{x}=0 \mathrm{ft}, \mathrm{y}=15 \mathrm{ft}$..

4.7 Total BTEX concentration in multilevel samplers at $17 \mathrm{ft}$ BGS before air injection (Oct. 2) and after 73 days of air injection (Dec. 14) in a single DP-GCW (Phase 2) located at $\mathrm{x}=0 \mathrm{ft}, \mathrm{y}=15 \mathrm{ft}$..

4.8 Total BTEX concentration in multilevel samplers at $22 \mathrm{ft} \mathrm{BGS} \mathrm{before} \mathrm{air} \mathrm{injection} \mathrm{(Oct.}$ 2) and after 73 days of air injection (Dec. 14) in a single DP-GCW (Phase 2) located at $\mathrm{x}=0 \mathrm{ft}, \mathrm{y}=15 \mathrm{ft}$..

4.9 Total BTEX concentration in multilevel samplers at $27 \mathrm{ft}$ BGS before air injection (Oct. 2) and after 73 days of air injection (Dec. 14) in a single DP-GCW (Phase 2) located at $\mathrm{x}=0 \mathrm{ft}, \mathrm{y}=15 \mathrm{ft}$. ....

4.10 Simulated total BTEX distribution in a vertical profile through the DP-GCW running from upgradient (left side) to downgradient (right side). Dark areas are zones with high BTEX concentrations.

4.11 Simulated total BTEX distribution in a horizontal slice through the aquifer at $12 \mathrm{ft}$ BGS. Light areas are zones with low BTEX concentrations where clean oxygenated water has been injected by the DP-GCW. Simulation results are for 75 days after startup of a single DP-GCW. Groundwater flow is from left to right.

4.12 Simulated head distribution and velocity vectors in a vertical profile through a DP$\mathrm{GCW}$. Identical DP-GCWs are located in a line $10 \mathrm{ft}$ on center perpendicular to the groundwater flow direction. 
4.13 Variation in dissolved oxygen concentrations inside the DP-GCWs during Phase 3. Dissolved oxygen concentrations are the average of concentrations measured in S, S1 and $\mathrm{S} 2$ at each depth 53

4.14 Variation in Total BTEX concentrations inside the DP-GCW during Phase 3. .............54

4.15 Total BTEX concentration at each sampling depth vs time for MLS-7 ..........................55

4.16 Total BTEX concentration at each sampling depth vs time for MLS-12.......................55

4.17 Total BTEX concentration in multilevel samplers at $7 \mathrm{ft} \mathrm{BGS} \mathrm{before} \mathrm{air} \mathrm{injection} \mathrm{(Feb.}$ 16) and after 141 days of air injection (July 7) in twelve DP-GCWs (Phase 3)..

4.18 Total BTEX concentration in multilevel samplers at $12 \mathrm{ft} \mathrm{BGS} \mathrm{before} \mathrm{air} \mathrm{injection} \mathrm{(Feb.}$ 16) and after 141 days of air injection (July 7) in twelve DP-GCWs (Phase 3)............58 4.19 Total BTEX concentration in multilevel samplers at $17 \mathrm{ft} \mathrm{BGS} \mathrm{before} \mathrm{air} \mathrm{injection} \mathrm{(Feb.}$ 16) and after 141 days of air injection (July 7) in twelve DP-GCWs (Phase 3)...........59 4.20 Total BTEX concentration in multilevel samplers at $22 \mathrm{ft}$ BGS before air injection (Feb. 16) and after 141 days of air injection (July 7) in twelve DP-GCWs (Phase 3)............60 4.21 Total BTEX concentration in multilevel samplers at $27 \mathrm{ft}$ BGS before air injection (Feb. 16) and after 141 days of air injection (July 7) in twelve DP-GCWs (Phase 3)............61 


\section{TABLES}

3.1 Linear regression results and correlation coefficients $\left(\mathrm{r}^{2}\right)$ for each DP-GCW design and air flowrate

3.2 Bromide dilution test results

3.3 Mass transfer coefficient and pressure drop for Sparger I.

3.4 Water pumping rates from two sets of recirculation time estimates

3.5 Mass transfer coefficient and pumping rate for the wick sparger (WS), collared sleeve (CS), and Geoprobe well screen (Geo). 


\section{ABBREVIATIONS}

\begin{tabular}{|c|c|}
\hline BGS & below ground surface \\
\hline BTEX & benzene, toluene, ethylbenzene, and xylenes \\
\hline CFD & computational fluid dynamics \\
\hline $\mathrm{DDC}$ & Density Driven Convection ${ }^{\circledR}$ well system \\
\hline DO & dissolved oxygen \\
\hline DP-GCW & direct push groundwater circulation well \\
\hline $\mathrm{EPA}$ & Environmental Protection Agency \\
\hline GCW & groundwater circulation well \\
\hline IAS & is-situ air sparger \\
\hline ID & inside diameter \\
\hline INEEL & Idaho National Engineering and Environmental Laboratory \\
\hline $\mathrm{K}$ & hydraulic conductivity \\
\hline LNAPL & light non-aqueous phase liquid \\
\hline MLS & multi-level sampler \\
\hline $\mathrm{NC}$ & North Carolina \\
\hline $\mathrm{NCSU}$ & North Carolina State University \\
\hline $\mathrm{OC}$ & on center \\
\hline OD & outside diameter \\
\hline PVC & polyvinyl chloride \\
\hline PVD & prefabricated vertical drain \\
\hline $\mathrm{r}$ & correlation coefficient \\
\hline TMB & trimethyl benzene \\
\hline UVB & Unterdruck-Verdampfer-Brunner well system \\
\hline
\end{tabular}




\section{ACKNOWLEDGMENTS}

This work was performed by the Idaho National Engineering and Environmental Laboratory and by North Carolina State University for the U.S. Department of Energy's National Petroleum Technology Office under DOE Idaho Operations Office Contract DE-AC07-99ID13727.

The work at INEEL was done by a team which included Robert S. Cherry, who managed the project and provided mass transfer expertise; Richard W. Johnson, who did the computational fluid dynamics work; and Karl Noah, who did the sparger tank and column experiments.

At NCSU, the project was led by Professor Robert Borden. Three MS students did thesis work on this project. Mary Ann B. Vergonio did much of the work with the Sparger I design. C. Tyrus Clayton, Jr. did a great deal of laboratory measurement of flow rates as well as supported the field work using multiple spargers. Elizabeth R. Stewart also assisted with data collection and modeling of the field results in the later stages of this project.

Special thanks go to Heide and Lisa Richardson for providing access to the field site. The American Petroleum Institute provided partial travel support for field work performed as part of this project. 


\section{INTRODUCTION}

Accidental release of fuels, wood preservatives, coal gasification wastes and related materials often results in contamination of shallow aquifers with a wide variety of hydrocarbons. At many sites, natural bioattenuation processes are effective in controlling the downgradient migration of these contaminants (Borden, 1994; Borden et al., 1995 and 1997; Rifai et al., 1995). However at some sites, natural bioattenuation processes are not fully effective and active remediation measures are required to reduce risks to human and environmental receptors.

Enhanced aerobic bioremediation is one of the most effective techniques for remediation of non-aqueous phase and liquid hydrocarbons. Most hydrocarbons are readily biodegraded by subsurface microorganisms under aerobic conditions (Lee et al., 1986; Chapelle, 1999). However oxygen exchange rates with the subsurface are low so oxygen must be added to increase the rate of contaminant biodegradation.

Two of the most common methods of adding dissolved oxygen to aquifers are in situ air sparging (IAS) and groundwater circulation wells. IAS is the direct injection of air into an aquifer below the water table (Johnson et al., 1993). The injected air then rises through the aquifer enhancing volatilization and oxygen exchange. IAS typically results in a roughly cone shaped zone of influence with the point of the cone at the air injection point and the widest portion of the cone near the water table. When light non-aqueous phase liquids (LNAPLs) are present near the water table, IAS can provide effective treatment of the LNAPL zone with a reasonable number of wells. However it can be more difficult to provide effective treatment at significant depths below the water table because of the narrow zone of influence near the air injection point.

Groundwater circulation wells (GCWs) operate by: (1) withdrawing contaminated groundwater from the aquifer (typically near the bottom of the well); (2) treating the contaminated water in the well by aeration, air stripping, carbon adsorption and/or biological treatment; and then (3) discharging the treated water at a different depth in the aquifer (typically near the water table). This induces a circulating flow field that carries clean water and oxygen throughout the contaminated regions of the aquifer.

Figure 1.1 shows the basic design of most GCWs. Air is injected into the bottom of the well reducing the density of water-gas mixture and reducing the fluid pressure at the bottom of the well. This draws water into the bottom of the well from the surrounding aquifer and induces an upward flow of water in the well similar to an air-lift pump or aquarium filter. As the water and gas mixture moves upward through the well casing, oxygen is transferred into the water and volatile contaminants are removed. The partially treated water then flows outward at the top of the well and is recirculated through the aquifer. Depending on the pumping rate of the GCW and the ambient groundwater flowrate through the aquifer, the treated groundwater may circulate through the well several times before migrating out of the GCW capture zone. 




Figure 1.1 Typical in-well aeration application (Hinchee, 1994)

\subsection{Currently available technologies}

There are three types of GCWs commonly available through commercial vendors: NoVOCs , UVB, and DDC. All of the systems follow the basic design shown in Figure 1.1. However each vendor has made modifications to the methods used to induce flow and/or treat the groundwater. All of the systems can be modified to release appropriate nutrients or chemicals to the groundwater to enhance desired reactions.

\subsubsection{NoVOCs}

The NoVOCs system was developed at Stanford University (Gvirtzman and Gorelick, 1992) and is distributed by EG\&C Environmental. This system includes: (a) a deflection plate near the water table to induce coalescence of the bubbles; and (b) an above ground component to remove and treat vapors from the well.

\subsubsection{UVB}

The Unterdruck-Verdampfer-Brunnen (UVB) or 'vacuum vaporizer well' system was developed in Germany by IEG Technologies Corporation (Herrling et al., 1991). This system includes: (a) a submersible pump and packer assembly to induce higher water flow rates; and (b) a stripper reactor to achieve more effective stripping and aeration of the water.

\subsubsection{DDC}

The Density Driven Convection (DDC) system was developed and patented by Wasatch Environmental, Inc. In this system, vapors are discharged to the unsaturated zone for treatment and to enhance stripping and/or biodegradation of contaminants present above the water table. 


\subsection{Limitations of current technology}

GCWs have been installed at more than 100 sites throughout the U.S. and Europe and have shown some success in remediating contaminated groundwater (Miller and Roote, 1997; US EPA, 1998). However there are major concerns about the substantial capital cost of these systems and the operational and performance problems that have occurred at some sites. The Naval Research Laboratory recently published a detailed review of the GCW technology (Allmon et al., 1999). The primary concerns raised in this review are summarized below.

\subsubsection{Recirculation}

GCWs work by causing vertical flow through the aquifer. For a GCW to generate significant vertical flow in the aquifer, the ratio of horizontal to vertical hydraulic conductivity (anisotrophy ratio) should be less than 10:1. When the anisotropy ratio is too high, discharged groundwater will not be recaptured at the bottom of the well preventing development of an effective circulation cell. However at some sites, clay layers and other heterogeneities lead to anisotropy ratios of 100:1 or greater. The presence of heterogeneities that reduce vertical permeability can be identified by very detailed site characterization. However these heterogeneities may be present at many sites, reducing the widespread applicability of this technology. In addition, identifying these heterogeneities can greatly increase site characterization costs.

\subsubsection{Proving recirculation}

At present, there are no reliable methods for designing GCW systems to ensure that the systems achieve adequate recirculation. As a consequence, detailed field monitoring is required to prove that recirculation is occurring in the adjoining aquifer. However clearly demonstrating recirculation is difficult because the vertical gradients induced by the GCWs are quite subtle at appreciable distances away from the GCW and cannot be monitored using conventional techniques. As a consequence, evaluation efforts have focused on indirect methods such as monitoring tracer, contaminant and/or indicator parameter concentrations in adjoining wells. While this can be effective, an extensive three-dimensional monitoring network is required to clearly demonstrate vertical circulation. This can substantially increase costs.

\subsubsection{In-well processes}

The physical design of most GCW systems results in certain problems that may reduce the efficiency and/or increase the operation and maintenance issues associated with these systems. While these effects can be mitigated, this increases the system cost and complexity.

In most GCW systems, air and water flow upward through the well. This co-current flow reduces the maximum treatment efficiency of the aeration and volatilization process. As a consequence, multiple passes of groundwater through the GCW may be required for complete treatment of the contaminants if all treatment is to occur within the well.

Aeration of the water in the $\mathrm{GCW}$ changes the $\mathrm{pH}$ and/or redox chemistry of the groundwater and often causes the formation of inorganic precipitates including calcium carbonate and iron hydroxides. Where contaminants are aerobically biodegradable, biological growth may also develop. Both of these processes can lead to clogging of the injection zone and a gradual loss of pumping efficiency. 


\subsection{New approach to the problem}

The objective of this work is to develop a reliable alternative to existing GCW technologies that overcomes the major limitations identified above. Our approach was to develop a very simple, low cost method for construction of GCWs following the basic design shown in Figure 1.1. The low cost would allow us to install sufficient redundancy in the system to overcome some of the problems identified above. To dramatically reduce construction costs, the GCWs would be installed using direct push techniques. There are two commonly used techniques for direct push installation of wells or drains: (1) installation of a prefabricated vertical drain using a large excavator mounted mandrel; and (2) installation of a rigid well screen and casing using a small pickup truck mounted vibratory hammer.

Most prefabricated vertical drains (PVDs) consist of an inner corrugated core to transmit water covered with a filter fabric. The fabric allows water to pass into the drain core while restricting the movement of soil particles that might clog the core. During installation, the PVD is enclosed in a tubular steel mandrel with a small steel anchor plate attached to the PVD at the bottom of the mandrel. The mandrel is then driven in to the soil with a large vibratory hammer mounted on a tracked excavator. When the design depth is reached, the mandrel is extracted leaving the anchor plate and attached PVD in the soil. This procedure is commonly used for installing closely spaced PVDs to enhance consolidation of low permeability sediments. As a consequence, productivity in the field must be very high to keep unit costs low for large installations. The primary disadvantage of this installation approach is the substantial mobilization cost for the required equipment.

Small diameter rigid well screen and casing can be installed using a small vibratory hammer mounted on a pickup truck similar to a Geoprobe or other commercially available equipment. The vibratory hammer is used to drive a hollow steel rod with an expendable point to the design depth. The well screen and casing is inserted into the hollow steel rod dislodging the expendable point and then the rod is removed leaving the well in place. Installation speeds using a pickup-mounted hammer are lower than for an excavator-mounted system. However mobilization and per day costs for the pickup-mounted vibratory hammer are also much lower, so the cost per linear foot of DPGCW installed should be similar for smaller projects.

Two preliminary designs for Direct Push - Groundwater Circulation Wells (DP-GCWs) were developed to match the physical limitations of the commercially available installation equipment. The first DP-GCW design consists of a very coarse open geotextile mesh surrounded by successive layers of progressively finer geotextile fabrics and was designed to allow installation with standard PVD equipment. Air would be supplied to the bottom of the DP-GCW through a small diameter flexible plastic tubing enclosed within the finer geotextile. The coarse inner mesh provides an open pathway for water and air flow. The finer outer geotextile fabrics will capture organic and inorganic precipitates before they can clog the aquifer material and prevent clay and silt size sediments from entering the DP-GCW. The second DP-GCW design consists of 1.0 inch outside diameter slotted PVC screen that contains an inner air supply tube. Other materials may be inserted inside the PVC screen to capture and retain precipitates if needed.

For both DP-GCW designs, the well will be open to the aquifer throughout the full vertical interval without a bentonite seal or packer to inhibit vertical flow in the aquifer immediately adjoining the DP-GCW. This allows the DP-GCW to automatically adjust to changes in water table elevation. As will be shown in Chapter 2, the hydraulics of the DP-GCW cause most of the water to be withdrawn from close to the bottom of the well and discharged close to the water table with very little flow into or out of the well in the mid-depth region. As a consequence, a seal at mid-depth is not necessary to reduce vertical flow as long as the aquifer formation collapses back around the well once 
the outer rod or mandrel is removed. If the formation does not collapse back around the well, then the DP-GCW approach will not be applicable because bentonite seals cannot be easily installed using direct push equipment. At sites where clay layers or other heterogeneities may inhibit vertical flow in the aquifer, additional DP-GCWs may be installed without an air supply to provide high permeability vertical conduits. Installation of the additional DP-GCW will typically be much less expensive than the additional site characterization required to identify any low permeability layers that might be present.

This report presents the results of the preliminary mathematical and laboratory studies conducted to develop the DP-GCW technology and the results of a detailed field evaluation of the DP-GCW technology at a shallow gasoline contaminated aquifer. 


\section{NUMERICAL SIMULATION OF THE SPARGER}

\subsection{Introduction}

Numerical simulation is a way to approximate and visualize what occurs in a fluid flow process. This is especially useful for a process that takes place underground and is difficult to monitor to yield a clear picture of what is happening. The simulations are made for an idealized model which approximates reality but allows the engineer to estimate the effectiveness of his process and see how it works.

In this chapter, a numerical model of a sparger pump is described. The primary assumptions are given along with the physical properties and numerical mesh used. This model is then used to investigate the flow patterns around a sparger, the effects on the flow patterns of putting a number of spargers in a row at various close spacings, the effect of a changing groundwater flow rate on an otherwise constant sparger, and the consequences of two forms of subsurface heterogeneity: a gradient of soil permeability and the presence of a thin impermeable clay layer which prevents the large scale vertical circulation normally generated by groundwater circulation wells.

\subsection{Basic numerical model}

The numerical simulation model is created within a commercial computational fluid dynamics (CFD) code, Fidap [Fidap 1999], which employs the finite element method. Fidap allows the definition of the mesh, the flow conditions, the boundary conditions, and the material properties. The flow is based on the assumption of porous media flow in the surrounding earth. The model is described in terms of the sparger itself, the surrounding soil, and the numerical mesh and boundary conditions.

The region of interest is the aquifer region where there exists a basically horizontal flow of contaminated water. The flow rate is assumed to be $U_{\text {flow }}=1.16 \times 10^{-6} \mathrm{~m} / \mathrm{sec}(0.1 \mathrm{~m} /$ day $)$. Figure 2.1 shows a basic schematic of the sparger pump and surrounding soil model used in the present study. The width and length of the computational region varies depending upon the case being studied. The depth of the region is ten meters, leaving two meters below the sparger to the bottom of the domain. The near plane of symmetry, where the sparger is located, cuts the sparger in half. The far plane of symmetry is an actual plane of symmetry when multiple spargers are assumed; when there is only one sparger, it is simply a far field boundary. The flow problem is assumed to be at steady state. The permeability of the soil is either assumed to be constant or to vary with depth in a known way depending upon the case studied. The horizontal permeability is assumed to be twice the vertical permeability in every case.

The porous media flow equation employed in Fidap for this steady flow is given as

$$
\left(\frac{\rho \hat{c}}{\sqrt{\kappa_{i}}}|\mathbf{u}|+\frac{\mu}{\kappa_{i}}\right) u_{i}=-\frac{\partial p}{\partial x_{i}}+\mu\left[\frac{\partial^{2} u_{i}}{\partial x_{j} \partial x_{j}}+\rho f_{i}\right.
$$

where $\rho$ is the density of the fluid, $\kappa i$ is the permeability in the ith direction, $|u|$ is the velocity magnitude of the flow, $p$ is the pressure, ui is the velocity in the ith direction, and $\mu$ is dynamic viscosity of the water. The first term on the left hand side of the porous flow equation is the Forchheimer (inertial) term which is important when the flow has a relatively high Reynolds number. The constant $\hat{c}$ in the Forchheimer term is set to zero because the Reynolds number is negligible for 
our study. The second term on the left hand side is the well known Darcy term, which is important for low Reynolds number (viscous) flow. The first term on the right hand side is the pressure gradient that develops from the flow. The second term on the right hand side is the Brinkman term which is added for numerical stability. The last term on the right hand side is the body force term, which accounts for the effects of gravity. The values used for the density and viscosity in the soil are those of water $(1000 \mathrm{~kg} / \mathrm{m} 3 ; 1.3 \times 10-3 \mathrm{Ns} / \mathrm{m} 2)$. It is assumed that water flows in the aquifer at a constant rate for constant permeability. For the case of variable permeability studied, an aquifer flow which varies with the permeability is used.

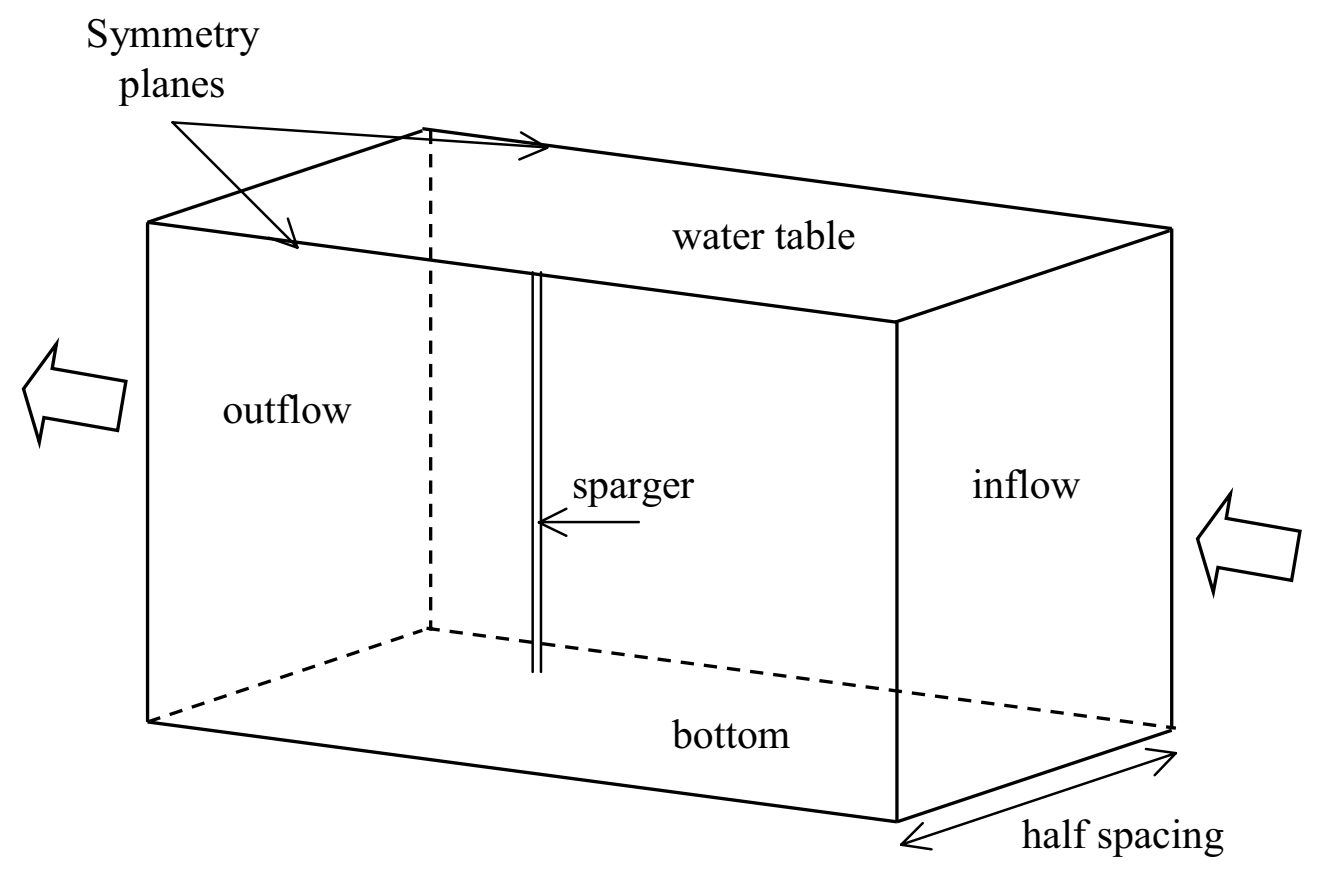

Figure 2.1 Schematic of the model for the sparger and surrounding soil showing the inflow and outflow planes of the aquifer, the water table, the bottom plane and the near and far planes of symmetry. The width of the computational domain is the distance halfway to the adjacent sparger for the case of multiple spargers.

The sparger pump model generally represents the GCW used in the field. The actual GCW is a tube with a $0.0254 \mathrm{~m}(1.0 \mathrm{in}$.) OD and a $0.02032 \mathrm{~m}(0.8 \mathrm{in}$.) ID. The sparger model is $8 \mathrm{~m}$ high, with the top being situated at the water table; the model does not include the region above the water table. To facilitate application of boundary conditions, the geometry of the sparger model and surrounding soil is chosen to be rectangular. To have the same flow area as the actual GCW, a square crosssectioned model, $0.018 \mathrm{~m}$ square, is used for the sparger.

The simulation uses a porous medium flow model inside the sparger, with the permeability there adjusted to give the high flow that an open circular tube would have. The simplified equation for fully-developed laminar incompressible flow in a round tube is [Roberson and Crowe 1985]

$$
\frac{32 \mu \bar{V}}{D^{2}}=-\frac{\partial p}{\partial x}+\rho f
$$


where $\bar{V}$ is the mean velocity, $D$ is the tube diameter, and the remaining symbols are the same as above. Comparing this equation to equation 2.1 for porous medium flow, if one assumes negligible inertial and Brinkman terms, then for a permeability $K$ equal to $\mathrm{D}^{2} / 32$ the two equations are the same. For the inside diameter of $0.02032 \mathrm{~m}$, the equivalent permeability of the pump is $1.29 \times 10^{-5} \mathrm{~m}^{2}$. To simulate the flow resistance of a round tube, the porous flow equation is used for the GCW with this permeability.

The fluid in the well is made to move in the simulation by adjusting its density. The physical GCW pumps air to the bottom of the tube and allows it to percolate upwards, causing a lower fluid density on average in that column of water. By assigning the density of the fluid in the simulated sparger to a value lower than that outside the sparger, the simulation will circulate water, drawing contaminated water into it and upwards as it oxygenates it. It is believed that the error from using a square sparger versus an axisymmetric one is negligible because the flow resistance is based on a round tube and the large scale of the subsurface volume affected by the sparger minimizes the consequences of local flow differences caused by the shape of the well.

The mesh used for the numerical calculations is a three-dimensional rectangular graded mesh. The mesh is uniformly divided into $16 \mathrm{~cm}$ intervals in the vertical direction. The sparger crosssection is $0.018 \mathrm{~m} \times 0.009 \mathrm{~m}$ (cut in half by symmetry planes). The mesh used for the sparger is $6 \times 4$ intervals in a horizontal plane. The intervals are increased in size in both horizontal directions moving away from the sparger. Different cases have different meshes because some require longer up and downstream domains; also, the width of the mesh (half spacing distance) varies depending on the case. Computational times to reach convergence usually in the range of 8 - 9 hours on a Sun Enterprise 5000 Unix workstation.

The boundary conditions applied for the flow domain are that the flow in the main flow direction is $\mathrm{U}_{\text {flow }}$ on the inlet, outlet, and bottom and that the other two velocity components are zero. For the far and near symmetry sides, the horizontal velocity component normal to this plane is set to zero. For the water table boundary, it is assumed that the vertical flow is zero. It is recognized that there actually is flow through the sparger above the water table, which flows outward and back into the saturated zone. However, the region where this occurs is small and the difference between the actual and idealized boundary condition probably has a very small effect on the overall operation of the sparger.

The simulations presented in this chapter are qualitatively good, but should not be used for exact quantitative calculations. When one compares the magnitudes of the terms in the equation above for flow in a tube, the two terms on the right hand side are each of the order of $10^{4} \mathrm{~N} / \mathrm{m}^{2}$. However, the term on the left side is of the order of $10^{1} \mathrm{~N} / \mathrm{m}^{2}$. Hence, the numerical simulation of the sparger is very sensitive to the vertical pressure gradient calculated inside the sparger. Unfortunately, it was found that the flow rate in the sparger can vary by up to a factor of two in an apparently converged run depending on the initial guess for the simulation. Therefore, while it is still believed that the simulations can be used to show trends in the operation of the sparger, their quantitative value may not be dependable.

\subsection{Isolated sparger in constant permeability soil}

The operation of an isolated sparger was modeled to investigate its working characteristics. The computational domain used begins $6 \mathrm{~m}$ upstream of the sparger and ends $6 \mathrm{~m}$ downstream. It is $6 \mathrm{~m}$ wide $(6 \mathrm{~m}$ between symmetry planes) and the standard $10 \mathrm{~m}$ high with the $8 \mathrm{~m}$ sparger. $\mathrm{T}$ he permeability used for the horizontal flow is $6.5 \times 10^{-12} \mathrm{~m}^{2}$; the value for the permeability for vertical flow is half this value. After a converged solution is obtained, post-processing of the solution is 
performed to investigate the flow field. In order to do this, massless particles are introduced into the converged solution for the flow field to see where they migrate as they follow fluid streamlines.

Figure 2.2 illustrates a series of particle paths of massless particles introduced into the flow domain at the upstream boundary. Four sets of particles are introduced at different depths. Each set consists of massless particles is uniformly spaced in the direction perpendicular to the plane of the figure. The lowest set of particles is introduced below the bottom end of the sparger. These particles are seen to be drawn upward by the pull of the sparger, although not all are captured. The next lowest set of particles flow with capture in nearly the same horizontal plane in which they were released. The second highest set of particles is drawn downward where they are captured. Some of the highest set of particles bypass the sparger, but are deflected away and downward as they pass by. The particle lines at the top of the sparger that emanate outwards and downstream are the captured particles which have been drawn up the sparger and expelled near the top. Some are expelled in the upstream direction where they are spread outward and come around the sparger as they head downstream.

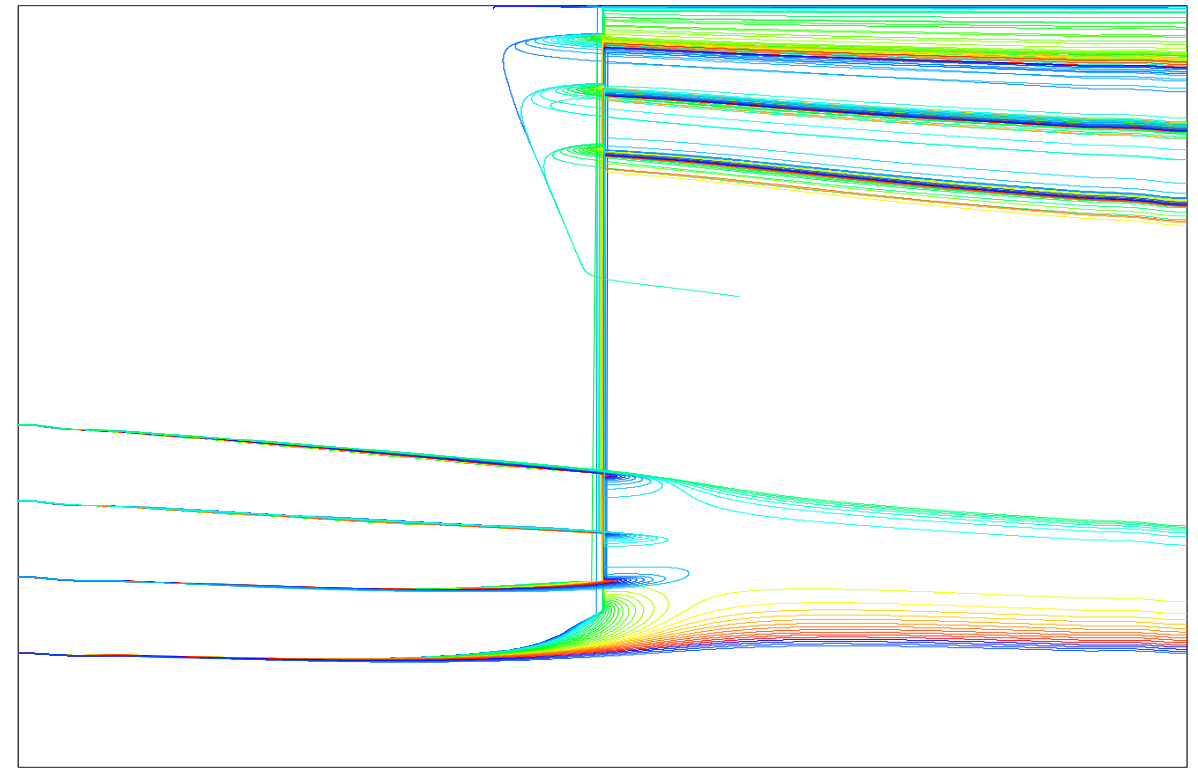

Figure 2.2 Massless particle traces for four sets of particles inserted from the inflow plane showing how the particles are captured by the sparger for the constant permeability case.

Figure 2.3 illustrates four sets of massless particles, which are inserted at the downstream boundary and moved 'backwards' in time to see where they originally came from. Many started near the same depth upstream, but they have been pushed outward and downward as they passed near the sparger. Many of the particles come from the lower end of the sparger where they were drawn in, having migrated from upstream at lower depths. Of course, real particles would not travel exactly as determined by the CFD code because they are well mixed inside the sparger. However, the pathlines outside the sparger are representative of the overall flow field. In a composite portrayal of similar information, Figure 2.4 shows the upstream and downstream windows of water treatment in the GCW. These capture zones are located at the inflow and outflow planes of the simulation, respectively, and contain all the fluid streamlines which eventually enter or came out of the sparger. Fluid near the bottom of the sparger is preferentially captured, with the capture zone spreading about equally horizontally and vertically when not constrained. 


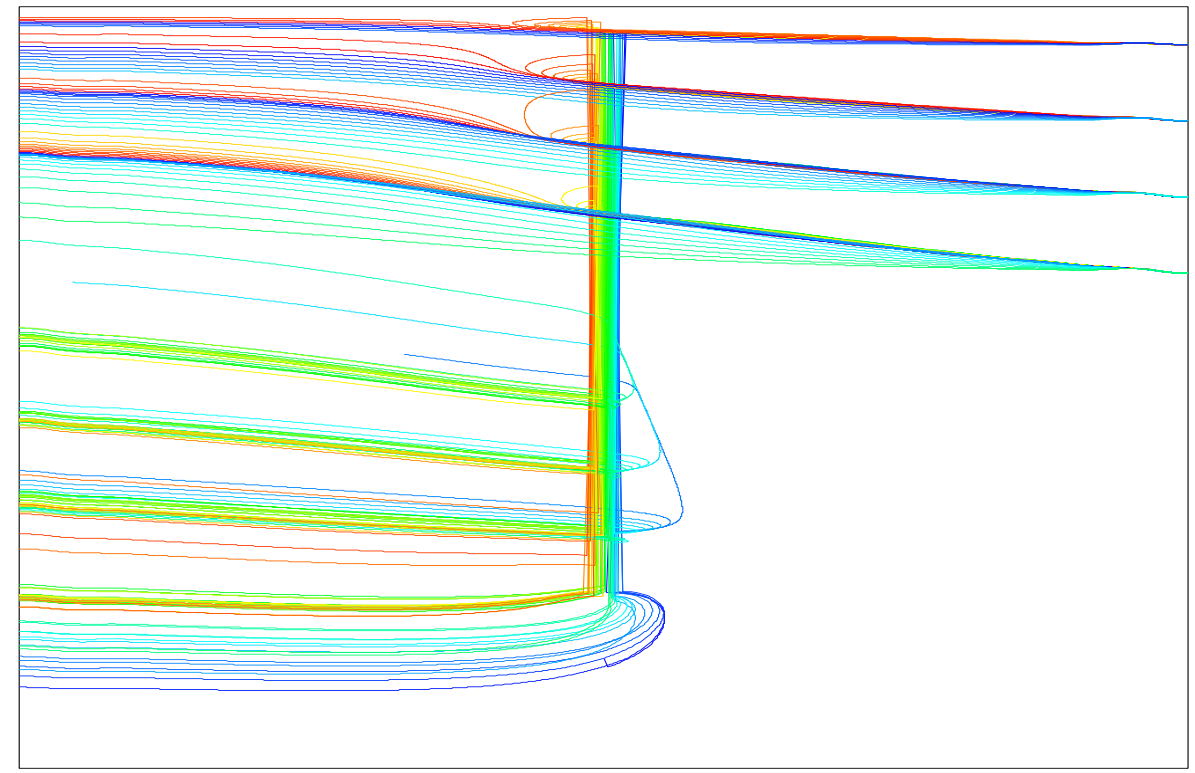

Figure 2.3 Massless particle traces for four sets of particles inserted into the outflow plane and moved backwards to show from where the particles came.

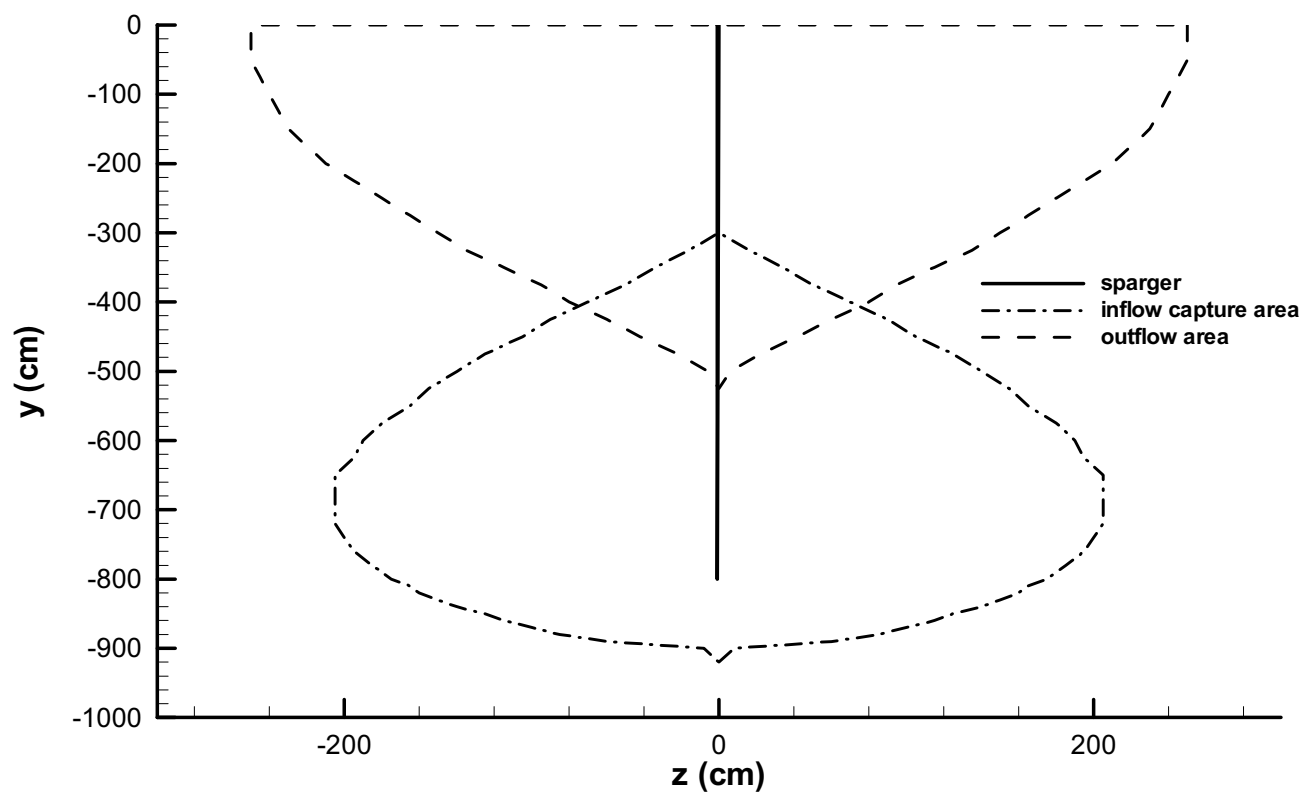

Figure 2.4 Capture window at the inlet of the computational domain, for the constant permeability case, showing which particles (equivalent to streamlines) will be captured by the sparger. Outflow area at the outlet of the computational domain shows which particles were captured by the sparger. 
The volumetric flow rate at different vertical positions inside the sparger is computed using the Fidap postprocessor. Fig ure 2.5 shows the distribution of volumetric flow rate along the length of the sparger. It is seen to be parabolic in shape, indicating (from the derivative of this curve with length along the sparger) that there is a linear variation of the flow into or out of the well along its length.



Figure 2.5 Distribution of vertical volumetric flow rate of liquid through the sparger for the constant permeability case.

\subsection{Isolated sparger in variable permeability soil}

The operation of the isolated sparger of the previous section is now simulated for more realistic conditions by causing the soil permeability to vary in the vertical direction. The distribution is based on field measurements. Figure 2.6 illustrates the data calculated using a cubic B-spline used to approximate the field measurements of permeability. The horizontal flow permeability is highest at the water table and decreases with depth. The permeability in the vertical flow direction is set to be half of the value of the permeability in the horizontal flow direction. The simulation's boundary conditions for the horizontal flow velocity were calculated from the permeability profile assuming the same hydraulic gradient that gave a uniform $0.1 \mathrm{~m} / \mathrm{d}$ groundwater velocity in the base case. Figure 2.7 shows this vertical distribution of the aquifer flow rate. The flow domain is the same as that for the isolated sparger with constant permeability discussed above. 


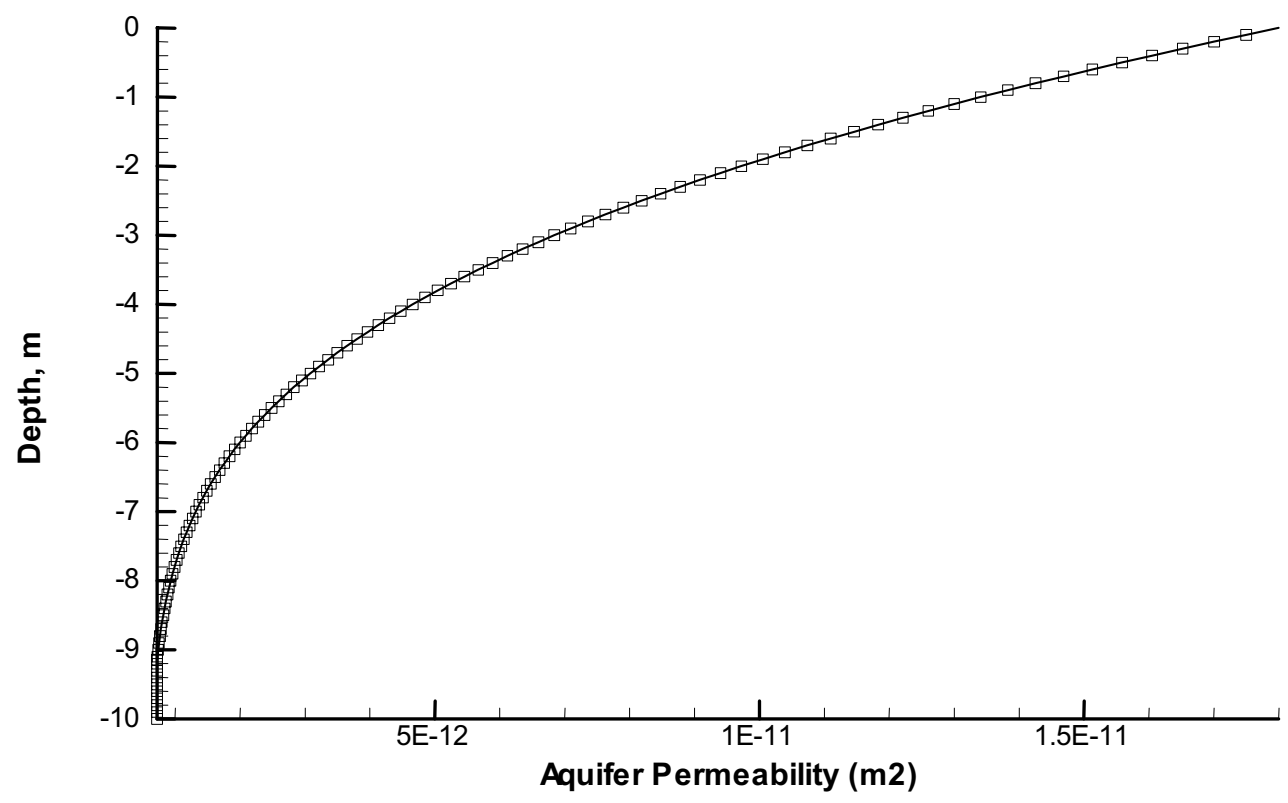

Figure 2.6 Vertical distribution of horizontal permeability for the variable permeability study. The permeability for flow in the vertical direction is locally half that for the horizontal direction.

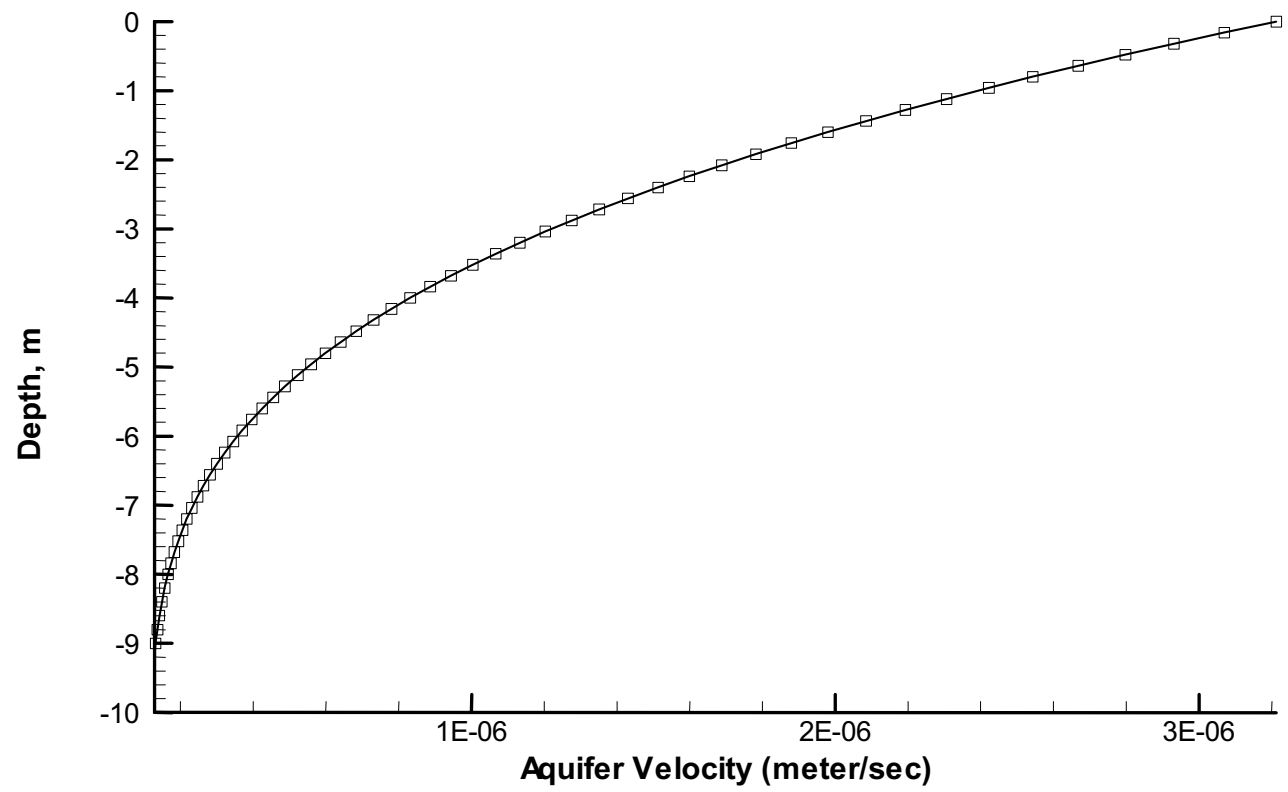

Figure 2.7 Vertical variation of the contaminated water flow for the variable permeability case used for the far field boundary conditions in the simulation. 
Figure 2.8 illustrates the pathlines of five sets of massless particles injected into the flow domain of the steady flow solution. Each set of particles is spaced uniformly in the direction perpendicular to the plane of the figure. As can be seen, the particles that are inserted below the depth of the bottom end of the sparger are drawn upward, with some being captured and others bypassing. The particles that are inserted above the bottom of the sparger are seen to be drawn down and around as some of them are captured by the sparger. The particles drawn up the sparger exit both forward and backward from the sparger as is seen above for the constant permeability case.

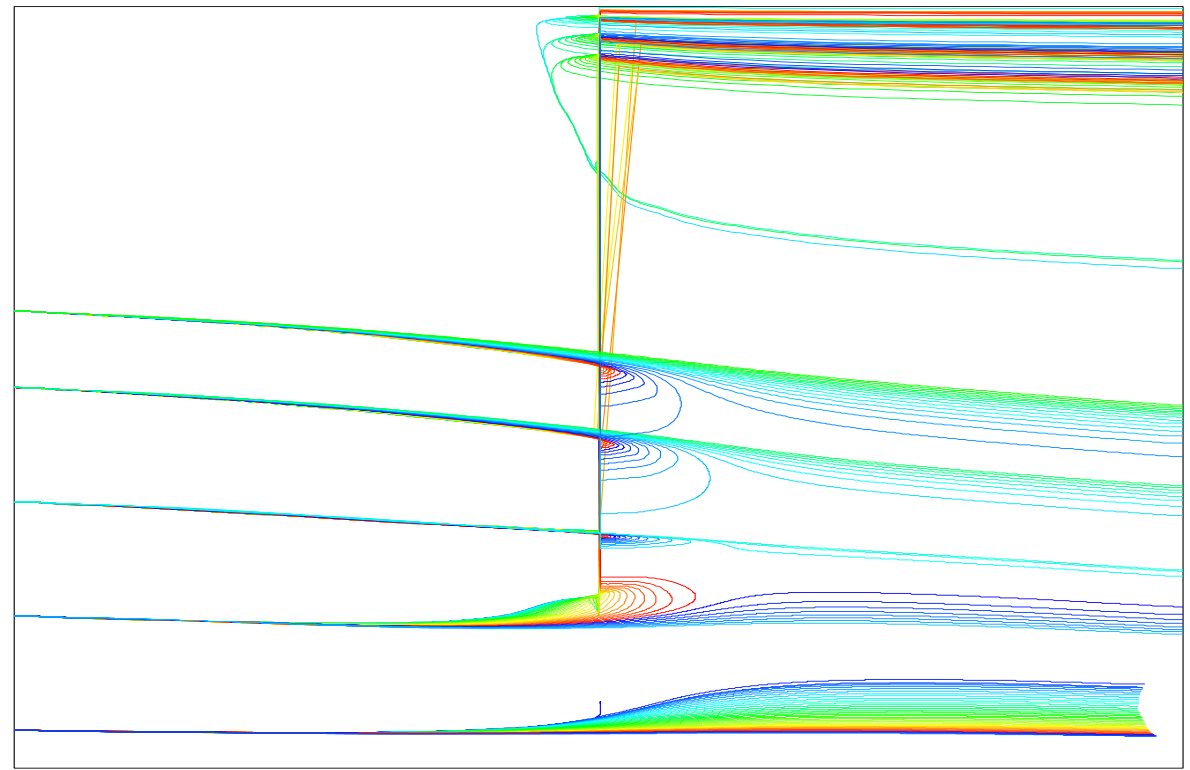

Figure 2.8 Massless particle traces for five sets of particles inserted from the inflow plane showing how the particles are captured by the sparger for the variable permeability case.

Figure 2.9 illustrates the area of capture zone at the inflow plane as well as the outflow window at the simulation's rear plane of those particles that exited the sparger. The areas are analogous to those for the constant permeability case, Fig. 2.4, except that the inflow window is much larger while the outflow window is smaller. The permeability profile requires the velocity of the aquifer flow to be much higher at the top and much lower at the bottom (because of the uniform hydraulic gradient, which does not change with vertical position). Because the velocity is lower in the area near the bottom of the sparger, mass conservation requires that the inflow must come from a larger area, while the outflow conversely requires a smaller area because the flow velocity is faster there. Figure 2.10 illustrates the vertical volumetric flow rate of water inside the sparger for the variable permeability case and is compared to the constant permeability case. As expected, the flow in the lower, tighter portion of the sparger is less for the variable permeability case. 


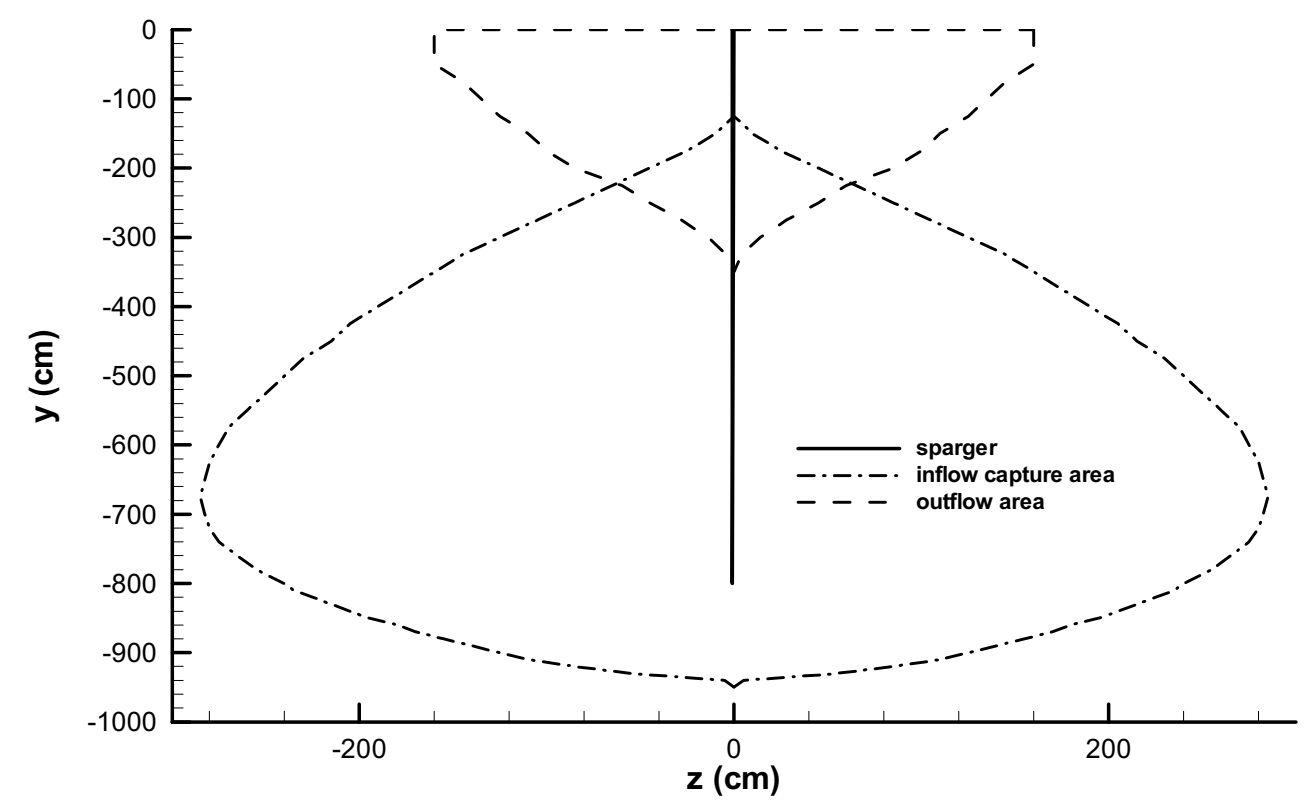

Figure 2.9 Capture window at the inlet of the computational domain for the constant permeability case showing which particles will be captured by the sparger. Outflow area at the outlet of the computational domain shows which particles were captured by the sparger.

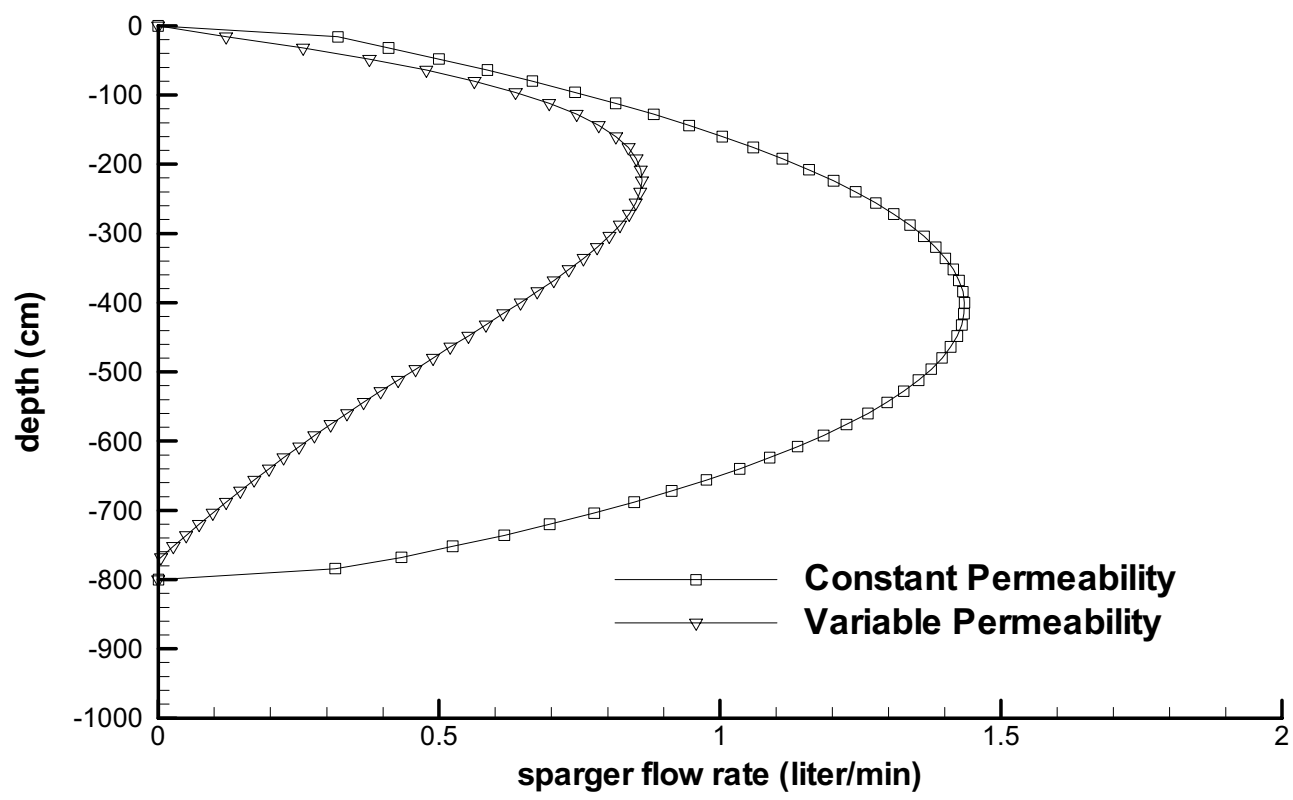

Figure 2.10 Distribution of vertical volumetric flow rate of liquid through the sparger for the variable permeability case compared to the constant permeability case. 


\subsection{Multiple spargers}

Simulations for the case of a line of spargers uniformly spaced in the direction transverse to the flow direction of the aquifer water are performed using the same mesh used for the isolated sparger above. This is because the far symmetry plane can be seen to be the half-spacing between two adjacent spargers. The half-spacing can then be adjusted to see the effects of spacing distance on the sparger and flow field characteristics.

Figure 2.11 illustrates the capture windows for streamlines at the inflow boundary plane. Shown are the sparger half-spacing cases of $6,2,1,0.5$, and 0.45 meters. The same constant permeability used for the isolated sparger in soil with constant permeability is used for these cases; the $6 \mathrm{~m}$ case is discussed in Section 2.3 as the base case simulation. The inflow and outflow planes are $6 \mathrm{~m}$ up and downstream of the sparger, respectively, as before. As the half-spacing is narrowed, the flow field is greatly affected. It can be seen in Fig. 2.11 that the capture window is progressively narrowed in the transverse direction and increased in height in the vertical direction. That is, the flow to the sparger is forced to come from higher in the flow field because competition from adjacent GCWs (represented by the symmetry plane which prevents flow from entering or leaving this simulation space) prevents the well from drawing its required volumetric flow of water from as wide a horizontal region. The $0.45 \mathrm{~m}$ half spacing captures nearly all of the flow.



Figure 2.11 Capture windows for water at the inflow boundary plane that is eventually captured by the sparger. Shown are the half-spacing cases of $6,2,1,0.5$, and 0.45 meters.

The optimal sparger spacing would fully capture the upstream flow, but further simulations with closer spacing were not possible because of time constraints. The trend is clear however. The expected optimal spacing would be such that the volumetric pumping capacity of the well should equal the amount of water to be treated by the well, which in turn should equal the average groundwater velocity times the area of the capture zone. That area is the depth of the sparger times 
the spacing between them. If the well pumps less water than that groundwater flow, some contaminated groundwater would remain untreated. If the well pumps more, some treated water at the top of the well would recirculated to the bottom of the well to be unnecessarily retreated.

Figure 2.12 shows the window of capture for the $0.45 \mathrm{~m}$ half-spacing at the inflow boundary and the window of outflow at the outflow boundary. There is some inflow that is not captured by the sparger for $0.45 \mathrm{~m}$ half spacing. However, due to qualitative nature of these results, it is not possible to state exactly when optimal spacing has been reached. It is expected that some recirculation is desired to ensure that almost all of the water in the aquifer flow is captured by the sparger to achieve nearly complete oxygenation, while keeping pumping costs to a minimum.



Figure 2.12 Capture window for the $0.45 \mathrm{~m}$ half-spacing at the inflow boundary and the window of outflow at the outflow boundary.

Figure 2.13 compares the volumetric flow rate in the sparger for the various sparger half spacings of Fig. 2.11. Clearly, the amount of water pumped by the sparger decreases as the half spacing decreases. This can be explained by a combination of two things. First, with a closer well spacing water can no longer be drawn from the same wide, low region as shown in Figure 2.2. That region is the zone of least resistance for drawing water. Pulling from further away, such as the higher regions of Figure 2.12, means the same volume of water must travel a slightly longer path, with a consequently slightly higher flow resistance and therefore a higher amount of work to be done by the GCW in moving that water. The second effect is the interaction of that extra work and the flow in the GCW. This is addressed in detail in Chapter 3, but for here it is sufficient to know that a modest resistance change can lead to a relatively large change in the amount of water pumped. This is seen in the reduced flows in the more closely spaced wells, although again it must be cautioned that these results should be used only qualitatively. Despite the reduced flow, the GCW at $0.45 \mathrm{~m}$ spacing does pull water from near the aquifer surface, as seen in Figure 2.14. 




Figure 2.13 Distribution of vertical volumetric flow rate of contaminated water through the sparger for the half-spacing cases of $6,2,1,0.5$, and 0.45 meters.

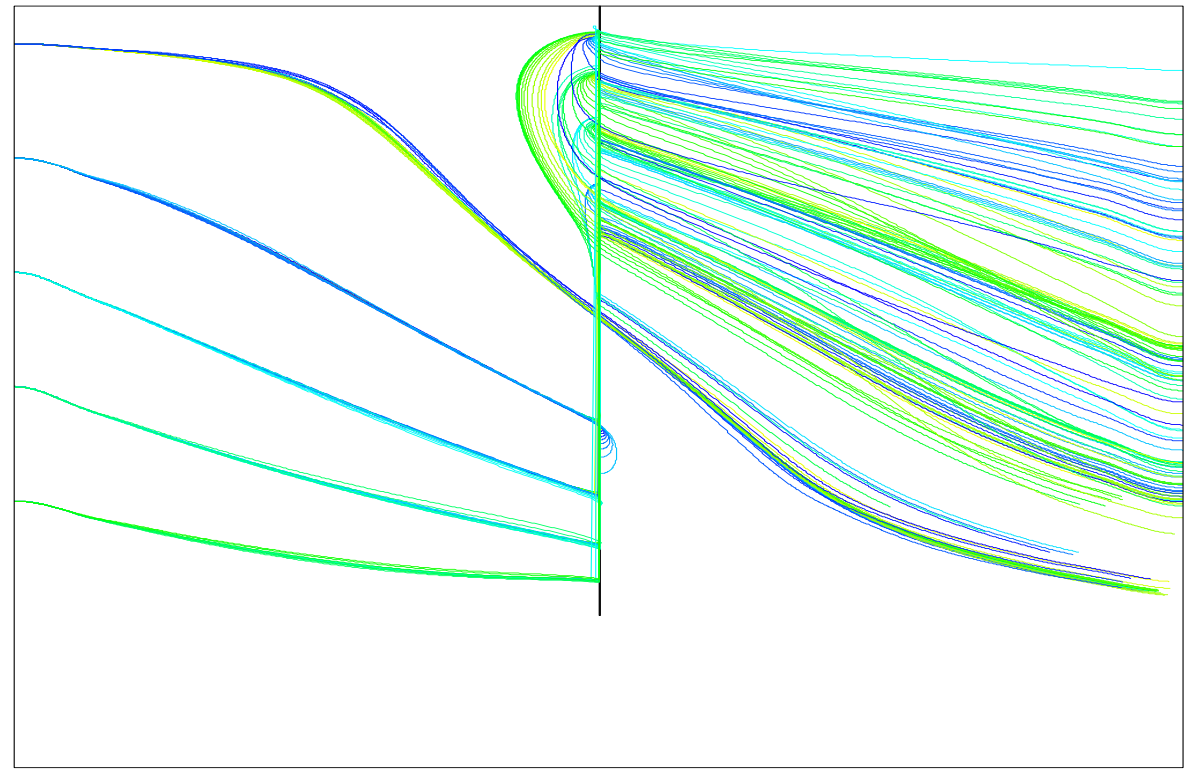

Figure 2.14 Massless particles traces for five sets of particles inserted from the inflow plane showing how the particles are captured by the sparger for the $0.45 \mathrm{~m}$ half spacing case. 


\subsection{Other field variability}

CFD simulations were used to explore two other potential field problems to see how well this GCW system would perform. The first of these was a decrease in the local groundwater velocity with the GCW at unchanged operating conditions. This situation might arise during a drought or if the well was designed based on aquifer data collected during a period of unusually high groundwater velocity.

Figure 2.15 shows the capture window for operation of the sparger at $0.45 \mathrm{~m}$ half spacing but with half the nominal aquifer flow. As can be seen, nearly all the flow down to $980 \mathrm{~cm}$ is captured. Figure 2.16 illustrates the flow of massless particles injected into the inflow plane at a distance of $17.5 \mathrm{~cm}$ to the side of the sparger. As can be seen, there is a significant amount of recirculation, as expected since the well is still trying to move essentially the same amount of water but the aquifer is supplying only half as much. The effect of decreasing the aquifer flow rate is the same as that of decreasing the transverse spacing of the spargers: the capture window is increased to capture more of the flow at the higher elevations. Clearly, the recirculation of the flow must increase until it reaches $100 \%$ as the aquifer flow drops to zero. The complementary case of a two-fold increase in aquifer flow rate shows the same effect as increasing the sparger half spacing: a smaller fraction of the flow through the simulation domain is captured, meaning that in the field some contaminated water would bypass the well and be untreated as it flows downgradient.

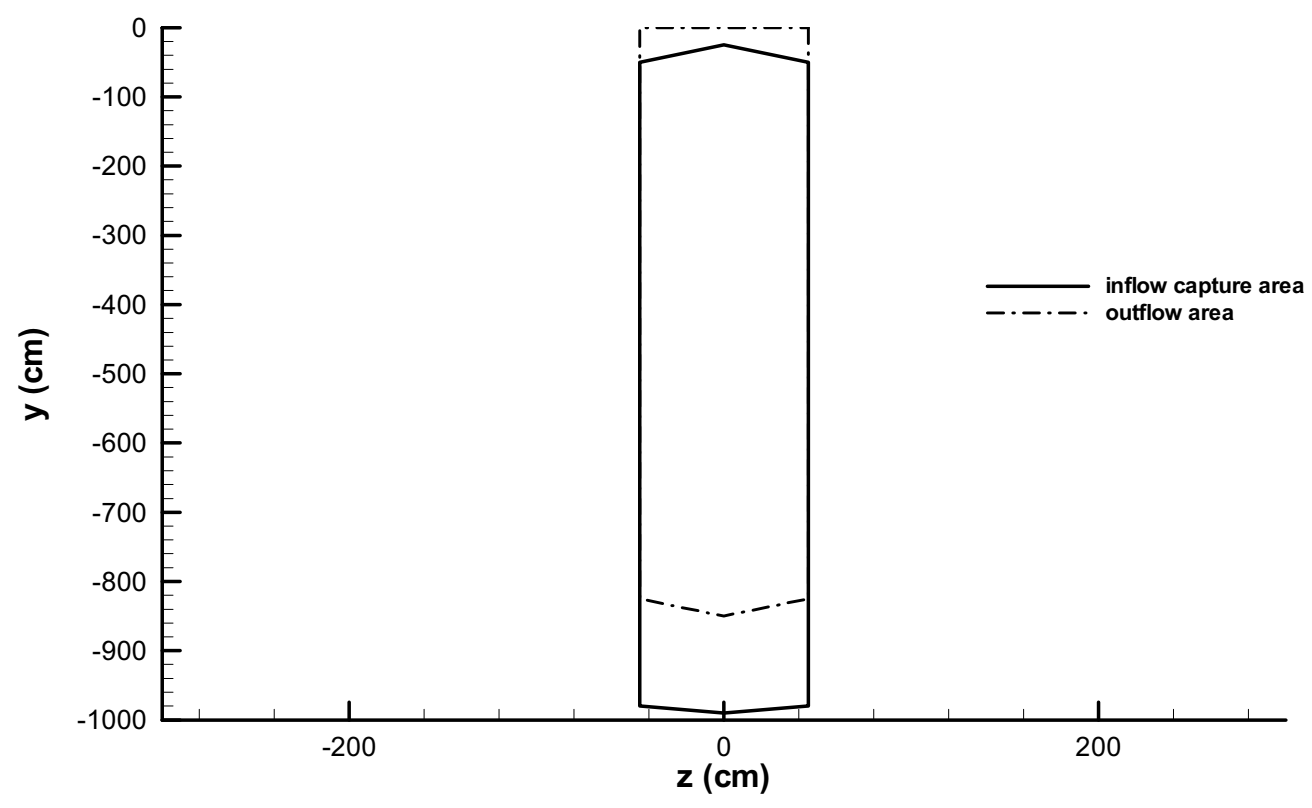

Figure 2.15 Capture window for the $0.45 \mathrm{~m}$ half-spacing at the inflow boundary and the window of outflow at the outflow boundary with halved aquifer flow velocity.

The second scenario tested evaluated the effect of horizontal layers of different permeability which might interfere with the vertical circulation that is the key feature of GCWs. To do this, simulations were run which included a $1 \mathrm{~cm}$ thick layer of solid material at the halfway depth of the sparger $(4 \mathrm{~m})$. The aquifer permeability is also maintained at the same values as for all of the constant permeability cases and the sparger half spacing was $0.5 \mathrm{~m}$. The sparger operation is simulated in this 
case (run early in the overall series of simulations) by setting the gravity term in the porous media flow equation above to zero and $\mu / \kappa_{y}$ in the viscous term to a value of $7.5 \times 10^{-6}$. This had the effect of making the sparger's apparent pumping rate less sensitive to changes in the work it had to do. The first case tested used a permeability in the thin layer of 1000 times larger than the remainder of the aquifer, so the $1 \mathrm{~cm}$ layer was equivalent to $10 \mathrm{~m}$ of regular aquifer. $T$ he shape of the streamlines was not affected significantly, so an impermeable layer was tested. Figure 2.17 shows a side view of massless particle paths for this case. The particles can not penetrate the impermeable layer outside of the sparger so the result is to create two sparger pumps, each $4 \mathrm{~m}$ in depth. For this case, all of the flow in the regions above and below the impermeable layer is captured by the sparger.

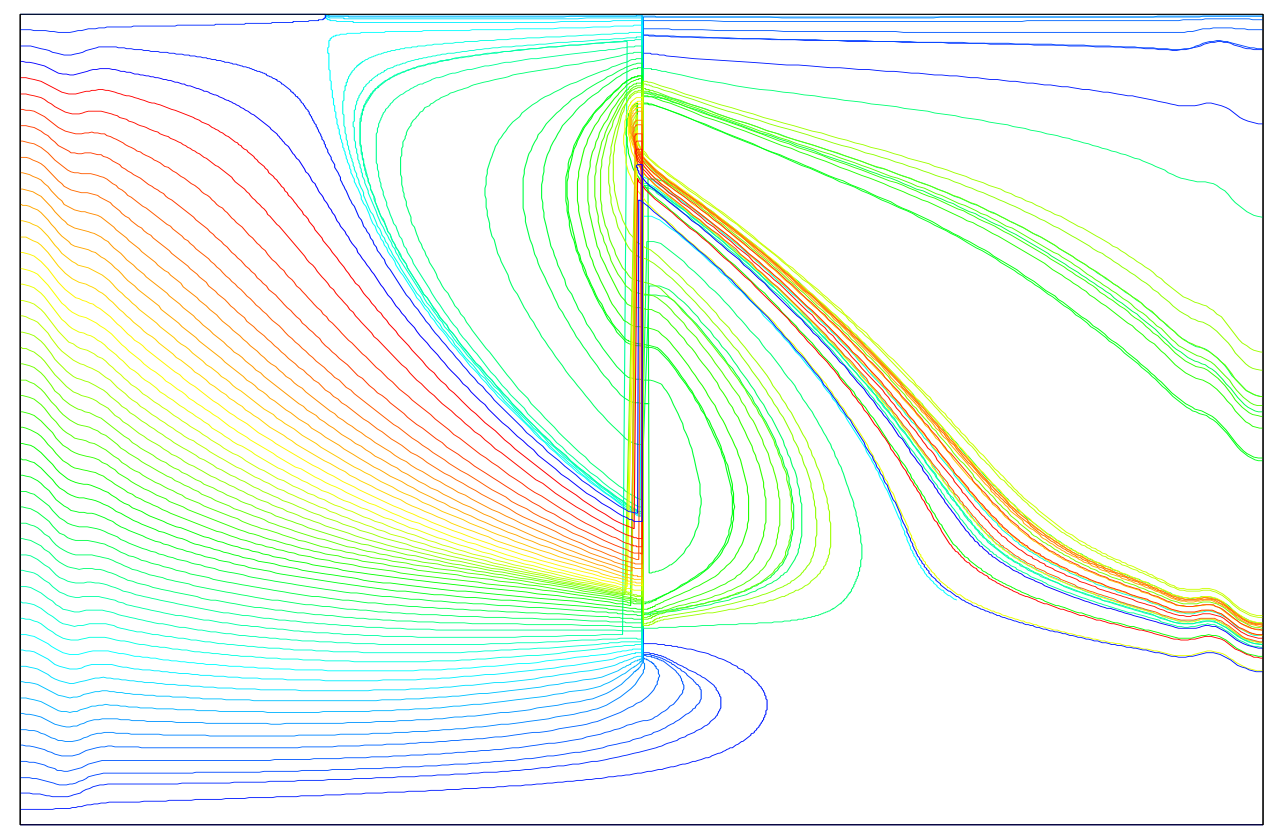

Figure 2.16 Massless particle traces for a set of particles inserted from the inflow plane at 17.5 $\mathrm{cm}$ from the near symmetry plane showing how the particles are captured and recirculated by the sparger for the $0.45 \mathrm{~m}$ half spacing case for the halved aquifer flow rate. 


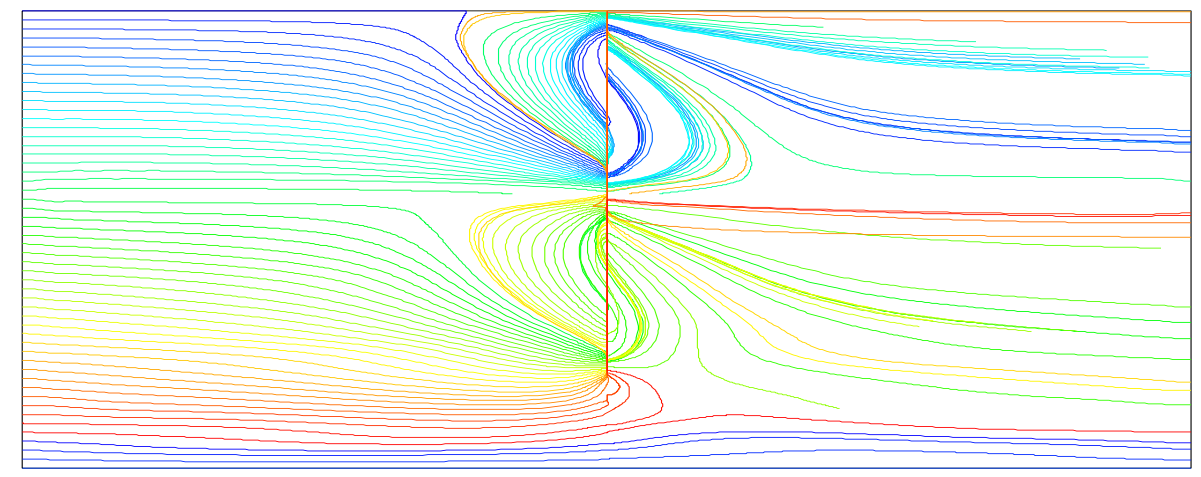

Figure 2.17 Massless particles traces for a set of particles inserted from the inflow plane for the impermeable layer case showing how the impermeable layer causes the sparger to behave as if it were two spargers.

\subsection{Primary findings of CFD work}

The numerical simulation of the operation of a direct push groundwater circulation well leads to the following major results:

- Because of the circulation induced by the well, the flow around a GCW has a distinct downward component on both the upgradient and downgradient side of the well itself.

- The capture window for spargers located in a row increases in height as the spargers are moved closer together, ultimately to the point that all the flow in the aquifer above the depth of the sparger bottom can be captured if the wells are close enough together.

- The sparger flow rates decrease somewhat as spargers are moved closer together in a row

- A decreased aquifer flow has the same effect as moving spargers closer together, that is, more of the flow at the higher elevations is captured. The converse is also true.

- The presence of an impermeable layer causes the sparger pump to operate as if it were two separate sparger pumps, one below and one above the layer. All the contaminated plume can be captured and treated though. 


\section{LABORATORY STUDIES}

\subsection{Purpose}

To develop an understanding of the ability of the various sparger designs to pump water and to add oxygen to that water, laboratory experiments were done in simplified configurations without soil. This made it easier to observe the system in operation and to collect data, and eliminated a factor which complicates the prediction of water pumping performance. This chapter discusses these studies, which were done at both INEEL and NCSU in several types of apparatus.

\subsection{Estimation of in situ pumping rates}

As with any pumping or injection well, the flow rate through the well is a function of the aquifer permeability, well geometry and pumping head supplied. In our system, the pumping head is supplied by air injection into the bottom of the well with higher air flowrates resulting in a greater pumping head. However some relationship is needed to estimate the flowrate through the system as a function of head supplied.

\subsubsection{Water flowrate vs. headloss in a vertical circulation well}

Schrauf and Pennington (1995) developed Equation 3.1 for estimating the water flowrate (Q) through a vertical circulation well assuming a hydrostatic head gradient within the wellbore.

$\mathrm{Q}=\mathrm{Q}_{\mathrm{D}} \Delta \mathrm{H} \mathrm{L} \mathrm{K}$

where

$\mathrm{Q}_{\mathrm{D}} \quad=$ dimensionless flow rate

$\Delta \mathrm{H} \quad=$ difference in head between the top and bottom of the well screen

$\mathrm{L} \quad=$ length of well screen

$\mathrm{K}_{\mathrm{r}} \quad=$ horizontal (radial) hydraulic conductivity

The dimensionless flow rate is a function of the dimensionless well radius $\left(\mathrm{r}_{\mathrm{wD}}\right)$.

$r_{w D}=\left(\frac{r_{w}}{L}\right)\left({\frac{K_{z}}{K_{r}}}^{0.5}\right.$

where

$\mathrm{r}_{\mathrm{w}} \quad=$ well radius

$\mathrm{L} \quad=$ aquifer thickness

$\mathrm{K}_{\mathrm{z}} / \mathrm{K}_{\mathrm{r}} \quad$ = ratio of vertical to horizontal (radial) hydraulic conductivity 
For a 1.0-inch diameter well with a $25 \mathrm{ft}$ long screen and ratio of vertical to horizontal hydraulic conductivity of 0.2 , the dimensionless well radius is 0.0007 . $Q_{D}$ can be estimated from Figure 3.1. For $\mathrm{r}_{\mathrm{wD}}=0.0007, \mathrm{Q}_{\mathrm{D}}$ extrapolates to approximately 0.1 .

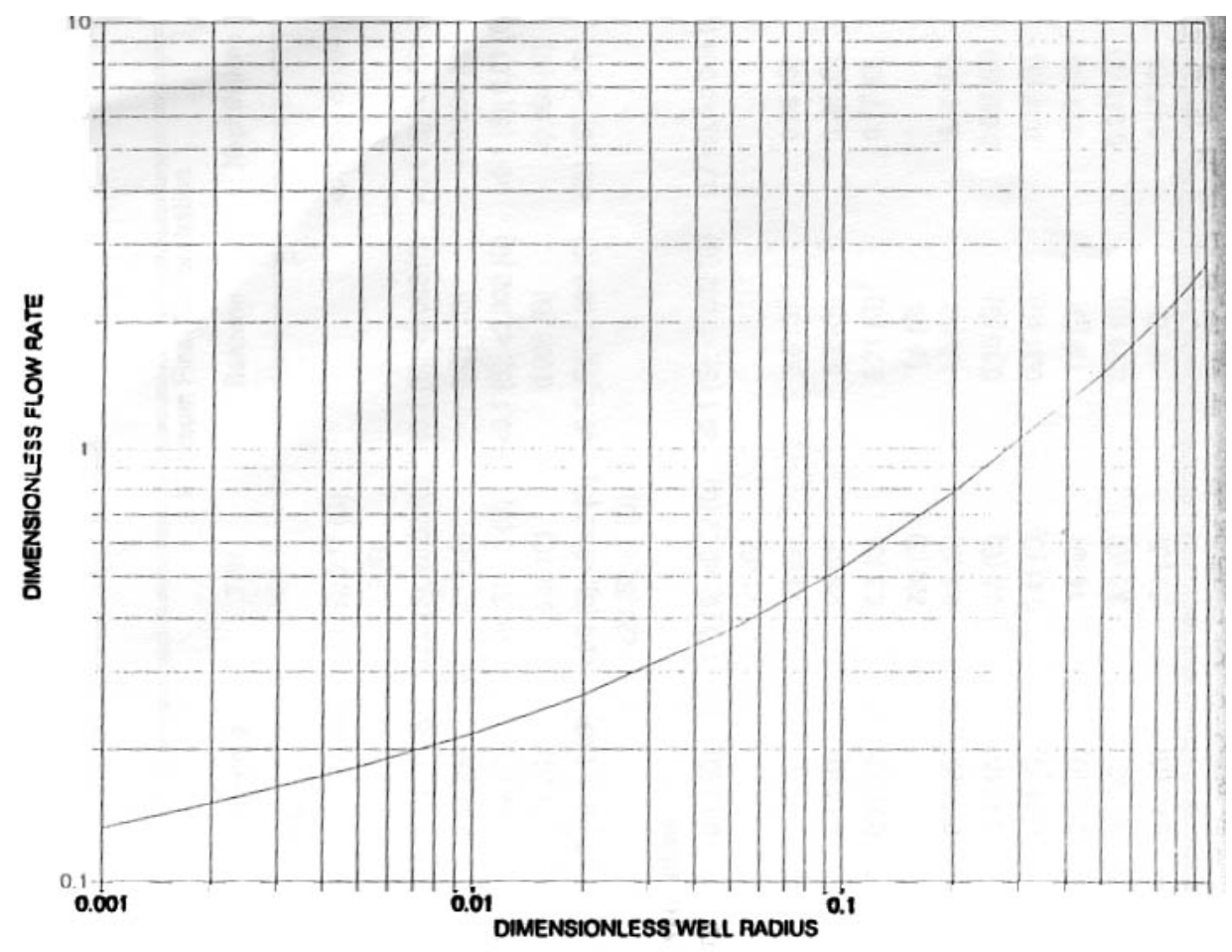

Figure 3.1 Dimensionless flow rate as a function of dimensionless well radius. (Schrauf and Pennington, 1995)

Using this Equation 3.1, the flowrate though the well can be estimated once the pumping head generated $(\Delta \mathrm{H})$, screen length $(\mathrm{L})$, and radial hydraulic conductivity $\left(\mathrm{K}_{\mathrm{r}}\right)$ are known. The radial hydraulic conductivity can be estimated from common site characterization data including slug or aquifer tests. The only unknown is head generated by the GCW for a given air flowrate.

\subsubsection{Head produced by air lift pump (DP-GCW)}

In a DP-GCW, pumping head is supplied by air introduced into the bottom of the well similar to commonly used airlift pumps. Laboratory measurements were conducted to estimate the head generated in five different types of DP-GCWs as a function of water and air flowrate. The first two DP-GCWs (Spargers I and II) were manufactured with geotextile materials sized to allow easy installation using common PVD installation equipment. The next three DP-GCWs (Spargers III, IV and V) were manufactured from 1-inch slotted PVC well screen for installation with a pickup truck mounted vibratory hammer.

\subsubsection{Spargers I and II}

Sparger I was manufactured with four geotextile materials that were layered with the most permeable material at the core (Figure 3.2). The core of Sparger I consisted of three layers of rigid geonet (Tenax Tendrain) with large openings to allow for high water and air flow. The inner core 
was covered on each side with two layers of Enkamat ${ }^{\circledR} 7010$ and then two layers of Landlok $\circledast$ Trm 450. The Enkamat ${ }^{2} 7010$ is a three-dimensional nonwoven geomatrix of heavy nylon monofilaments fused at their intersections. The Landlok ${ }^{\circledR}$ Trm 450 is a dense, three-dimensional nonwoven web of polyolefin fibers. The Enkamat and Landlok materials were included to provide a high surface area for microbial growth and precipitation of inorganic materials that might clog the surrounding aquifer. All three of these geotextile materials were fastened together using cable ties. Air was supplied through 5/16-inch OD flexible tubing fastened to the outside of the geotextiles using cable ties. The end of the air supply line was turned toward the center and fastened 11.3 inches from the bottom. The outermost layer was a woven, polypropylene monofilament geotextile (Geotex SFTM $117 \mathrm{~F}$ ) to keep aquifer material out of the DP-GCW.

Sparger II was similar to Sparger I. However in Sparger II, a coarse bubble air diffuser was installed at the bottom of the DP-GCW to more evenly distribute air bubbles throughout the inner core. The coarse bubble diffuser consisted of 0.5-inch ID PVC pipe with seven 5/64-inch holes evenly spaced on the upper side.

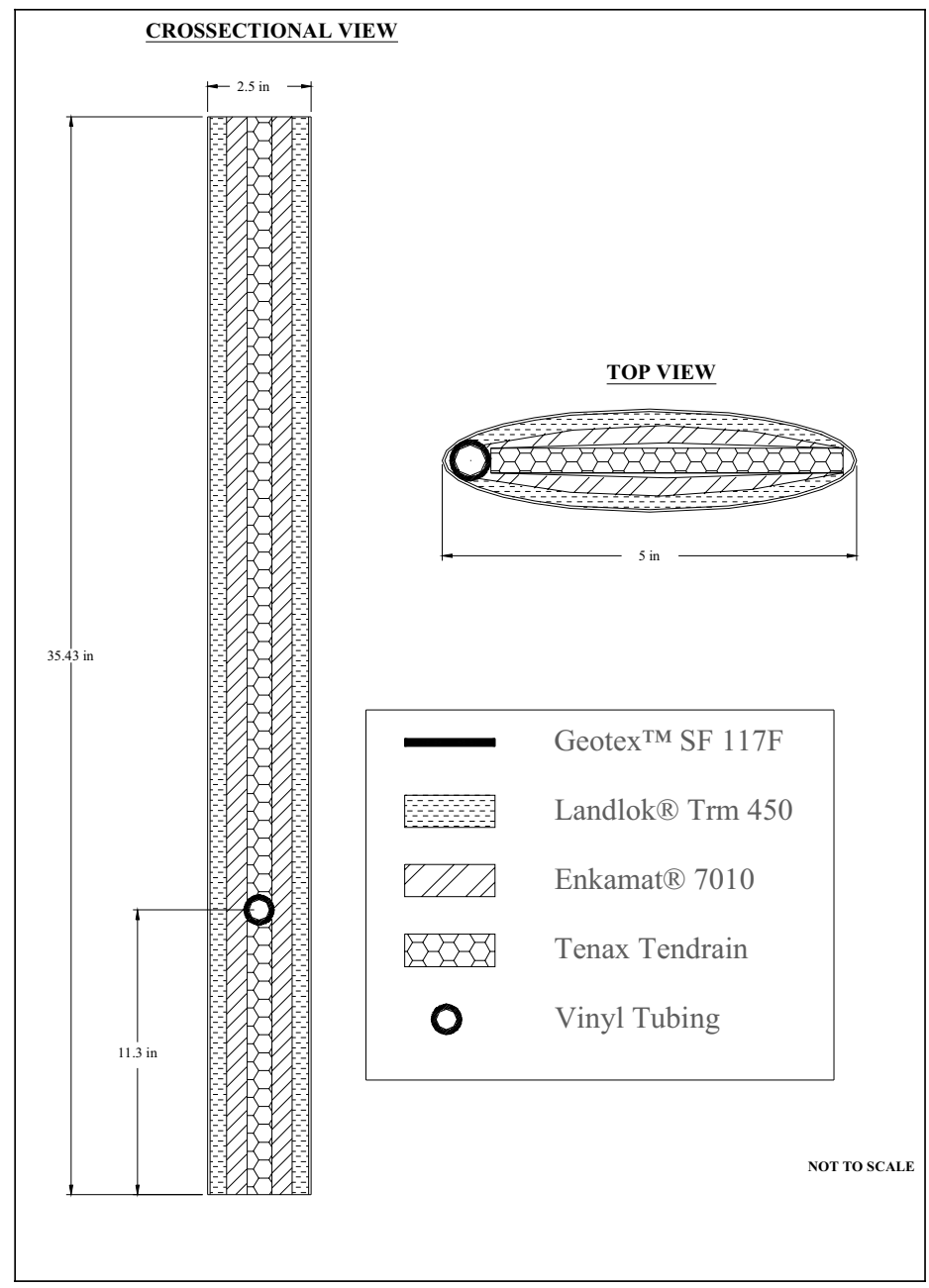

Figure 3.2 Schematic of Sparger I 
Figures 3.3 and 3.4 show the observed lift and water flow for each of the tested airflow rates for Sparger I and II. Both Sparger I and II had a submerged depth in an open tank of water of approximately $2 \mathrm{ft}$. The addition of an air diffuser in Sparger II increased the lift, water flow and overall pumping efficiency of the system. However the results were more variable than Sparger I. Both Sparger I and II produced adequate flow and lift. However pumping efficiencies for both designs were very low (less than 5\%). Properly designed airlift pumps commonly achieve pumping efficiencies of 30 to $50 \%$. The low pumping efficiency of Spargers I and II indicates that there was excessive friction loss and/or short circuiting with these designs.

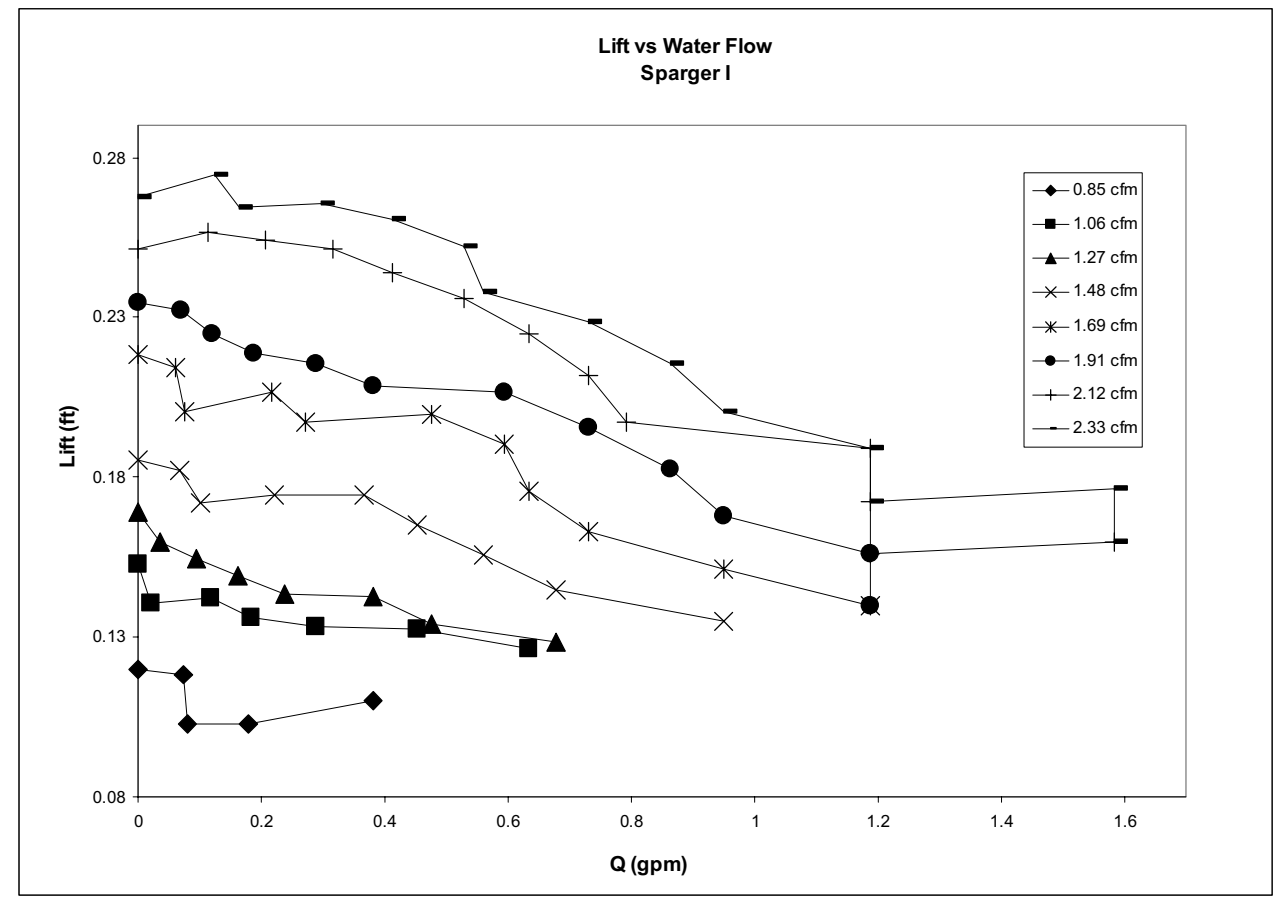

Figure 3.3 Lift versus water flowrate produced by Sparger I for several different air flowrates. 


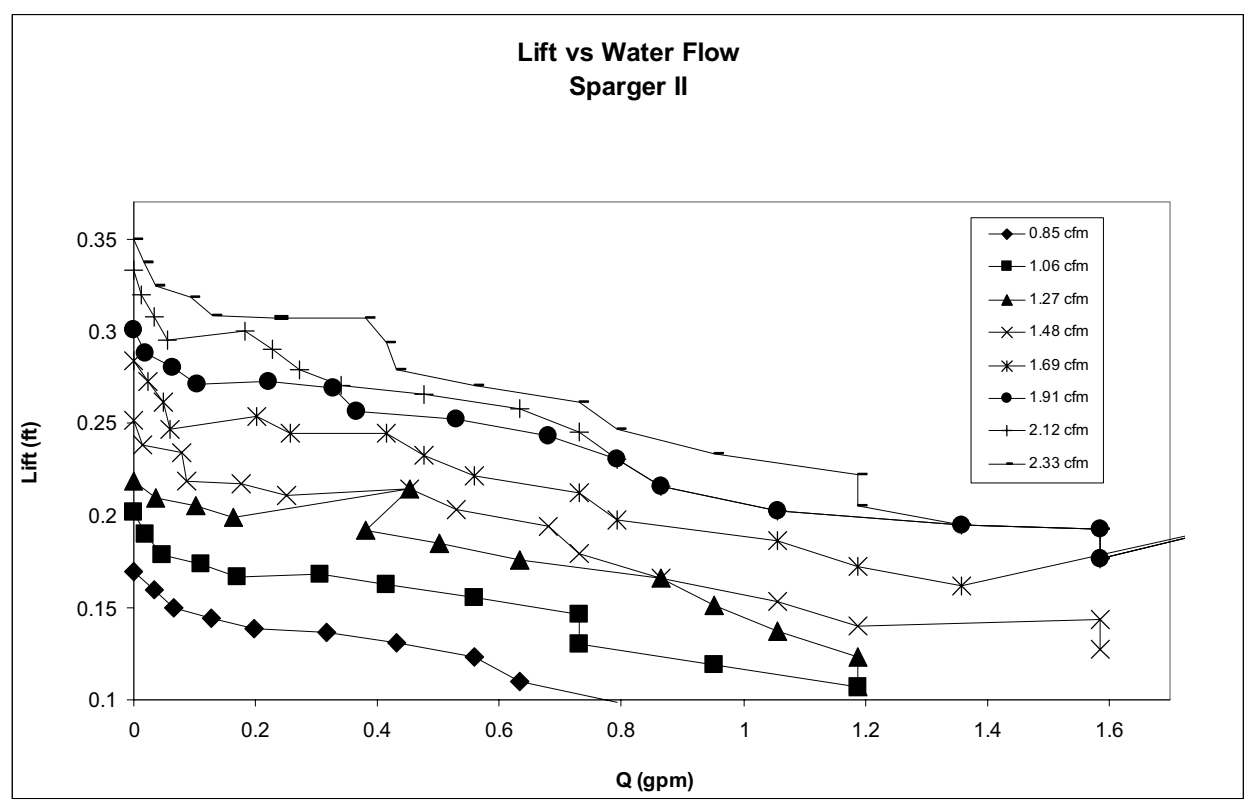

Figure 3.4 Lift versus water flowrate produced by Sparger II for several different air flowrates.

\subsubsection{Spargers III, IV and V}

Spargers III, IV and V were manufactured from 1-inch ID slotted (0.020 inch) PVC well screen. Air to Sparger III was supplied through 3/16-inch flexible tubing. A metal spacer was placed on the end of the airline to keep the air supply line from floating and keep the air supply line in the center of the DP-GCW. However, the spacer was not large enough to excessively restrict airflow in the well. Air to Sparger IV was supplied through 3/16-inch flexible tube fit with a 1.5-inch long by 0.75 -inch square medium-pore diffuser (Sweetwater ${ }^{\circ}$ AS2). Air to Sparger V was provided through 3/16-inch tubing where 15 percent of the tubing length was wrapped in a tangled mesh drainage mat geotextile (Enkamat $\left.{ }^{2} 7010\right)$ to provide surface area for microbial growth and formation of inorganic precipitates. The Enkamat was wrapped around the air supply line to provide a reasonably tight fit between the air supply line and the PVC screen.

Figures 3.5, 3.6 and 3.7 show the observed variation in water pumping rate in Spargers III, IV, and $\mathrm{V}$, respectively, as a function of relative lift for three different air flowrates. Relative lift is the ratio of head generated by the DP-GCW (lift) divided by the depth of the air injection tube below the normal water surface. All three PVC designs provided good results producing substantial pumping heads at much lower airflow rates than Spargers I and II. Sparger IV with the air diffuser stone produced somewhat higher lifts than both Sparger III (no diffuser) and Sparger V (tangled mesh geotextile). The maximum water flowrates produced by Spargers III and IV were approximately 1.7 gallon per minute (gpm). The maximum flowrate produced by Sparger III was $1.0 \mathrm{gpm}$. Based on the much higher pumping efficiency of Spargers III, IV, and V, additional work focused on the field evaluation of these designs. 


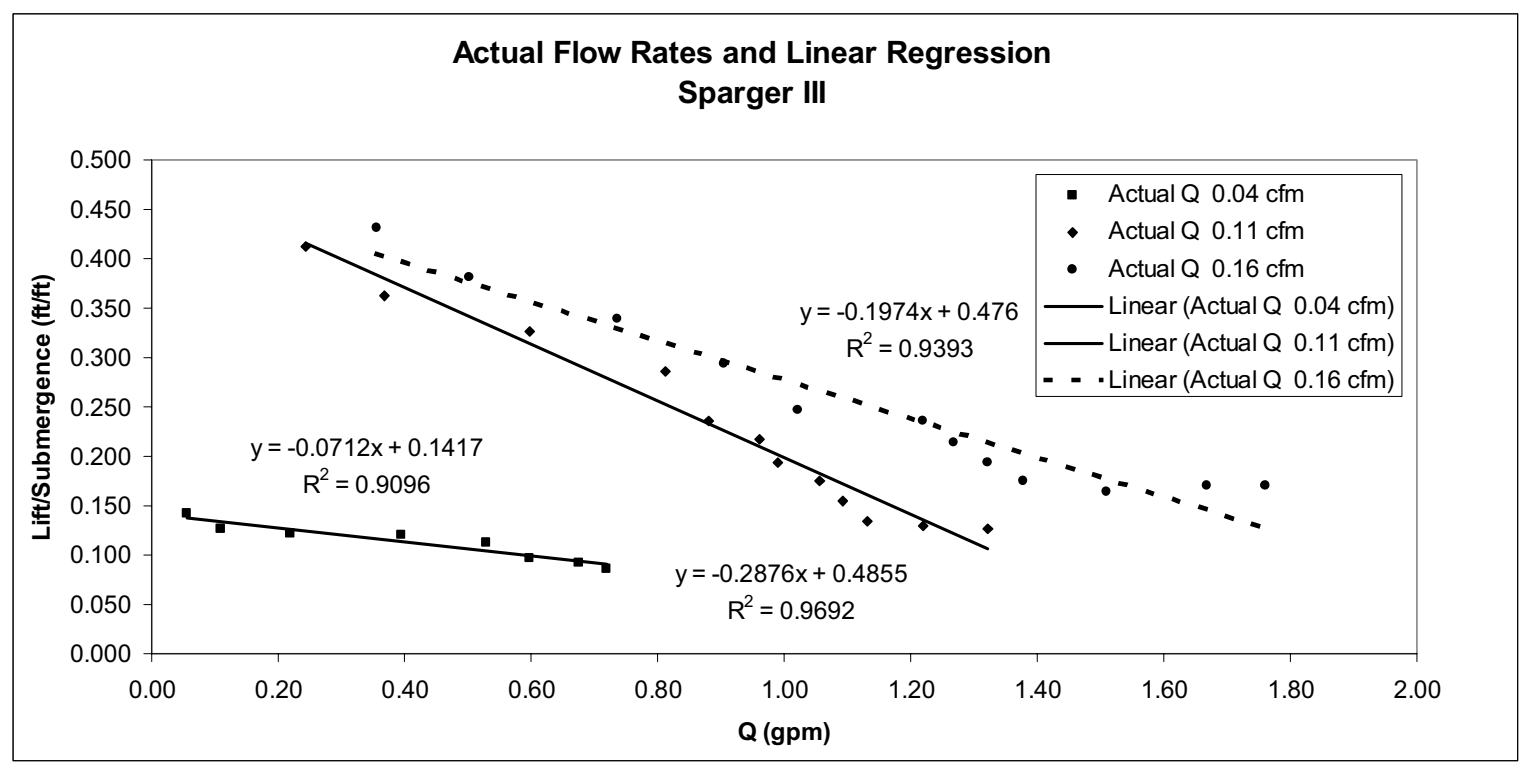

Figure 3.5 Relative lift versus water flowrate produced by Sparger III for three different air flowrates.

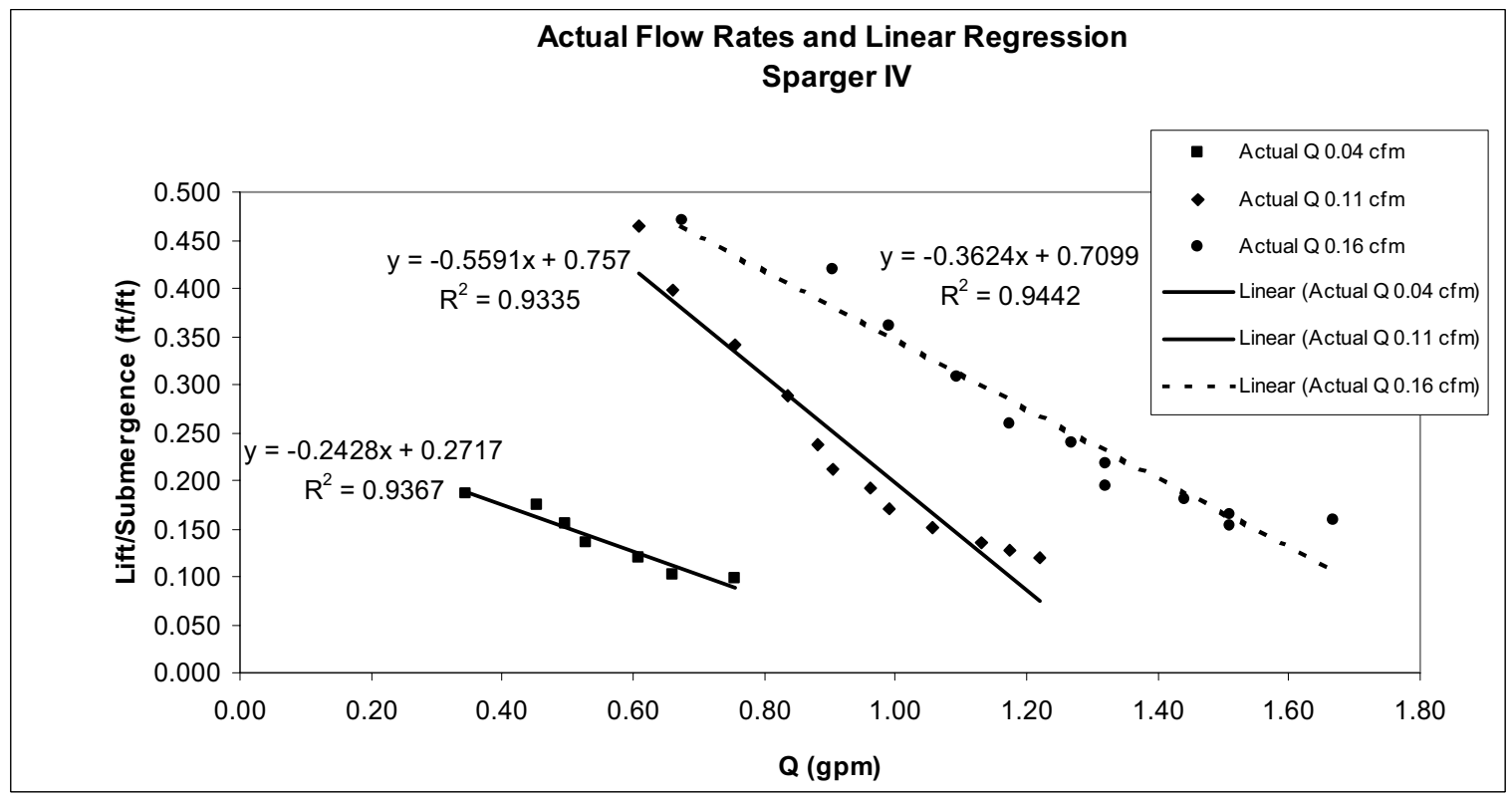

Figure 3.6 Relative lift versus water flowrate produced by Sparger IV for three different air flowrates. 


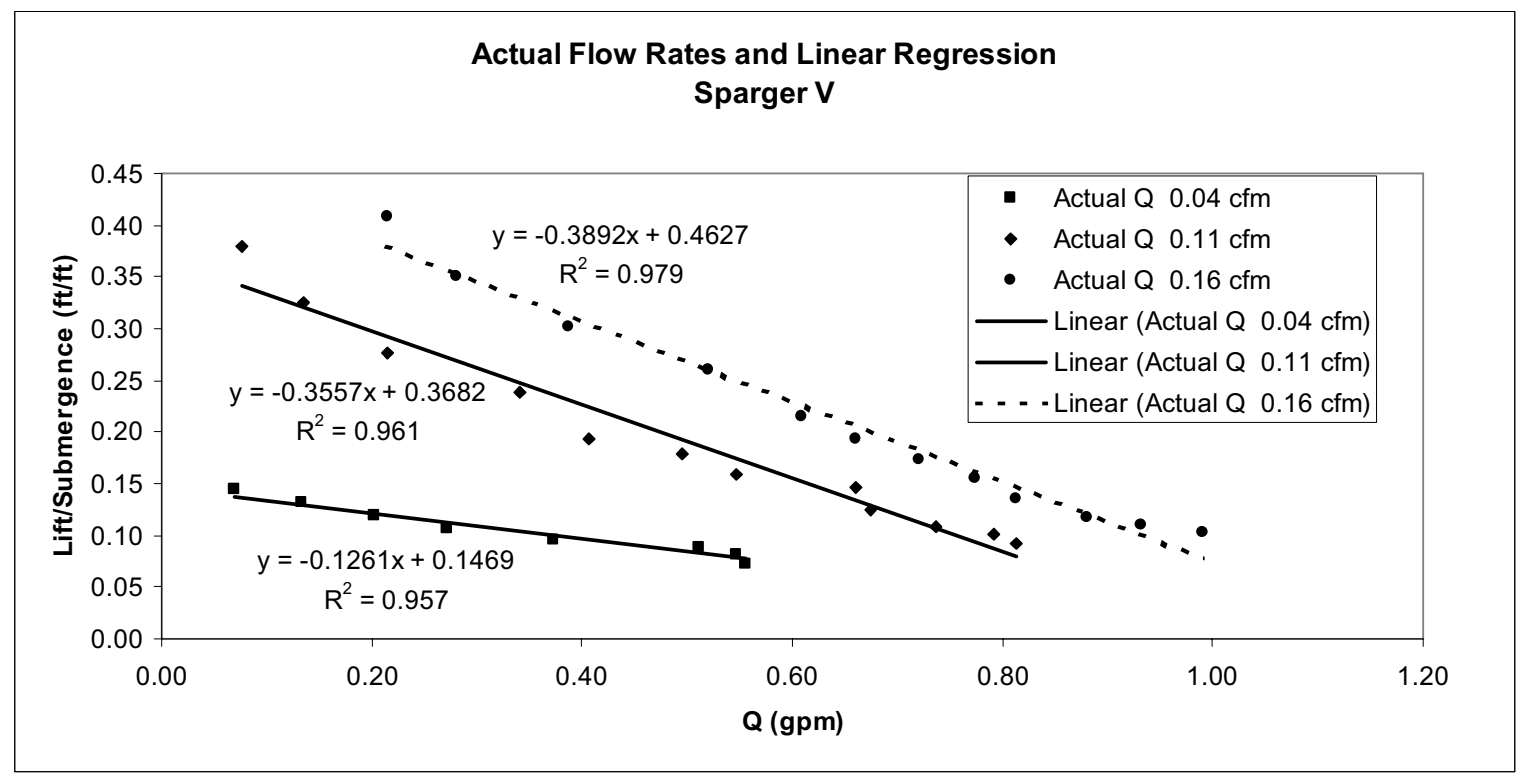

Figure 3.7 Relative lift versus water flowrate produced by Sparger V for three different air flowrates.

Also shown in Figures 3.5, 3.6 and 3.7 are the best fit linear regressions of relative lift versus water flow rate for each air flow rate. Hyperbolic relationships were also evaluated. However the linear relationships provided a better fit to the experimental results. A summary of the linear regression results is provided in Table 3.1 .

Table 3.1 Linear regression results and correlation coefficients $\left(r^{2}\right)$ for each DP-GCW design and air flowrate

\begin{tabular}{cccc}
\hline \hline $\begin{array}{c}\text { Sparger } \\
\text { Type }\end{array}$ & $\begin{array}{c}\text { Air Flow } \\
\text { Rate }(\mathrm{cfm})\end{array}$ & Linear Regression & $\mathrm{R}^{2}$ \\
III & 0.04 & $\mathrm{~L} / \mathrm{S}=-0.0712 \mathrm{Q}+0.1417$ & 0.910 \\
& 0.11 & $\mathrm{~L} / \mathrm{S}=-0.2876 \mathrm{Q}+0.4855$ & 0.969 \\
& 0.16 & $\mathrm{~L} / \mathrm{S}=-0.1974 \mathrm{Q}+0.476$ & 0.939 \\
IV & 0.04 & $\mathrm{~L} / \mathrm{S}=-0.2428 \mathrm{Q}+0.2717$ & 0.937 \\
& 0.11 & $\mathrm{~L} / \mathrm{S}=-0.5591 \mathrm{Q}+0.757$ & 0.934 \\
& 0.16 & $\mathrm{~L} / \mathrm{S}=-0.3624 \mathrm{Q}+0.7099$ & 0.944 \\
$\mathrm{~V}$ & 0.04 & $\mathrm{~L} / \mathrm{S}=-0.1261 \mathrm{Q}+0.1469$ & 0.957 \\
& 0.11 & $\mathrm{~L} / \mathrm{S}=-0.3557 \mathrm{Q}+0.3682$ & 0.961 \\
& 0.16 & $\mathrm{~L} / \mathrm{S}=-0.3892 \mathrm{Q}+0.4627$ & 0.979 \\
\hline \hline
\end{tabular}

$* \mathrm{Q}=$ Water flow rate (gpm)

$\mathrm{L} / \mathrm{S}=$ Pumping lift divided by submergence $(\mathrm{ft} / \mathrm{ft})$ 


\subsubsection{In situ flowrate measurement}

Short-term in situ pumping tests were performed to measure the hydraulic performance of Spargers III, IV and V in a gasoline-contaminated aquifer near Rocky Point, North Carolina. Three wells were installed to a depth of $30 \mathrm{ft}$ below ground surface (BGS) with $25 \mathrm{ft}$ of 1.0-inch slotted (0.020 inch) PVC well screen. Each well was located approximately $10 \mathrm{ft}$ apart and perpendicular to the groundwater gradient. Internal air supply lines corresponding to a single sparger type were inserted into the three PVC wells to obtain triplicate flowrate measurements for each design. The lower end of the air supply tube was set at $28 \mathrm{ft} \mathrm{BGS.} \mathrm{A} \mathrm{low} \mathrm{airflow} \mathrm{rate} \mathrm{of} 0.04 \mathrm{cfm}$ was selected due to the shallow water table ( 3 to $5 \mathrm{ft}$ BGS) at this location. The wells were designated Well A, Well $\mathrm{B}$ and Well $\mathrm{C}$ going from east to west.

At this site, there is a pronounced vertical variation in hydraulic conductivity $(\mathrm{K})$. A low permeability clayey-sand confining layer $(\mathrm{K}=3 \mathrm{ft} / \mathrm{d})$ is present from the land surface to approximately $5 \mathrm{ft} \mathrm{BGS}$ where there is an abrupt transition to a fine uniform sand. The maximum hydraulic conductivities are $\sim 50 \mathrm{ft} / \mathrm{d}$ from 7 to $10 \mathrm{ft} \mathrm{BGS}$. K then declines with increasing depth to $5 \mathrm{ft} / \mathrm{d}$ at 25 BGS. The vertically averaged $\mathrm{K}$ is $25 \mathrm{ft} / \mathrm{d}$ directly adjoining Well A.

In situ water flowrates generated by each DP-GCW were measured using a bromide (Br-) dilution test conducted twenty-four hours after turning on the air supply. Water flowrates in the DPGCWs could not be measured using conventional methods because the fluid flowing through the DPGCW consists of a complex mixture of air and water that varies along the length of the sparger due to entry and discharge of water from the surrounding aquifer. The dilution test was conducted by continuously injecting a bromide solution of known high concentration at a low flowrate near the bottom of the DP-GCW (Figure 3.8). Water samples were then collected over time from near the top of the sparger to measure the diluted bromide concentration. Once the bromide concentration reached steady-state, the in situ water flowrate was calculated using equation 3.3.



Figure $3.8 \quad$ Schematic of bromide dilution test 


$$
Q_{\text {pump }}=Q_{\text {inject }}\left(\frac{C_{\text {inject }}}{C_{\text {pump }}}\right)
$$

$\mathrm{Q}_{\text {pump }}=\mathrm{DP}-\mathrm{GCW}$ flowrate

$Q_{\text {inject }}=$ Tracer injection rate

$\mathrm{C}_{\text {inject }}=$ Concentration of tracer in injection solution

$\mathrm{C}_{\text {pump }}=$ Average steady-state tracer concentration

Table 3.2 shows the average concentrations of the bromide tracer after breakthrough and the inwell pumping rates. In situ flowrates varied as expected with the highest water flow rates observed for Spargers III and IV with somewhat lower flowrates for Sparger V. There was a significant variation in water flowrates between the three test wells (A, B and C). The highest water flowrates were consistently observed in the Well A, with moderate flowrates in Well B and the lowest flowrates in Well C. This is believed to be due to the higher hydraulic conductivity of the formation on the eastern side (Well A) and the lower hydraulic conductivity on the western side (Well C).

Table $3.2 \quad$ Bromide dilution test results

\begin{tabular}{|c|c|c|c|c|}
\hline Injection Concentration = & $10,000 \mathrm{mg} / \mathrm{l}$ & & Sparger Types & \\
\hline & & III & IV & $\overline{\mathbf{V}}$ \\
\hline Injection Rates (ml/s) & Well A & 0.350 & 0.340 & 0.350 \\
\hline & Well B & 0.260 & 0.380 & 0.350 \\
\hline & Well C & 0.260 & 0.350 & 0.330 \\
\hline \multirow[t]{3}{*}{ Average Conc. In $7 \mathrm{ft}$. Intake (mg/l) } & Well A & 76.0 & 73.5 & 97.3 \\
\hline & Well B & 77.6 & 135 & 142 \\
\hline & Well C & 99.9 & 175 & 233 \\
\hline \multirow[t]{6}{*}{ In-well Flow Rates $(\mathrm{ml} / \mathrm{s})$} & Well A (ml/s) & 46.0 & 46.3 & 36.0 \\
\hline & Well B (ml/s) & 33.5 & 28.2 & 24.6 \\
\hline & Well C (ml/s) & 26.0 & 20.0 & 14.2 \\
\hline & Well A (gpm) & 0.730 & 0.733 & 0.570 \\
\hline & Well B (gpm) & 0.531 & 0.447 & 0.390 \\
\hline & Well C (gpm) & 0.413 & 0.317 & 0.225 \\
\hline
\end{tabular}

\subsubsection{Prediction of in situ pumping rates}

Flowrates in typical pump and pipeline systems are determined from the intersection of the pump curve (relationship between flowrate and head produced by the pump) and the system curve (relationship between flowrate and head loss in the piping system).

In the DP-GCW system, the 'pump' is the head produced by injecting air into the DP-GCW and the pump curve is the relationship between head generated and flowrate found in the laboratory pumping studies. The system curve is the relationship between pumping head generated and water 
flowrate through the aquifer represented by Equation 3.1. The in situ flowrate should then be the flowrate at the intersection of the Equation 3.1 and the appropriate equation from Table 3.1.

Figures 3.9, 3.10 and 3.11 show a comparison of predicted and observed pumping rates in the aquifer for Spargers III, IV and V, respectively. Equation 1 is plotted on each figure for three different values of radial hydraulic conductivity $(\mathrm{K})$. The three values of $\mathrm{K}$ were selected to provide low, medium, and high estimates for the average hydraulic conductivity at the field site. Arrows located along the $\mathrm{x}$-axis of each figure represent the measured water flow rates within each of the three test wells. Numerical values corresponding to each arrow can be found in Table 3.2.

For all three designs, measured water flowrates in Well A closely match predicted flowrates using a hydraulic conductivity of $25 \mathrm{ft} / \mathrm{d}$. However measured flowrates in Wells B and $\mathrm{C}$ were lower and did not as closely match the flowrates predicted using a $\mathrm{K}$ of $25 \mathrm{ft} / \mathrm{d}$. The lower pumping rates observed in Wells B and C are believed to be due to the lower hydraulic conductivity of the aquifer near these wells. The vertically averaged hydraulic conductivity of $25 \mathrm{ft} / \mathrm{d}$ was measured directly adjoining Well A.

These results indicate that analysis procedure presented here can provide reliable estimates of the initial in situ water pumping rates achieved with DP-GCWs. However pumping rates may decline over time if there is significant clogging of the DP-DCWs. Periodic in situ flow measurements will be required to evaluate the long-term pumping performance of the DP-GCWs.

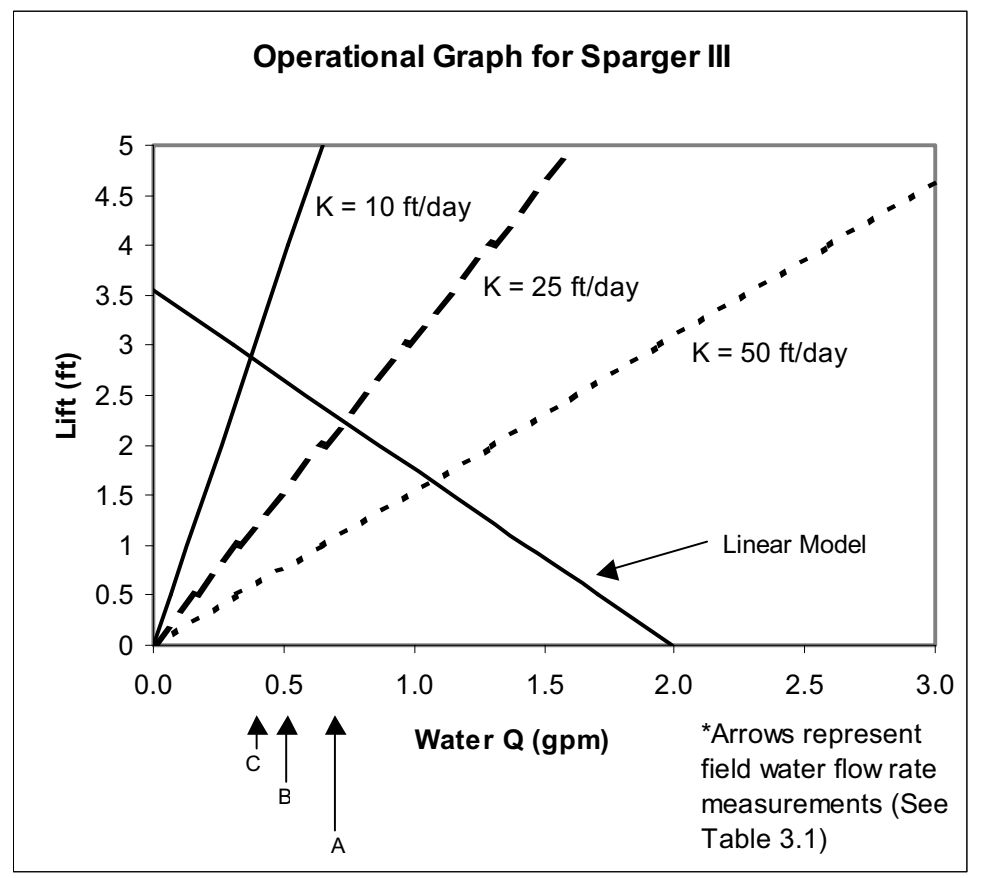

Figure 3.9 Comparison of predicted and observed in situ pumping rates for Sparger III. 


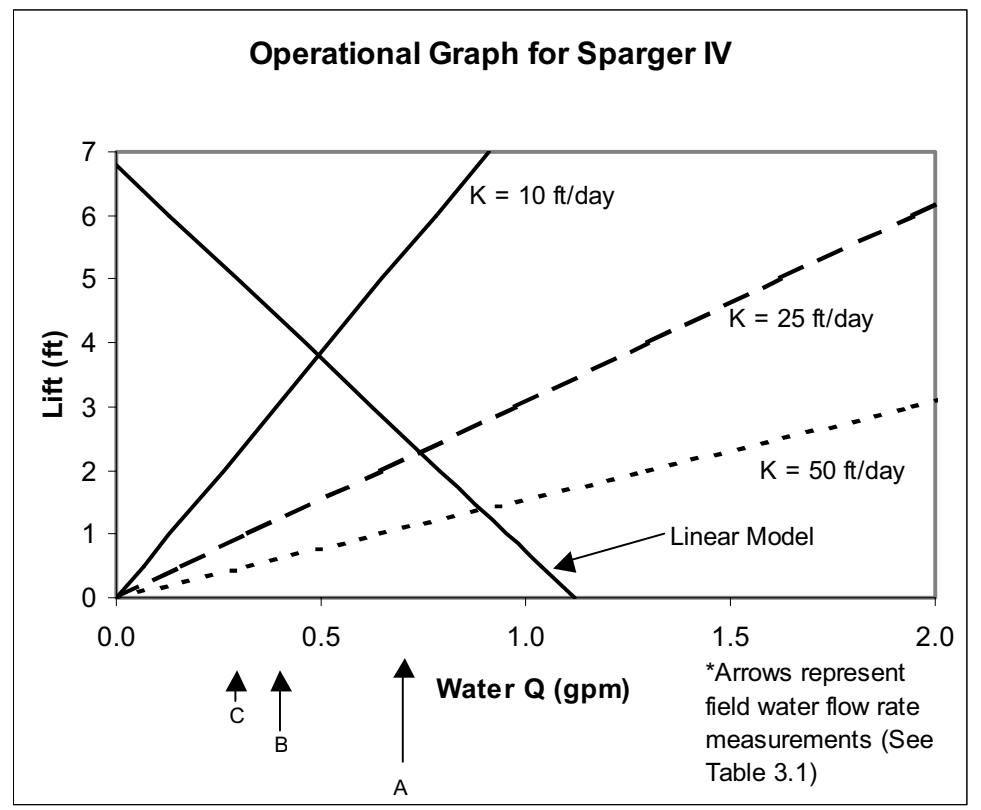

Figure 3.10 Comparison of predicted and observed in situ pumping rates for Sparger IV.



Figure 3.11 Comparison of predicted and observed in situ pumping rates for Sparger V. 


\subsection{Oxygenation and water circulation rates}

\subsubsection{Water column experiments}

These experiments to measure the rates at which spargers could oxygenate water were primarily done with the early version of the sparger design, the so-called wick sparger or Sparger I. The tests were performed by placing the sparger in a 6" ID x 56" vertical glass column holding $21 \mathrm{~L}$ of water. The water column was significantly larger than the sparger, which was held so that its top extended about 5" above the water level. Regulated house nitrogen or air was fed through a calibrated rotameter to the sparger. A $1 / 8$ " ID Tygon U-tube water manometer was connected between the sparger and rotameter to measure the pressure drop over the sparger.

Oxygenation rates were measured by first deoxygenating the water in this system by running nitrogen through the sparger until an Orion dissolved oxygen (DO) probe in the water column, outside of the sparger and near the bottom of the water column, was below $1 \mathrm{ppm}$, preferably down to $<0.2 \mathrm{ppm}$. Preliminary tests showed that there was no difference in DO readings between the top and bottom of the water column. The nitrogen was then turned off and the water level marked on the column. A chart recorder connected to the DO meter was then started and the air to the sparger was turned on at the appropriate flow rate. DO readings were recorded until the DO leveled out or for 15 minutes. Also, during a run the water manometer readings were taken and the new water leveled marked on the column. The process was then restarted for a different air flow rate over an air flow range of 1.8 to $40 \mathrm{~L} / \mathrm{min}$. Typical data is shown in Figure 3.12, where "external" refers to the DO reading in the water column, while the other curves show DO readings measured inside the sparger to determine how rapidly the water was oxygenated inside the sparger.

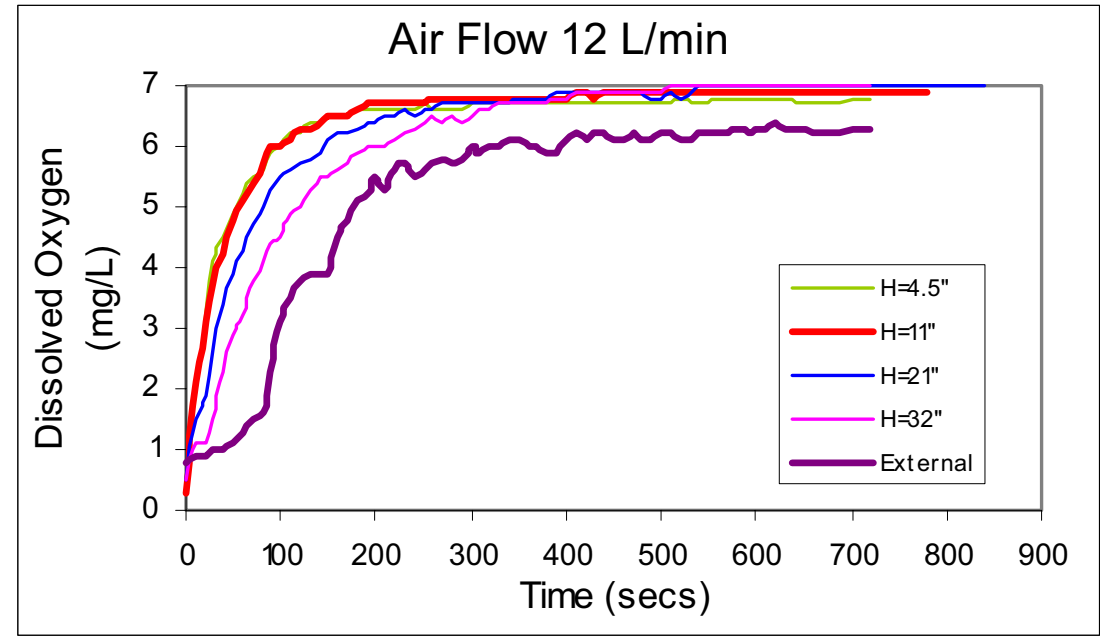

Figure 3.12 Typical oxygenation rate data from water column tests

The numerical mass transfer coefficient was obtained by the following equation:

$$
\mathrm{V}_{\text {col }} \mathrm{DC}_{\mathrm{O} 2} / \mathrm{dt}=\mathrm{V}_{\text {sparger }} \mathrm{k}_{1} \mathrm{a}\left(\mathrm{C}^{*}-\mathrm{C}_{\mathrm{O} 2}\right)
$$

where $\mathrm{V}_{\text {col }}$ is the volume of water in the column, $\mathrm{V}_{\text {sparger }}$ is the volume of sparger covered with water when the air was flowing, $\mathrm{C}_{\mathrm{O} 2}$ is the concentration of oxygen in the water, $\mathrm{C}^{*}$ is the saturation concentration of oxygen in the water, and $\mathrm{k}_{1} \mathrm{a}$ is the mass transfer coefficient of oxygen. Solving the equation yields: 


$$
\ln \left(\mathrm{C}^{*}-\mathrm{C}_{\mathrm{O} 2}\right)=-\left(\mathrm{V}_{\text {sparger }} / \mathrm{V}_{\text {col }}\right) \mathrm{k}_{1} \mathrm{a} \mathrm{t}
$$

Therefore, by plotting $\ln \left(\mathrm{C}^{*}-\mathrm{C}_{\mathrm{O} 2}\right)$ versus time and determining the slope of the best fit line through that data, $\mathrm{k}_{\mathrm{l}} \mathrm{a}$ can be obtained since the oxygen saturation value and volume of the column are known and the volume of the sparger could be calculated.

The mass transfer coefficient and pressure drop measured for each flow rate are shown in Table 3.3. The pressure drop numbers include two effects: a constant value of about 33-34 inches simply for the amount that the air supply line was submerged, plus a variable amount of several inches for the pressure drop related to the flowing air/water mixture inside the sparger. During these runs, some slugging occurred at 18,25 and $40 \mathrm{~L} / \mathrm{min}$ and could be seen in the way the water surged out of the upper part of the sparger. As expected the mass transfer coefficient and pressure drop increased with increased air flow.

Table 3.3 Mass transfer coefficient and pressure drop for Sparger I. Shown are the two measurements for each flow rate.

\begin{tabular}{|c|r|r|r|c|}
\hline \multirow{2}{*}{$\begin{array}{c}\text { Air Flow } \\
(\mathrm{L} / \mathrm{min})\end{array}$} & \multicolumn{2}{|c|}{$\begin{array}{c}\mathrm{k}_{\mathrm{l}} \mathrm{a} \\
\left(\mathrm{min}^{-1}\right)\end{array}$} & \multicolumn{2}{c|}{$\begin{array}{c}\text { Pressure Drop } \\
\left.\text { (inches } \mathrm{H}_{2} \mathrm{O}\right)\end{array}$} \\
\cline { 2 - 6 } & Run A & Run B & Run A & Run B \\
\hline 1.8 & 0.4 & 0.8 & 35.6 & 33.6 \\
\hline 3.6 & 0.7 & 1.8 & 36.3 & 33.4 \\
\hline 6 & 1.4 & 1.3 & 32.7 & 34.5 \\
\hline 9 & 1.6 & 2.1 & 37.2 & 35.0 \\
\hline 12 & 2.4 & 1.6 & 39.1 & 35.4 \\
\hline 18 & 2.5 & 1.8 & 37.6 & 36.6 \\
\hline 25 & 7.0 & 5.1 & 35.9 & 38.1 \\
\hline 40 & 5.2 & -- & 40.6 & 43.0 \\
\hline
\end{tabular}

Other runs were performed to determine if there was a difference in the rate of oxygenation of the water inside and outside the sparger and at different depths within the sparger. This was done by placing the DO probe inside the sparger at 4.5, 11, 21, and 32" from the top of the sparger. Runs were conducted at $3.6 \mathrm{~L} / \mathrm{min}$ and $12 \mathrm{~L} / \mathrm{min}$ air flow, with similar results except for the speed of the response (Figure 3.12). The data from these runs showed that the water in the sparger was rapidly oxygenated, moving more than halfway to saturation in only about 30 " of sparger length even when the external water entering the sparger was essentially devoid of oxygen. T he potential intake of water through the entire length of the porous sparger sides did not appear to interfere with what looks like an exponential approach to saturation upwards over the length of the sparger, which corresponds to contact time between the air bubbles and the rising water being pumped by the sparger.

These $\mathrm{k}_{\mathrm{l}} \mathrm{a}$ values show that the water flowing through a field scale sparger should be very well aerated, and similarly should be very well equilibrated with respect to stripping of volatile organic contaminants. A field scale well one inch in diameter and eight meters long has an internal volume of about four liters, or about four minutes liquid residence time if pumping at about $1 \mathrm{~L} / \mathrm{min}$. With a ka value of even as low as $1 \mathrm{~min}^{-1}$, the air and water would come to within $1-\exp \left[-(4 \mathrm{~min})\left(1 \mathrm{~min}^{-1}\right)\right]=$ 0.982 of full approach to equilibrium saturation with oxygen. Higher values of $k_{1} a$ or longer residence times would make the approach even greater. A similar essentially complete approach to BTEX stripping equilibrium would also be achieved since the mass transfer coefficient for the two processes should be similar. 
In many of the runs collecting data in the water column, there were evident steps in the DO history (readily seen in the "external" data of Figure 3.12). These were attributed to the stepwise recirculation of unaerated, once-aerated, twice-aerated, etc. water through the sparger, with the initial step jump in oxygen concentrations from the starting value near zero being the most consistently identifiable. Under this assumption, the time for the first jump from the deaerated value coupled with the known volume of the water column allowed estimation of the sparger's water pumping rate. Table 3.4 shows these results for two sets of data with Sparger I, indicating that in an open vessel of water this 36 " long sparger could pump between one and three times as much water as the amount of air flowing through it.

Table $3.4 \quad$ Water pumping rates from two sets of recirculation time estimates

\begin{tabular}{|c|c|c|}
\hline $\begin{array}{c}\text { Air Flow } \\
(\mathrm{L} / \mathrm{min})\end{array}$ & $\begin{array}{c}\text { Pumping rate } \\
(\mathrm{L} / \mathrm{min})\end{array}$ & $\begin{array}{c}\text { Pumping rate } \\
(\mathrm{L} / \mathrm{min})\end{array}$ \\
\hline 1.8 & 4.2 & 12.6 \\
\hline 3.6 & 18.0 & 21.0 \\
\hline 6 & 18.0 & 21.0 \\
\hline 9 & 25.2 & 25.2 \\
\hline 12 & 31.5 & 31.5 \\
\hline 18 & 25.2 & 42.0 \\
\hline 25 & 42.0 & 42.0 \\
\hline 40 & 63.0 & 42.0 \\
\hline
\end{tabular}

\subsubsection{Sand tank experiments}

The spargers were also tested in a laboratory mockup which included the effects of flow resistance from the aquifer material. The apparatus for this consisted of $1200 \mathrm{lbs}$. of silica sand (-30 mesh size) in a 100 gallon Nalgene tank, 32" in diameter with a conical bottom. While the sand was placed in the tank with the sparger installed at the center of the tank, 3/4" PVC pipes of various lengths were put in the sand. The PVC pipes had a large number of 1/6" holes drilled through the sides of the bottom 1" of the pipe to let water enter these "sampling wells". Rubber stoppers were inserted in the bottom of each pipe to prevent sand from filling the bottom of the tube. These wells were installed in several different configurations for different tests; one such pattern is illustrated in Figure 3.13. Eight of the tubes were placed in a circle 10" from the center of the wick sparger at an 11 " sampling depth, and 3 of the tubes (F, J, and K) were 12" from the center to 24 " depth. Deaerated water was then slowly added to the tank till it reached approximately 1 " below the sand level. This was calculated to be 147 to $158 \mathrm{~L}$ of water. 




Figure 3.13 Configuration of sampling tubes and sparger in the sand tank

Before air was introduced into the system, the water in the tank was deaerated by flowing nitrogen through the wick sparger. Because this took about one to two days, a humidification column after the air supply rotameter and covering the tank with a plastic bag were used to reduce evaporative losses of water. A DO reading was done in the sampling wells by first pulling $60 \mathrm{mls}$ of water from the bottom of the tube with a syringe; the water that flowed in to replace this sample ensured that the water in the tube was representative of the water in the sand. Then, the DO probe was lowered down the PVC pipe until just above the rubber stopper. The need for this water exchange was shown by one example where the DO measured in the tube prior to pulling water was $0.3 \mathrm{ppm}$ (similar to the unaerated starting condition), but after was $4.4 \mathrm{ppm}$. We assumed that this $60 \mathrm{ml}$ disturbance was minimal compared to the $150 \mathrm{~L}$ water in the whole tank.

Typical data collected in these runs is shown in Figure 3.14, with this test conducted at 25 $\mathrm{L} / \mathrm{min}$ air. These data suggest that the aeration was symmetrical. The DO increased at about the same rate for the tubes at 11 " depth followed by the tubes at the 24 " depth. From this kind of raw data, it was possible to estimate the flow rate of water pumped by the sparger. The time it took for the DO concentration at each point to rise to $50 \%$ of final value was determined and used to mark the time it took for well-aerated water from the sparger to reach that sample point's location. By creating a map of all well locations and estimating the volume of water between the various wells and the top of the sparger (w here most water came out), it was possible to estimate how fast water flowed out of the sparger. Depending on how the progress of the aerated front was measured (from sparger to wells, or from one well to another), different flow rates could be obtained. However, for Sparger I all values were less than $10 \mathrm{~L} / \mathrm{h}$ for air flow rates of 6,12 , and $25 \mathrm{~L} / \mathrm{min}$. These were very low values compared to the flows seen in Table 3.4, indicating that the resistance of porous medium around the sparger is very significant in determining the overall performance of the sparging system. 


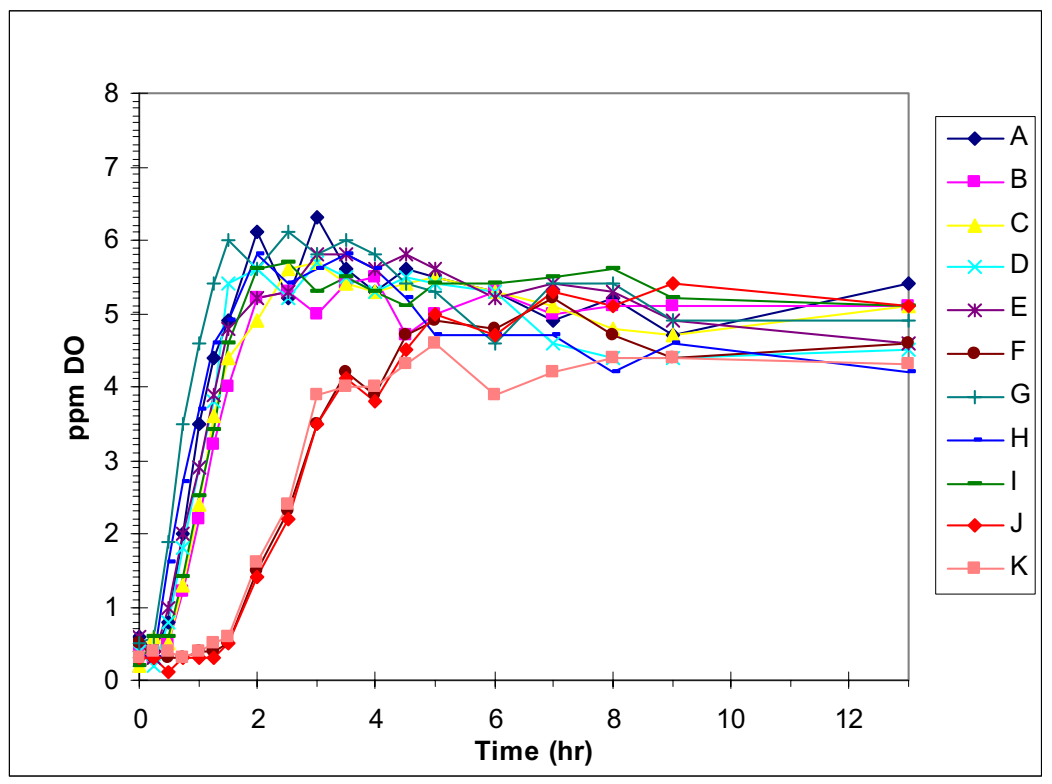

Figure 3.14 DO response in sampling wells of Figure 3.13 at $25 \mathrm{~L} / \mathrm{min}$ air flow to Sparger I.

Another observation in the sand tank was that the water level next to the sparger was indeed higher than at the walls during operation, as expected. The water levels were measured by digging into the sand to find the water level, then measuring its depth from a horizontal reference bar. This was done next to the sparger and every 2 " out to the wall out from the face of the sparger $\left(0-180^{\circ}\right)$ and along the width of the sparger $\left(90-270^{\circ}\right)$ at $0,6,12$, and $25 \mathrm{~L} / \mathrm{min}$ of air. The results are shown in Figure 3.15. The higher the flow rate the greater the difference in height of water from the sparger towards the wall, with the water level being highest at the sparger. Because of the medium fine sand used, the permeability of the sand tank was fairly high and the bulge in water level at the sparger did not extend for any great distance away from the sparger. The non-level readings at zero air flow in the upper graph were repeatable and are believed to be caused by upward capillary wicking of water in most of the sand bed. At that one face of the sparger however, where the textile wrap around the sparger tended to try to unwrap and allow water to enter the sparger easily, it appeared that the water tended to drain into the sparger thereby depressing the local water level. 

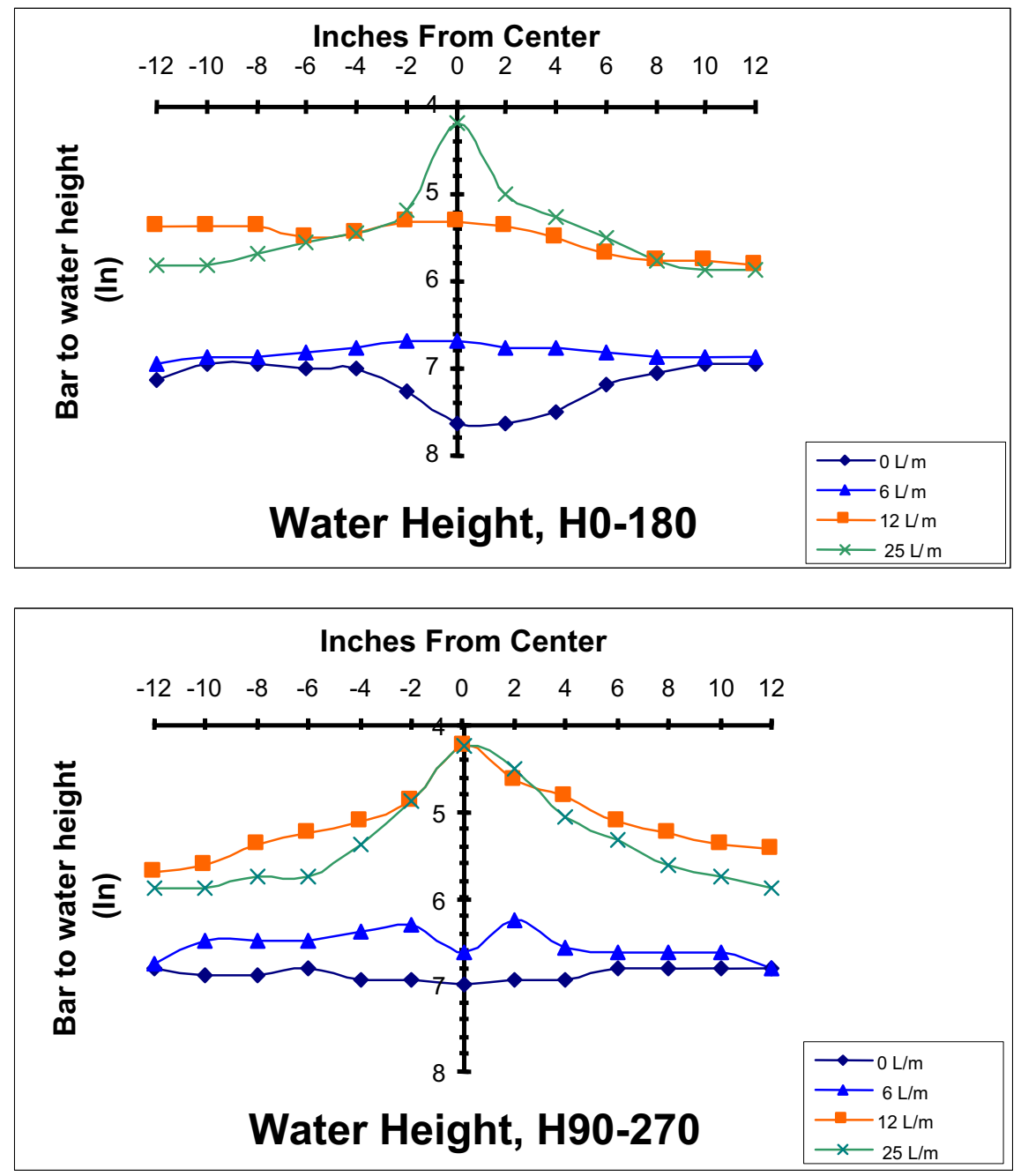

Figure 3.15 Water level in sand tank along the face (H0-180) and width (H90-270) of Sparger I

\subsubsection{Tests of other sparger types}

As part of the early development of these spargers, two other sparger designs were tested in the water column as described above. T he first was a collared sleeve, which was conceived to both hold the air supply centered in the sparger and to provide baffles which would help break up rising air bubbles to increase their surface area and therefore their ability to transfer oxygen. A collared sleeve was a 3 " length of stainless steel tubing 1.5 " in diameter with 8 tabs, each about 0.5 " square, cut into the tubing and bent radially inward such that they would slide over a $7 / 16$ " OD piece of Tygon tubing. There were four tabs, 90 degrees apart, at each end of the sleeve. Three collared sleeves where placed on a length of 7/16" OD Tygon tubing which was connected to the air supply. The Tygon tubing with the collared sleeves was placed inside an acrylic plastic tube, 1.5" ID x 1.75" OD, 51.75 " in length. The collared sleeves where spaced equal distance between the top and bottom of the Acrylic tube. This sparger was then placed inside the 6" ID glass column holding $23 \mathrm{~L}$ of water. The 
air would discharge out of the Tygon tubing near the open bottom of the Acrylic tube, rise up the tube and the bubbles dispersed by the collared sleeves.

The second sparger was a 3-foot Geoprobe ${ }^{\circledR}$ Prepacked Screen Monitoring Well, 1.4” OD x 0.5 " ID (Geoprobe part \# GW2010). The inner component of the prepacked screen consists of 0.5 " Schedule 80 PVC with 0.01 " slots. The outer component of the screen is stainless steel wire mesh with a pore size of 0.11 ". The screens are prepacked with 20/40 grade silica sand. A snap-lock connector was placed on the bottom of the prepacked screen and a 3/8" ID piece of Tygon tubing stuffed down the inside till just above the bottom of the screen. The $3 / 8$ " ID tubing was connected to the air supply. Twenty-one liters of water was used in the glass column while testing the Geoprobe well screen for use as a sparger.

The mass transfer coefficient and gas holdup for the collared sleeve and Geoprobe prepacked screen were obtained in the same manner as for the wick sparger (Sparger I). The pumping rates were calculated as in Table 3.4. As shown in Table 3.5, the mass transfer coefficient for the collared sleeve and Geoprobe are about equivalent to each other and the wick sparger up to $12 \mathrm{~L} / \mathrm{min}$ of air. The pumping rate for the Geoprobe was reported as $126 \mathrm{~L} / \mathrm{min}$ because the data was collected in 10 second intervals. However, the DO started dropping rapidly at the higher air flow rates which would mean higher pumping rates. The primary conclusion from these data is that an open tube sparger design seems preferable to the Sparger I design and its internal packing, which contributes to pressure drop and reduced pumping rates.

Table 3.5 Mass transfer coefficient and pumping rate for the wick sparger (WS), collared sleeve (CS), and Geoprobe well screen (Geo).

\begin{tabular}{|c|c:c|c|c|c|c|}
\hline \multirow{2}{*}{$\begin{array}{c}\text { Air Flow } \\
(\mathrm{L} / \mathrm{min})\end{array}$} & \multicolumn{3}{|c|}{$\begin{array}{c}\mathrm{k}_{\mathrm{a}} \mathrm{a} \\
\left(\mathrm{min}^{-1}\right)\end{array}$} & \multicolumn{3}{c|}{$\begin{array}{c}\text { Pumping Rate } \\
(\mathrm{L} / \mathrm{min})\end{array}$} \\
\cline { 2 - 8 } & WS & $\mathrm{CS}$ & Geo & WS & $\mathrm{CS}$ & Geo \\
\hline 1.8 & 0.6 & 0.5 & 0.3 & 8.4 & 3.6 & 2.8 \\
\hline 3.6 & 1.25 & -- & -- & 19.5 & -- & -- \\
\hline 6 & 1.35 & 1.7 & $0.5(?)$ & 19.5 & 5.5 & 4.1 \\
\hline 9 & 1.85 & -- & -- & 25.2 & -- & -- \\
\hline 12 & 2.0 & 4.4 & 5.8 & 31.5 & 13.8 & 63 \\
\hline 18 & 2.15 & 10.2 & 13.6 & 32.6 & 19.7 & 126 \\
\hline 25 & 6.05 & 22.5 & 22.5 & 42 & 19.7 & 126 \\
\hline 40 & 5.2 & -- & -- & 52.5 & -- & - \\
\hline
\end{tabular}




\section{FIELD EVALUATION OF DIRECT PUSH GROUNDWATER CIRCULATION WELLS}

A detailed field evaluation of the DP-GCWs was conducted in a gasoline contaminated aquifer near Rocky Point, NC. This evaluation was conducted in three separate phases in an intensively instrumented test area approximately $600 \mathrm{ft}$ downgradient from the location of the original spill.

In the Phase 1, a single geotextile DP-GCW identical to Sparger I was installed and monitored over a 163 day period to evaluate its field scale performance. While the geotextile well was effective in adding dissolved oxygen to the groundwater and removing dissolved hydrocarbons, its pumping efficiency was low as predicted by the relationships presented in Chapter 3. Based on this field test, the Sparger I design was judged not to be an effective approach for groundwater remediation at most sites. However it may be possible to develop other alternative geotextile designs that are effective. Complete results from the Phase 1 tests can be found in Vergonio (1999).

Phases 2 and 3 focused on the development and evaluation of the 1.0-inch PVC DP-GCWs. In Phase 2, a single DP-GCW was installed and monitored over a 73-day period. In Phase 3, a barrier consisting of twelve DP-GCWs were installed $5 \mathrm{ft}$ on-center (OC) perpendicular to the groundwater flow direction and monitored over a 141 day period. The DP-GCWs in Phases 2 and 3 were constructed from 1.0-inch PVC with 15 percent of the air supply tubing length wrapped in a tangled mesh drainage mat geotextile (Enkamat 7010 ) to provide surface area for microbial growth and formation of inorganic precipitates similar to the Design V. While Design V provided the lowest water flowrate of the PVC designs for a given airflow, this limitation was not judged to be severe given the very low airflow rates required for these designs. Air was supplied to the DP-GCW from a heavy-duty, $3 \mathrm{Hp}$, oil-less air compressor. During Phases 2 and 3, the airflow rate was maintained between 0.03 and $0.04 \mathrm{cfm}$ to each DP-GCW.

The hydrogeology and contaminant distribution at this site have been previously described by Borden et al (1995). The aquifer near the test area consists of dark gray and green micaceous fine sand overlain by a 3-6 ft confining layer of orange brown clayey-sand. The hydraulic conductivity (K) varies from $\sim 50 \mathrm{ft} / \mathrm{d}$ at 7 to $10 \mathrm{ft}$ BGS to $\sim 5 \mathrm{ft} / \mathrm{d}$ at $25 \mathrm{BGS}$. The vertically averaged $\mathrm{K}$ is $25 \mathrm{ft} / \mathrm{d}$ based on four hydraulic conductivity profiles surrounding the test area (Stewart, 2000). Groundwater flow is from north to south at an average velocity of $0.65 \mathrm{ft} /$ day. The depth to the water table varies between 0 and $5 \mathrm{ft}$ BGS depending on recent rainfall.

Figure 4.1 shows the layout of the test area during Phase 3. The single DP-GCW evaluated in Phase 2 is designated S on Figure 4.1. DP-GCWs S, S1 and S2, have ports at 7, 16, and $27 \mathrm{ft}$ BGS to allow water sample collection from inside the DP-GCW. Water level monitoring piezometers P1 and P2 were installed with intakes at 7, 17 and $27 \mathrm{ft} \mathrm{BGS.} \mathrm{Groundwater} \mathrm{samples} \mathrm{were} \mathrm{collected} \mathrm{using}$ twenty multi-level sampling (MLS) wells installed upgradient and downgradient of the DP-GCW barrier. The MLS sampling ports were constructed of 0.25 -inch polyethylene tubing with intakes at 7, 12, 17, 22 and $27 \mathrm{ft} \mathrm{BGS.} \mathrm{The} \mathrm{MLS} \mathrm{wells} \mathrm{and} \mathrm{DP-GCWs} \mathrm{were} \mathrm{monitored} \mathrm{periodically} \mathrm{for}$ benzene, toluene, ethylbenzene, xylene isomers, and trimethylbenzene isomers (BTEX-TMB), dissolved oxygen (DO), total and dissolved iron (Fe) and $\mathrm{pH}$ following standard analytical procedures. 


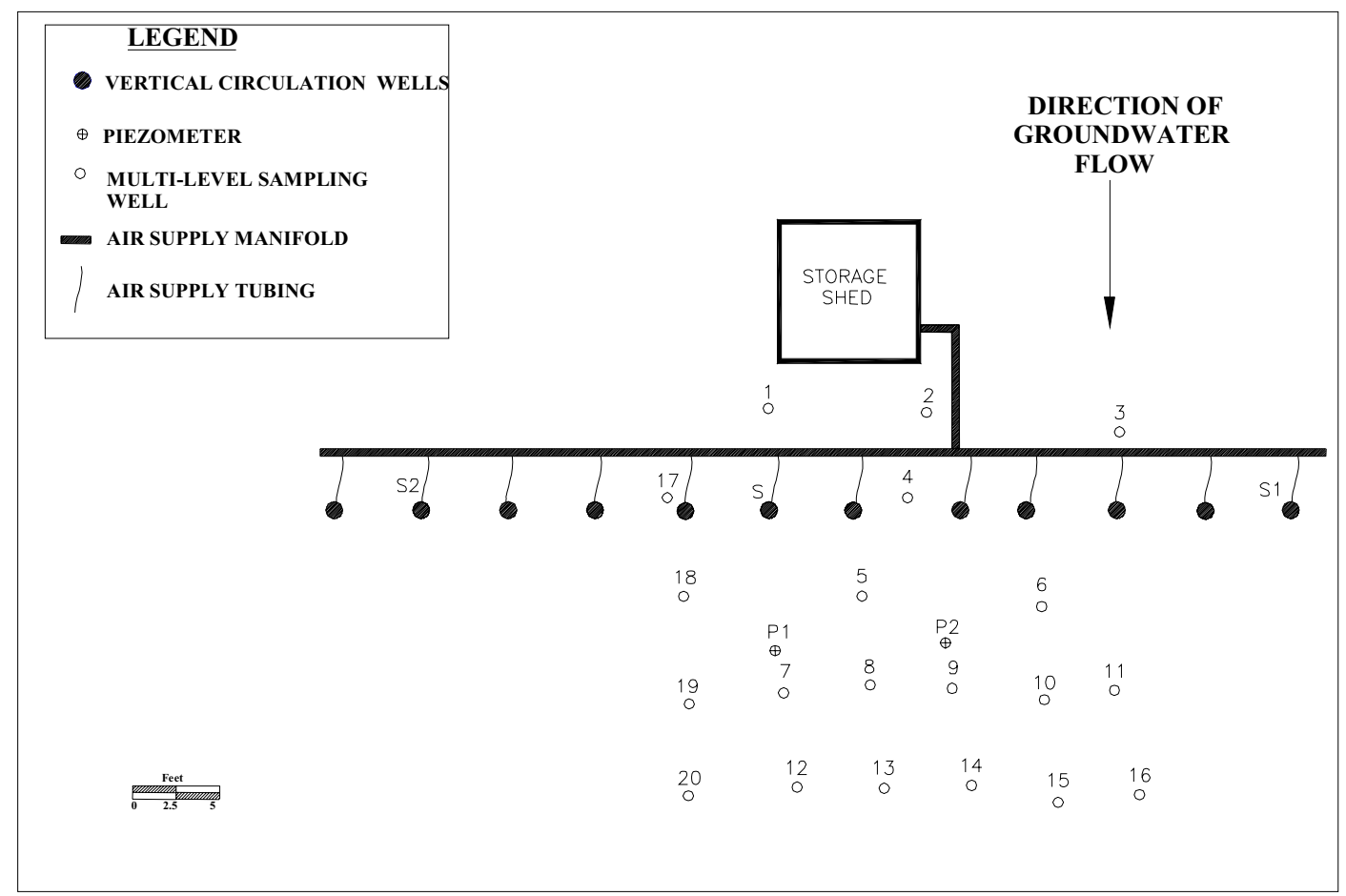

Figure 4.1 Arrangement of the field test site

\subsection{Phase 2 - Single DP-GCW test}

In Phase 2, air was supplied to a single DP-GCW over a 73-day period. During this period, monitoring data were collecting from inside the DP-GCW to evaluate the oxygenation and air stripping efficiency of the DP-GCW and evaluate the potential for clogging with iron hydroxides. Monitoring data were collected from the surrounding MLSs to evaluate the efficacy of the DP-GCW and determine the zone of influence.

\subsubsection{Monitoring inside the DP-GCW}

Figure 4.2 shows the variation in dissolved oxygen inside the single DP-GCW over time. Dissolved oxygen concentrations were lower $(\sim 4-5.5 \mathrm{mg} / \mathrm{L})$ at the bottom of the DP-GCW directly above the air injection point ( $27 \mathrm{ft}$ depth) and then increased to $6-8 \mathrm{mg} / \mathrm{L}$ as the water rose up inside the well indicating effective aeration within the well. There may also have been a slight upward trend in dissolved oxygen after the initial startup period as a small portion of the surrounding aquifer became oxygenated. However dissolved oxygen was never detected in any significant concentration $(>1 \mathrm{mg} / \mathrm{L})$ in the downgradient monitoring points during Phase 2. 


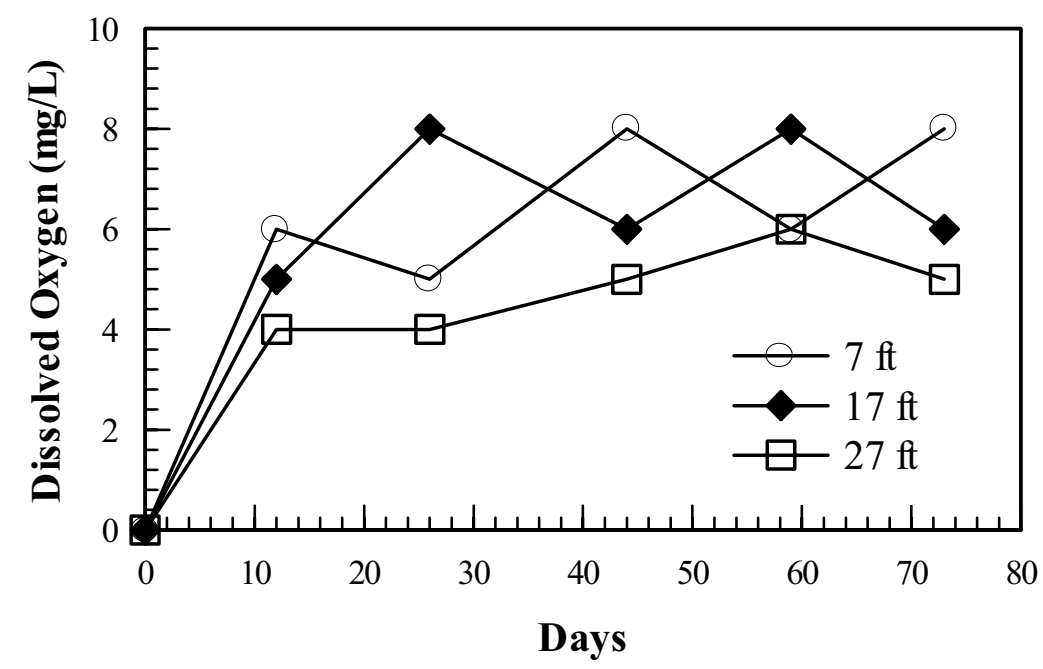

Figure 4.2 Variation in dissolved oxygen concentrations inside the DP-GCW during Phase 2

Figure 4.3 shows the variation in total BTEX (sum of the benzene, toluene, ethylbenzene and xylene concentrations) inside the DP-GCW over time. Total BTEX concentrations were very similar in all three sampling ports indicating that volatilization was approaching equilibrium by the first intake $(27 \mathrm{ft})$. After the initial startup period, there was a slight downward trend in BTEX concentration with time; total BTEX in the $7 \mathrm{ft}$ port immediately adjoining the discharge zone declined from $92 \mu \mathrm{g} / \mathrm{L}$ on day 12 to $65 \mu \mathrm{g} / \mathrm{L}$ on day 73 . The hydraulic residence time inside the DPGCW is between 0.6 and 2.0 minutes so biodegradation was probably not a significant process inside the well. However the dissolved oxygen present in the water should be sufficient to biodegrade 2,000 to $2,700 \mu \mathrm{g} / \mathrm{L}$ of total BTEX, so the BTEX that was not volatilized should rapidly be biodegraded when it enters the aquifer.

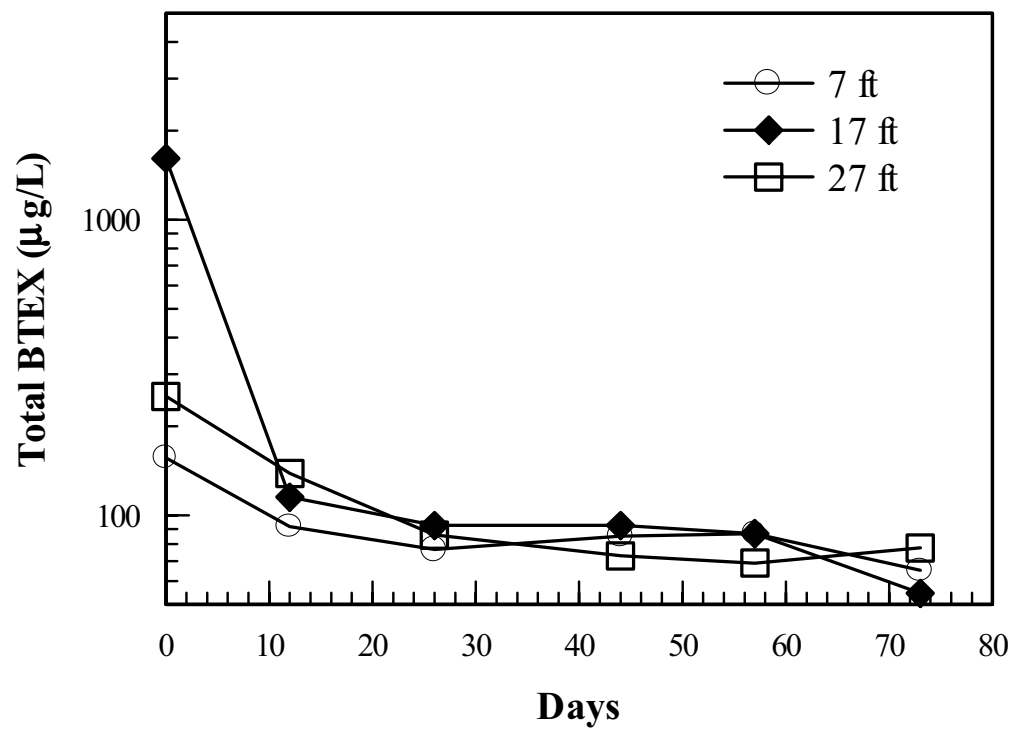

Figure 4.3 Variation in total BTEX concentrations inside the DP-GCW during Phase 2. 
Total and dissolved iron concentrations inside the DP-GCW were monitored over the course of the study due to concerns over the potential for iron clogging of the aquifer immediately adjoining the DP-GCW. Dissolved iron concentrations in the surrounding aquifer are high varying from 5 to 75 $\mathrm{mg} / \mathrm{L}$ depending on the depth in the aquifer. Throughout the study, total and dissolved iron concentrations were essentially identical indicating that all of the iron present was in a form that passed through a $0.45-\mu \mathrm{m}$ filter. Immediately after startup of air injection, dissolved iron inside the sparger varied from $24 \mathrm{mg} / \mathrm{L}$ in the $5 \mathrm{~m}$ intake to $30 \mathrm{mg} / \mathrm{L}$ in the $2 \mathrm{~m}$ intake indicating some precipitation of iron due to oxygen addition. Inspection of the tubing and tangled mesh geotextile netting at the completion of the test showed some iron staining but no significant clogging of the mesh. At the end of the 73-day test period, dissolved iron had declined to less than $1 \mathrm{mg} / \mathrm{L}$ at each intake inside the DP-GCW. Outside the well in the aquifer, there was no detectable change in dissolved iron concentrations over the test period. The decline in dissolved iron inside the well was presumably due to precipitation of iron in a small aerobic zone immediately adjoining the DP-GCW. However Br dilution tests conducted immediately after startup and at the end of the 73-day test period showed no detectable change in the DP-GCW pumping rate so any clogging that did occur must have been relatively minor.

\subsubsection{Aquifer monitoring}

There are large vertical variations in contaminant concentrations in the aquifer at the pilot test location with the highest total BTEX-TMB concentrations present at 12 and $17 \mathrm{ft} \mathrm{BGS.} \mathrm{Contaminant}$ concentrations are much lower just below the water table ( $7 \mathrm{ft} \mathrm{BGS)} \mathrm{and} \mathrm{deeper} \mathrm{in} \mathrm{the} \mathrm{aquifer} \mathrm{(22} \mathrm{and}$ $27 \mathrm{ft}$ BGS). Natural bioattenuation processes have degraded most of the toluene and o-xylene near the source area (Borden et al. 1995). As a consequence, benzene, m, p-xylene, ethylbenzene, and the trimethylbenzene isomers are the primary contaminants near the test area.

Figure 4.4 shows the variation in total BTEX concentrations over time in MLS-7 which is located approximately $10 \mathrm{ft}$ directly downgradient of the DP-GCW. BTEX levels decreased from 25 $\mu \mathrm{g} / \mathrm{L}$ to $7 \mu \mathrm{g} / \mathrm{L}$ at the $7 \mathrm{ft}$ depth. The BTEX levels at this depth were already low to begin with, so it is not certain how much of a role the DP-GCW plays in this decline. At the $12 \mathrm{ft}$ depth, BTEX levels declined sharply during the first 26 days of operation, experienced a slight increase at day 44 and then continued to decline. At the $17 \mathrm{ft}$ depth, BTEX levels decreased from $1898 \mu \mathrm{g} / \mathrm{L}$ to $196 \mu \mathrm{g} / \mathrm{L}$. There were no significant changes at the $22-\mathrm{ft}$ and $27-\mathrm{ft}$ depths. 


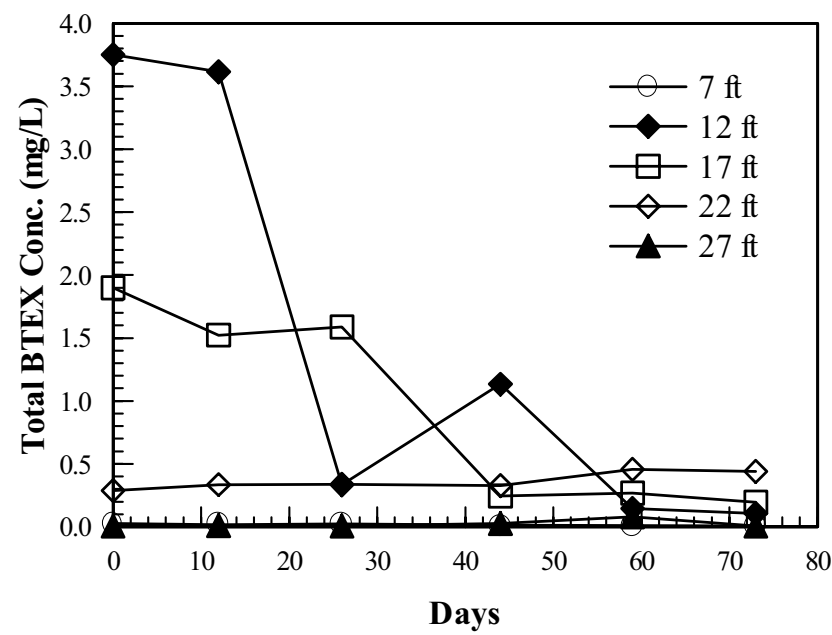

Figure 4.4 Total BTEX concentration at each sampling depth vs time for MLS-7.

The effect of the DP-GCW on the total BTEX distribution at the $7 \mathrm{ft}, 12 \mathrm{ft}, 17 \mathrm{ft}, 22 \mathrm{ft}$ and $27 \mathrm{ft}$ depths is illustrated in Figures 4.5 to 4.9. The area of the black circles shown in the figure is proportional to the measured total BTEX concentration. Prior to air injection on October 2nd, total BTEX was uniformly distributed upgradient and downgradient of the DP-GCW. After 73 days of air injection (December 14th), total BTEX concentrations were substantially reduced directly downgradient of the DP-GCW at the $12 \mathrm{ft}$ and $17 \mathrm{ft}$ depths. At the $12 \mathrm{ft}$ depth, total BTEX concentrations have been substantially reduced in a $\sim 10 \mathrm{ft}$ wide zone downgradient of the DP-GCW. At the $17 \mathrm{ft}$ depth, the DP-GCW appears to have had little effect on wells that were not directly downgradient (i.e. $5 \mathrm{ft}$ to the left or right). At the $22 \mathrm{ft}$ depth, the DP-GCW had no effect on total BTEX concentrations directly down gradient. However total BTEX concentrations may have increased slightly to the left and right suggesting some vertical flow. The single DP-GCW did not appear to have any effect on total BTEX concentrations at the $27 \mathrm{ft}$ depth during Phase 2.

To aid in understanding the results of the Phase 2 evaluation, the numerical models MODFLOW (McDonald and Harbaugh, 1983) and RT3D (Clement, 1997) were used to simulate the groundwater flow field and contaminant distribution in the vicinity of a single DP-GCW. MODFLOW was used to simulate the hydraulic effects of the DP-GCW on the pressure distribution in the aquifer and generate input for RT3D. Input parameters for MODFLOW included the DP-GCW injection and withdrawal rates, ambient hydraulic gradient, permeability distribution of the aquifer and the ratio of horizontal to vertical permeability (assume to be 5:1). RT3D was used to simulate the effects of discharging oxygenated and partially treated groundwater on the Total BTEX distribution in the aquifer using the instantaneous reaction package. Input parameters for RT3D include the initial Total BTEX distribution in the aquifer, effective sorption parameters for oxygen and BTEX, and the oxygen and BTEX concentrations in the water discharged from the DP-GCW.

Figure 4.10 shows the simulated total BTEX distribution 75 days after startup in a vertical profile along a streamline passing from the upgradient boundary through a single DP-GCW to the downgradient boundary. Upgradient of the DP-GCW, the highest contaminant concentrations are present at 12 to $17 \mathrm{ft} \mathrm{BGS} \mathrm{(7} \mathrm{to} 12 \mathrm{ft}$ below the water table). The single DP-GCW operates by capturing the contaminated water from the middle and bottom of the aquifer, aerating the water and stripping volatiles, and then discharging the treated water near the water table. The numerical simulations (Figures 4.10) predict that a single DP-GCW should result in the formation of a roughly $\mathrm{V}$-shaped cleanup zone directly downgradient of the DP-GCW with widest part of the $\mathrm{V}$ at the water 
table and the point of the $\mathrm{V}$ approximately midway vertically through the aquifer. However a single DP-GCW will not force clean water deeper into the aquifer and does not result in a closed circulation cell. Figure 4.11 shows the simulated treatment zone in a horizontal slice through the aquifer at $\sim 12$ BGS, 75 days after startup of a single DP-GCW. The predicted cleanup zone is 8 to $16 \mathrm{ft}$ wide (gray area in Figure 4.11) while the field monitoring indicates the actual cleanup zone in the aquifer is between 10 and $20 \mathrm{ft}$ wide. In summary, the field monitoring results reasonably match the mathematical model predictions indicating the single DP-GCW performed roughly as expected.

Additional simulations were conducted using MODFLOW and RT3D to understand how multiple DP-GCW would interact. Figure 4.12 shows a vertical profile of the simulated flow field when DP-GCWs are installed $10 \mathrm{ft}$ on center perpendicular to the groundwater flow direction. These results illustrate that when DP-GCWs are installed in a line next to each other, groundwater will be forced deeper into the aquifer resulting in effective treatment throughout the full vertical interval. 


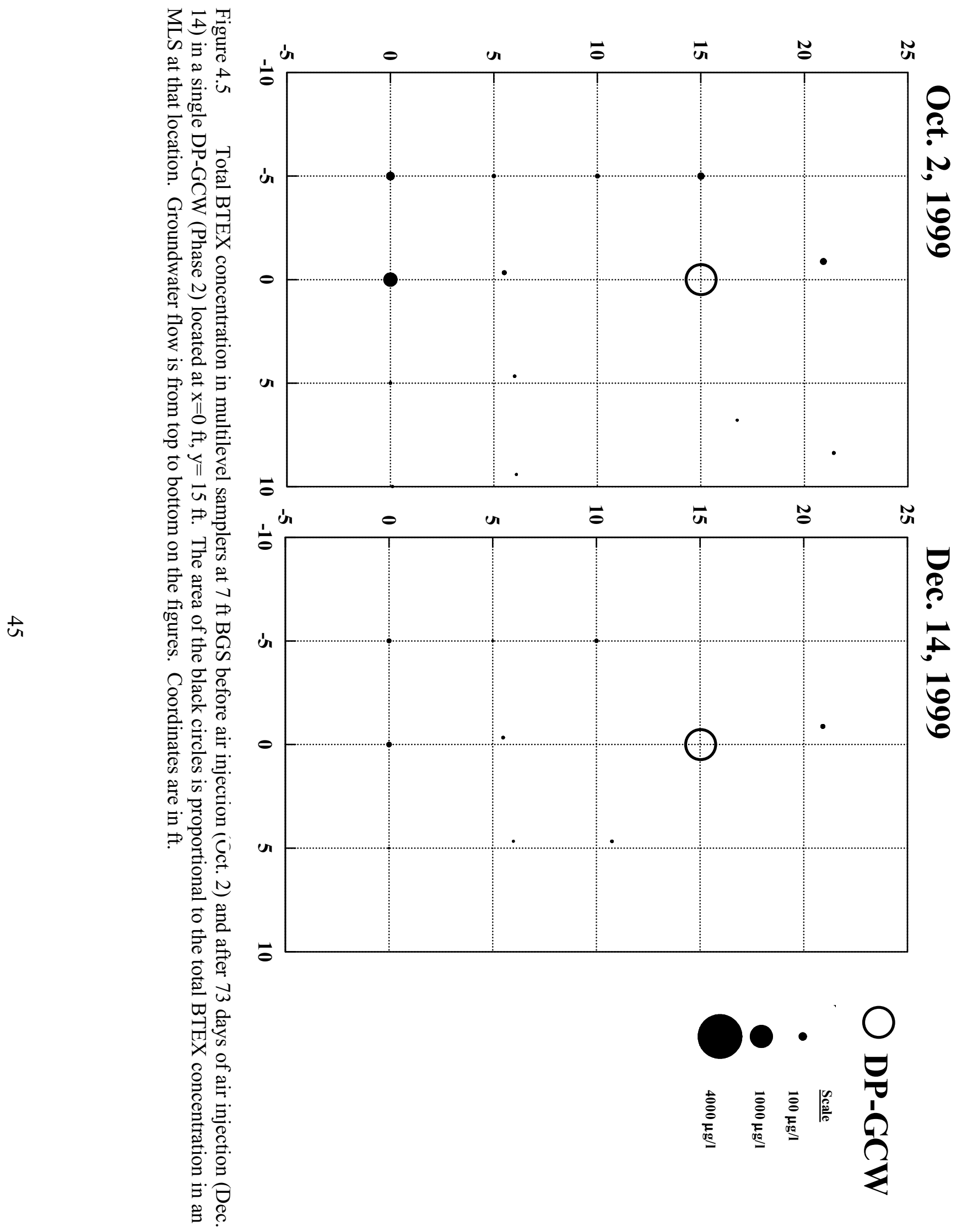




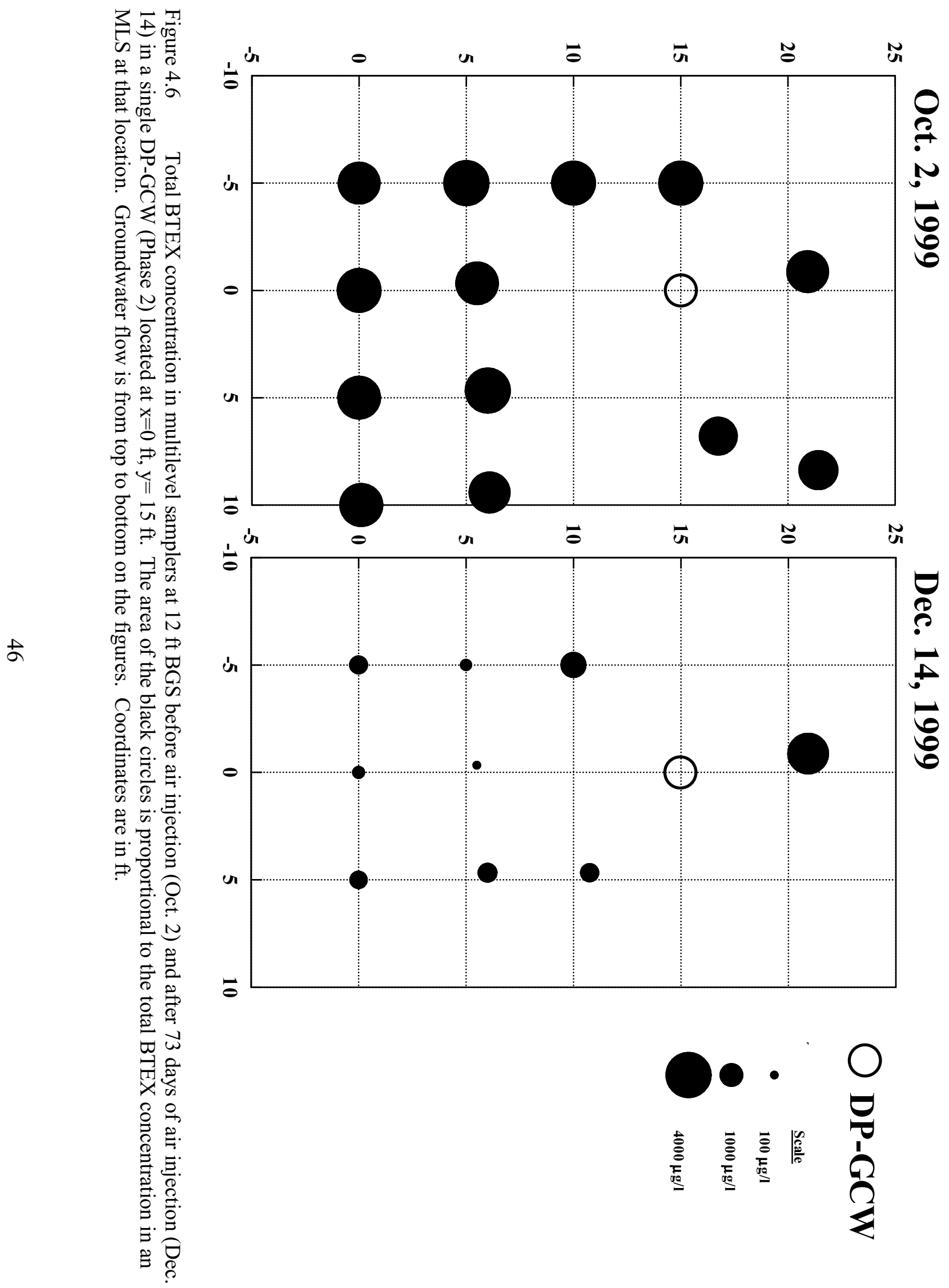




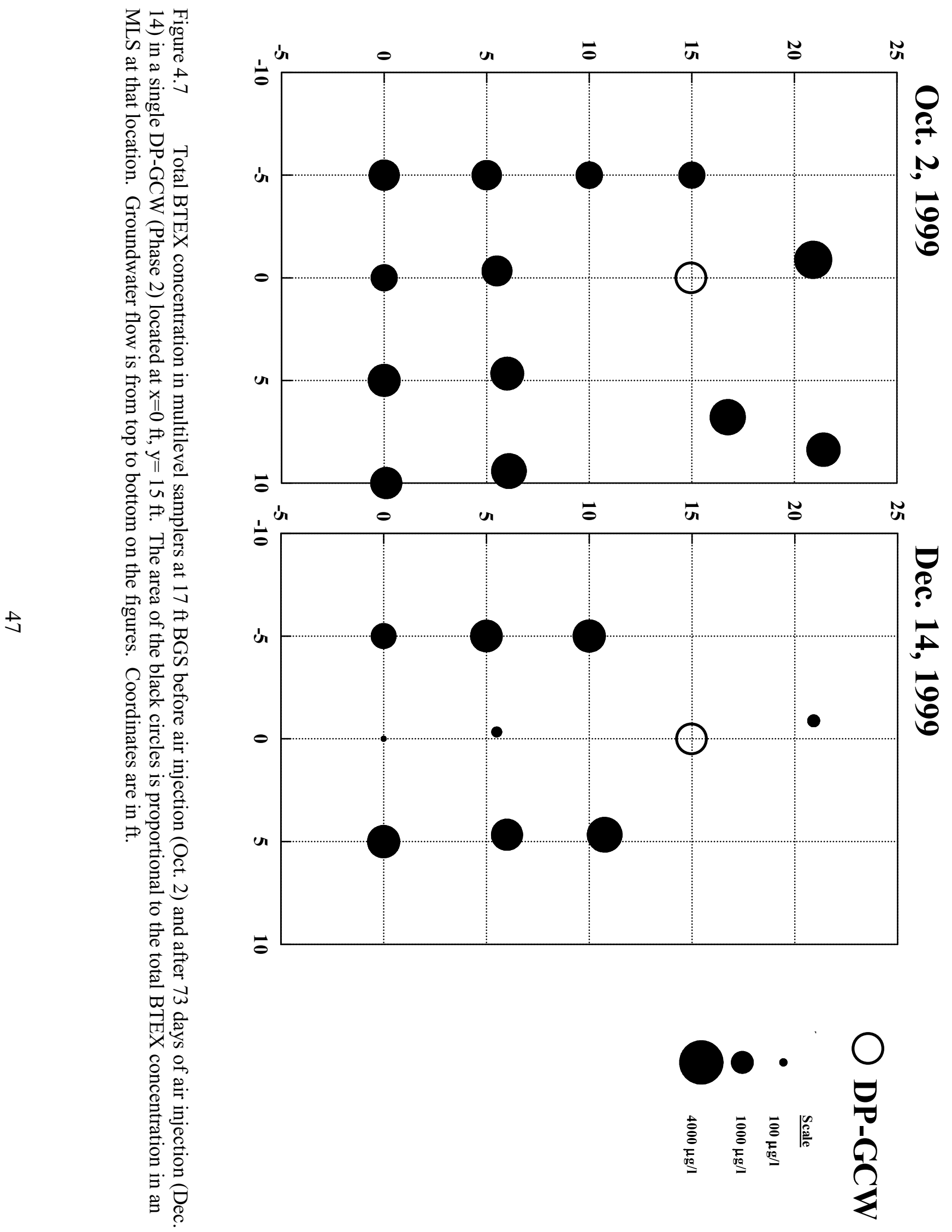




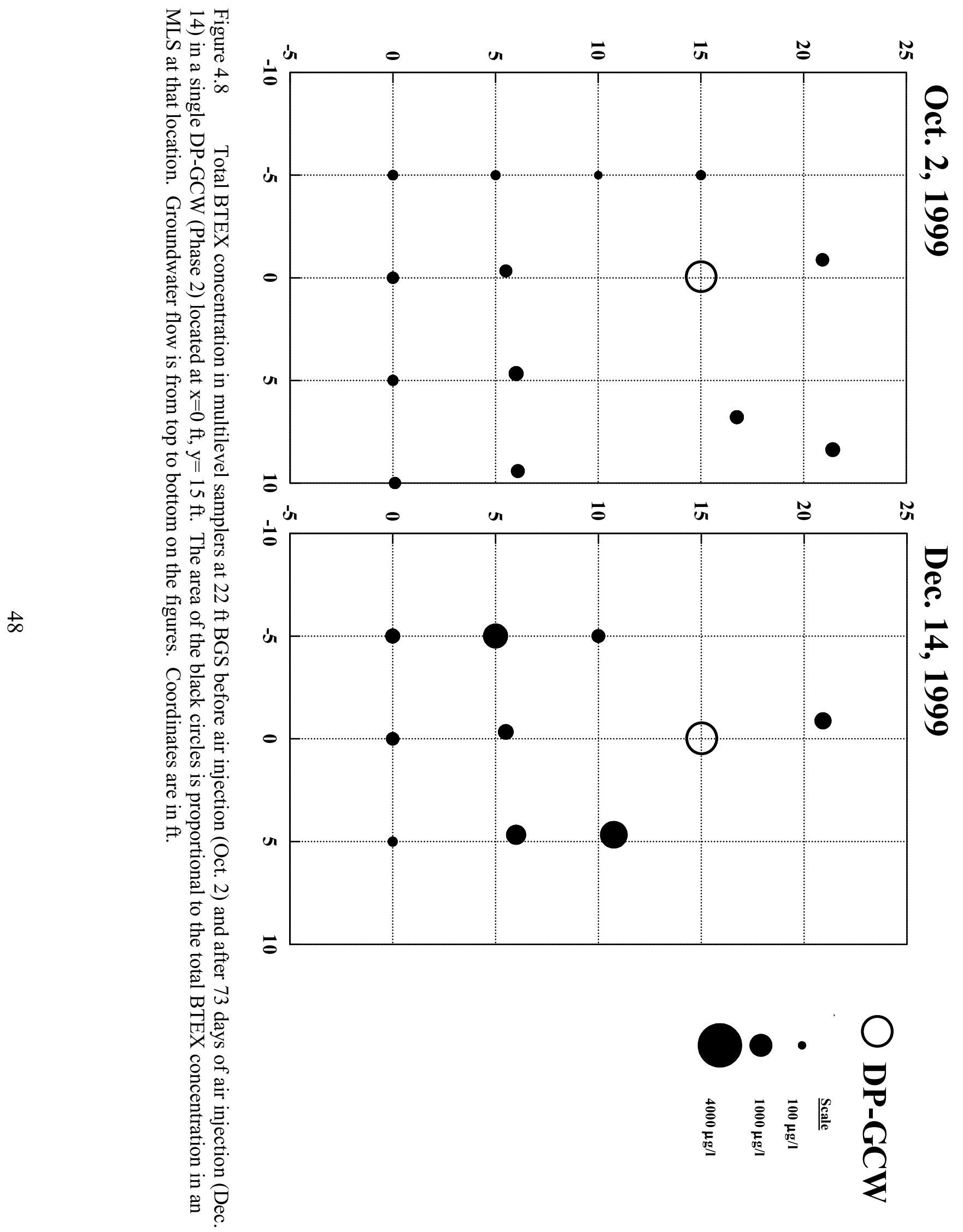








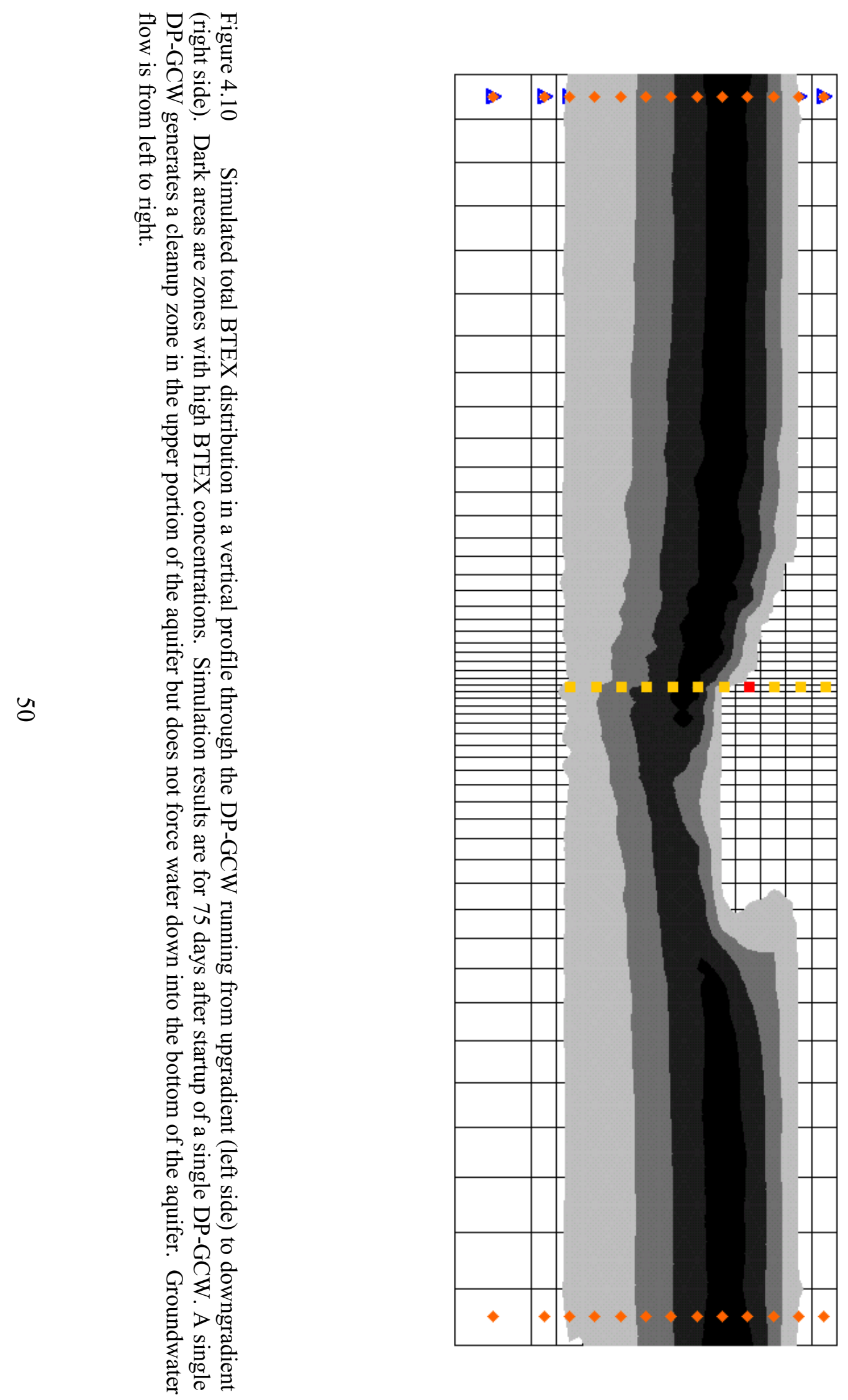


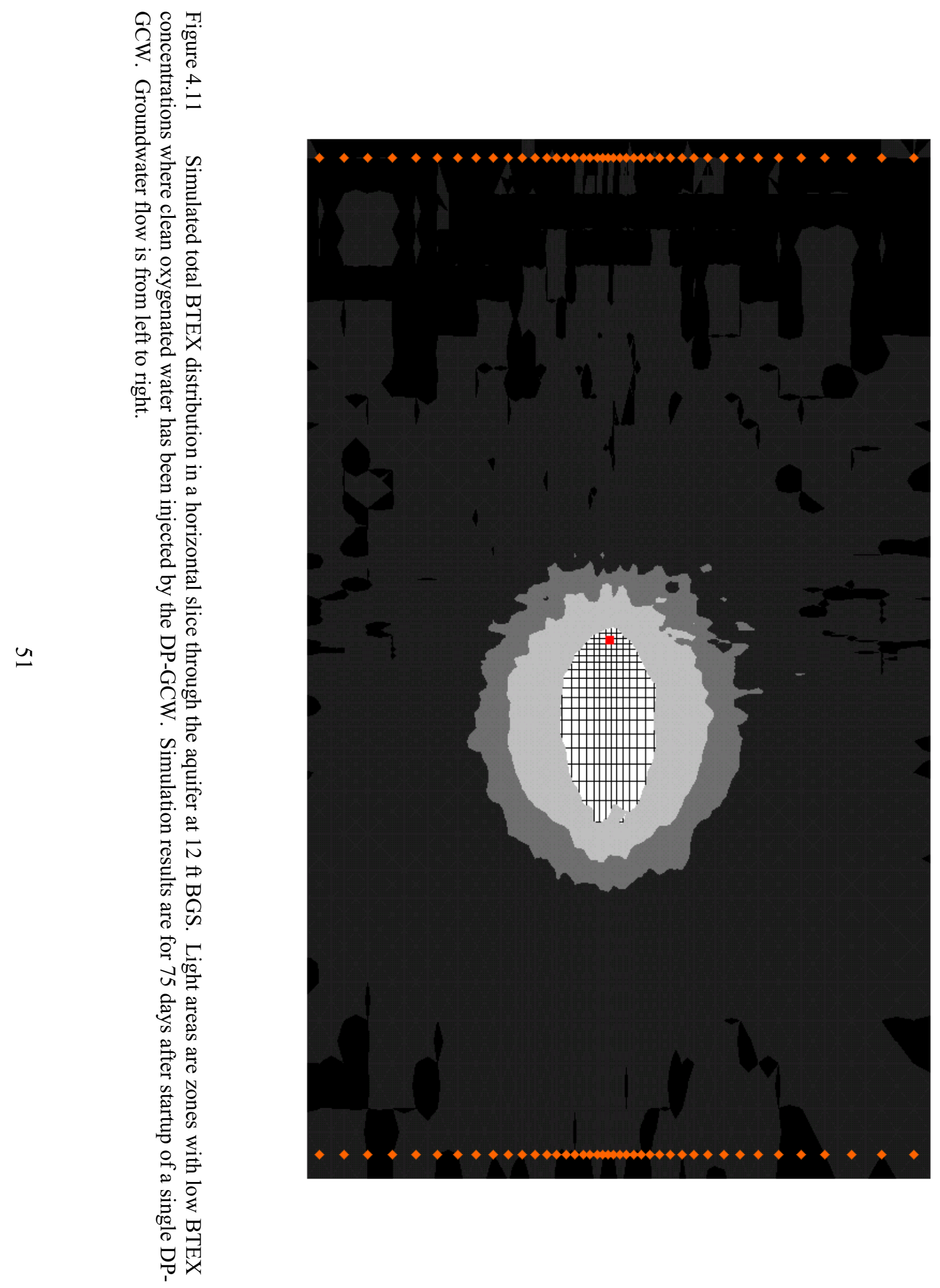




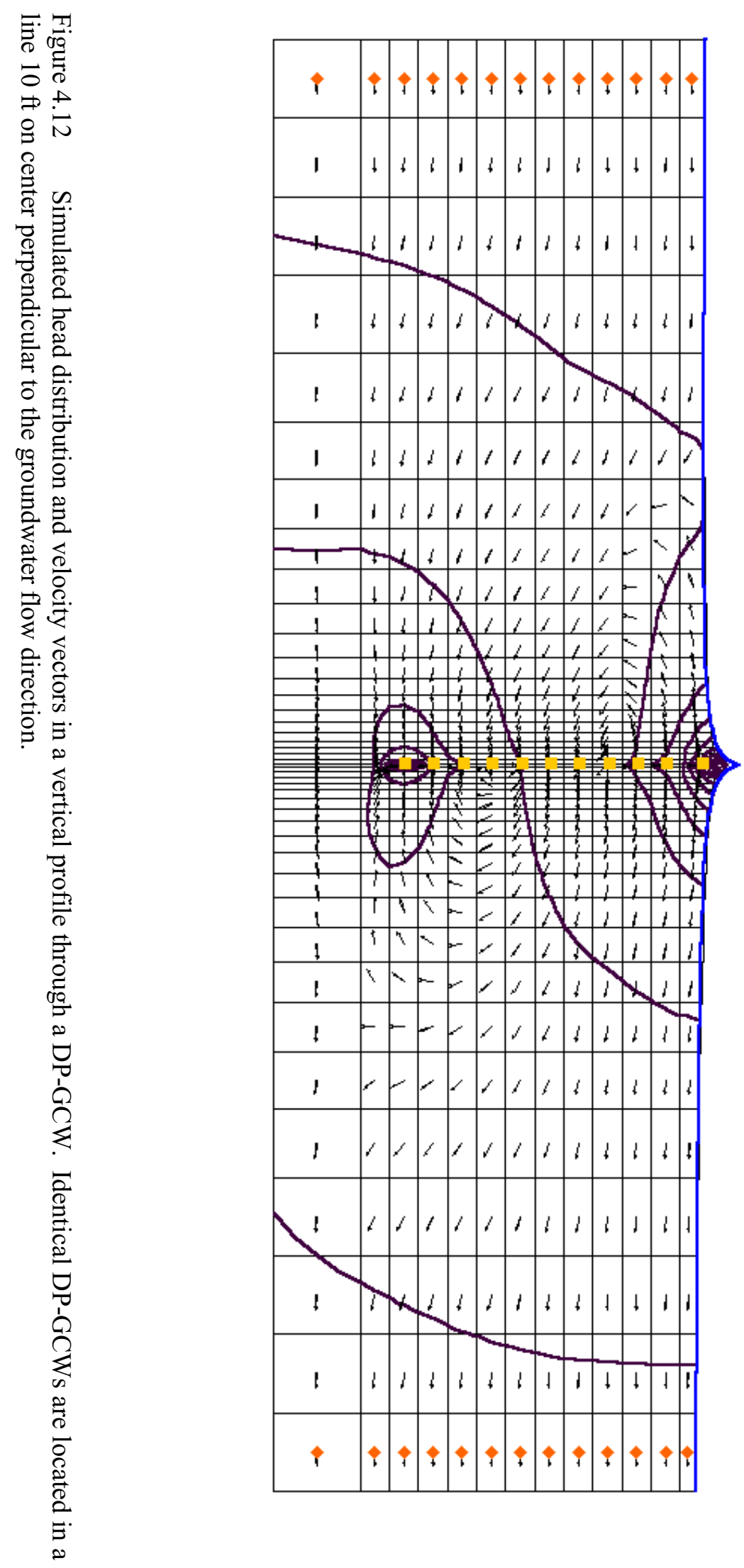




\subsection{Phase 3 - DP-GCW barrier evaluation}

In Phase 3, air was supplied to a line of DP-GCW over a 141 day period. A total of twelve DPGCWs were installed approximately $5 \mathrm{ft} \mathrm{OC}$ perpendicular to the groundwater flow direction. During the first 44 days of operation, air was supplied to every other well while the other wells were allowed to operate as passive recirculation wells allowing water to more easily circulate down through the aquifer. Starting at day 45, all twelve DP-GCWs received air. Monitoring data were collecting from inside the DP-GCW to evaluate the oxygenation and air stripping efficiency of the DP-GCW and evaluate the potential for clogging with iron hydroxides. Monitoring data were also collected from the surrounding MLS to evaluate the overall efficacy of the DP-GCW barrier and to determine if groundwater recirculation through the DP-GCWs could be achieved.

\subsubsection{Monitoring inside the DP-GCWs}

Figure 4.13 shows the variation in dissolved oxygen inside three of the DP-GCWs during Phase 3. Dissolved oxygen concentrations in the $27 \mathrm{ft}$ intakes of the DP-GCWs increased from less than $2 \mathrm{mg} / \mathrm{L}$ immediately after start up to over $8 \mathrm{mg} / \mathrm{L}$ by the end of the test period. Dissolved oxygen concentrations in the $17 \mathrm{ft}$ and $7 \mathrm{ft}$ intakes increased from $5-7 \mathrm{mg} / \mathrm{L}$ to saturation values $(\sim 10$ $\mathrm{mg} / \mathrm{L}$ )by the end of the test. The steady increase in dissolved oxygen in the lower portion of the DPGCW is likely due to recirculation of oxygenated water back down into deeper portions of the aquifer adjoining the DP-GCW intake zone.

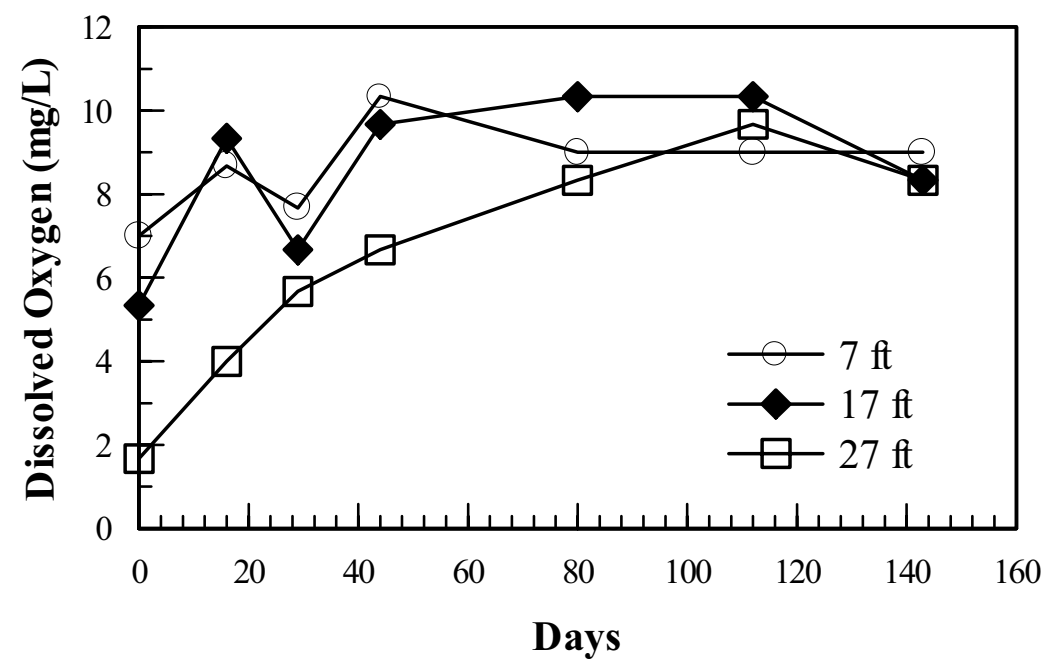

Figure 4.13 Variation in dissolved oxygen concentrations inside the DP-GCWs during Phase 3. Dissolved oxygen concentrations are the average of concentrations measured in S, S1 and S2 at each depth.

Figure 4.14 shows the variation in Total BTEX (sum of the benzene, toluene, ethylbenzene and xylene concentrations) inside the DP-GCW over time. Throughout the test period, total BTEX concentrations were higher in the $27 \mathrm{ft}$ intake than at the $7 \mathrm{ft}$ intake indicating volatilization was occurring as air and water flowed upward through the well. Over the course of the 141 day operating period, total BTEX concentrations decreased at all depths. The reason for this decrease is not known but may be due to biodegradation of BTEX in aerobic portions of the aquifer before the groundwater enters the DP-GCW. This suggests that multiple DP-GCW may be causing oxygenated, treated groundwater to flow downward through the aquifer resulting in a complete recirculation cell. 




Figure 4.14 Variation in Total BTEX concentrations inside the DP-GCW during Phase 3.

Total and dissolved iron concentrations inside the DP-GCW were monitored over the course of the study due to concerns over the potential for iron clogging of the aquifer immediately adjoining the DP-GCW. Dissolved iron concentrations in the surrounding aquifer are high varying from 5 to 75 $\mathrm{mg} / \mathrm{L}$ depending on the depth in the aquifer. Total and dissolved iron concentrations inside the DPGCWs were 1 to $3 \mathrm{mg} / \mathrm{L}$ immediately after startup of the barrier and then dropped below our analytical detection limit $(<0.5 \mathrm{mg} / \mathrm{L})$. Inspection of the tubing and tangled mesh geotextile netting inside the DP-GCWs did not show any evidence of iron fouling. The decline in dissolved iron inside the well was presumably due to precipitation of iron in an aerobic zone adjoining the intake section of DP-GCW. These results also suggest that multiple DP-GCW were causing oxygenated groundwater to flow downward through the aquifer completing a recirculation cell.

\subsubsection{Aquifer monitoring}

As previously discussed, the highest total BTEX-TMB concentrations are present in the aquifer at 12 and $17 \mathrm{ft}$ BGS. Figure 4.15 shows the variation in total BTEX concentrations over time in MLS-7 located approximately $10 \mathrm{ft}$ directly downgradient of the DP-GCW operated in the Phase 2 evaluation. As previously discussed, the BTEX levels at the $7 \mathrm{ft}$ depth were already so low that it is difficult to determine if the DP-GCWs had an impact. At the $12 \mathrm{ft}$ depth, BTEX levels declined sharply and then slowly increased until they reached about half of the initial concentration. At the 17 $\mathrm{ft}$ depth, total BTEX has slowly declined from $3 \mathrm{mg} / \mathrm{L}$ to $1 \mathrm{mg} / \mathrm{L}$ while at the $22 \mathrm{ft}$ depth there has been a steady increase in total BTEX from 0.2 to $1.0 \mathrm{mg} / \mathrm{L}$. At the $27 \mathrm{ft}$ depth there has been a small gradual decline in BTEX. These initial results might suggest that the multiple DP-GCWs installed in Phase 3 are having less effect than the single DP-GCW operated in Phase 2. However closer analysis shows the delayed impacts of the deeper groundwater circulation. The $12 \mathrm{ft}$ and $17 \mathrm{ft}$ intakes are being cleaned more slowly because more water is being forced deeper into the aquifer. This is also causing a steady increase in BTEX in the $22 \mathrm{ft}$ intake as more highly contaminated groundwater from the 12 to $17 \mathrm{ft}$ depth is pushed downward in the aquifer. Ultimately, the DP-GCW system should be effective in flushing clean groundwater throughout the aquifer. However the cleanup time is being delayed by the slow rates of groundwater flow and sorption of BTEX to the aquifer material. 




Figure 4.15 Total BTEX concentration at each sampling depth vs time for MLS-7.

Figure 4.16 shows the variation in total BTEX concentrations over time in MLS-12 located approximately $5 \mathrm{ft}$ downgradient of MLS-7. Monitoring results at this well are similar to MLS-7 but somewhat delayed in time. At the $12 \mathrm{ft}$ and $17 \mathrm{ft}$ depths, BTEX levels declined over the first 80 days and then appeared to level out. At the $22 \mathrm{ft}$ depth there has been a steady increase in total BTEX from 0.3 to $0.8 \mathrm{mg} / \mathrm{L}$. At the $27 \mathrm{ft}$ depth there has been been no detectable change in BTEX.



Figure 4.16 Total BTEX concentration at each sampling depth vs time for MLS-12. 
The effect of the DP-GCW on the total BTEX distribution at the $7 \mathrm{ft}, 12 \mathrm{ft}, 17 \mathrm{ft}, 22 \mathrm{ft}$ and $27 \mathrm{ft}$ depths is illustrated in Figures 4.17 to 4.21. The area of the black circles shown in the figure is proportional to the measured total BTEX concentration. Prior to air injection on February 16th, total BTEX was uniformly distributed upgradient and downgradient of the DP-GCW. After 141 days of air injection (July 7th), total BTEX concentrations downgradient of the barrier were reduced by $86 \%$, $67 \%$ and $58 \%$ at the $7 \mathrm{ft}, 12 \mathrm{ft}$ and $17 \mathrm{ft}$ depths, respectively. At the $22 \mathrm{ft} \mathrm{depth}$, the DP-GCW barrier total BTEX increased from an average of $387 \mu \mathrm{g} / 1$ to $673 \mu \mathrm{g} / \mathrm{l}$. This is believed to result from the downward flow that is carrying more highly contaminated groundwater deeper into the aquifer. The DP-GCW barrier did not have any detectable effect on total BTEX concentrations at the $27 \mathrm{ft}$ depth during first 141 days of barrier operation. 


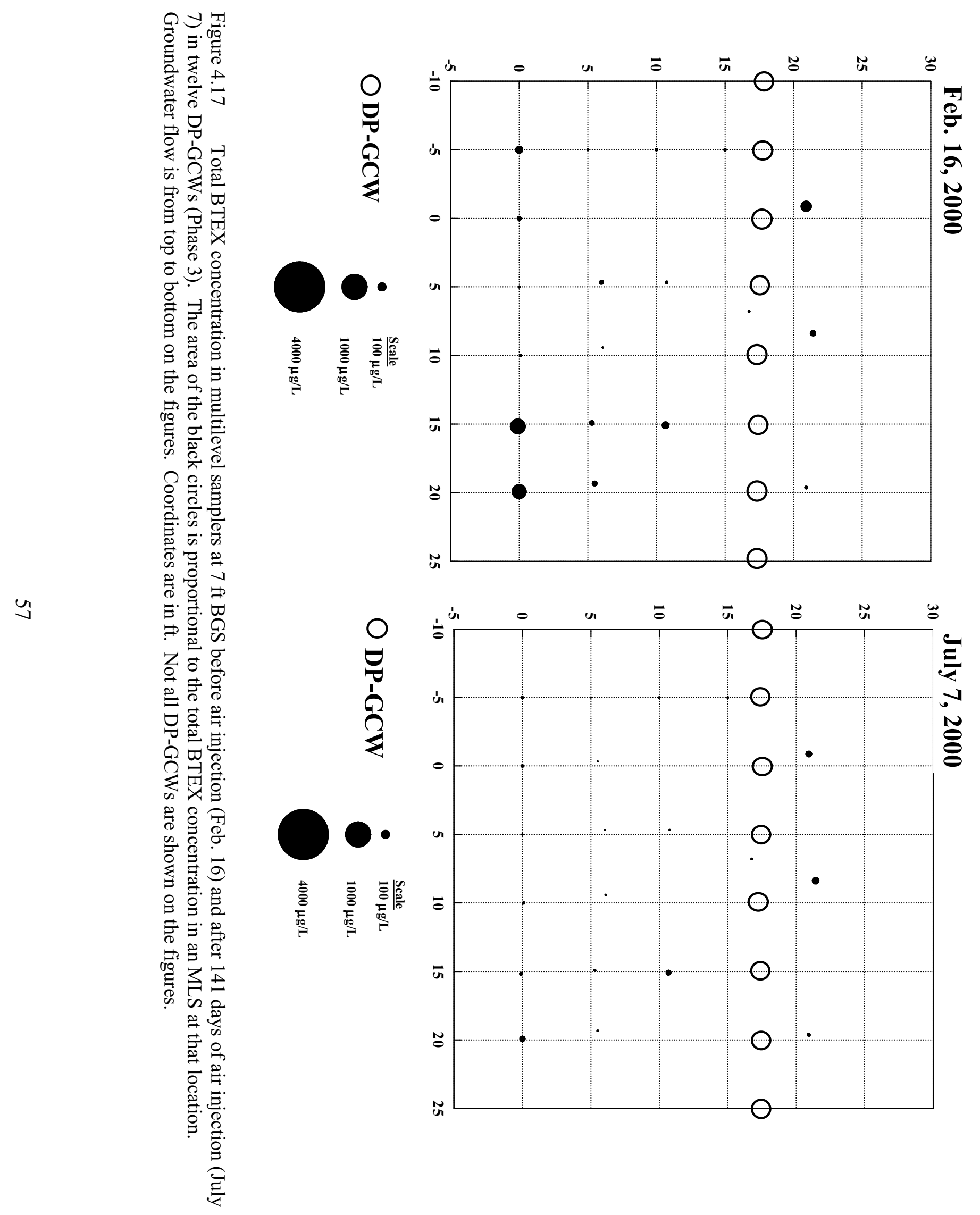




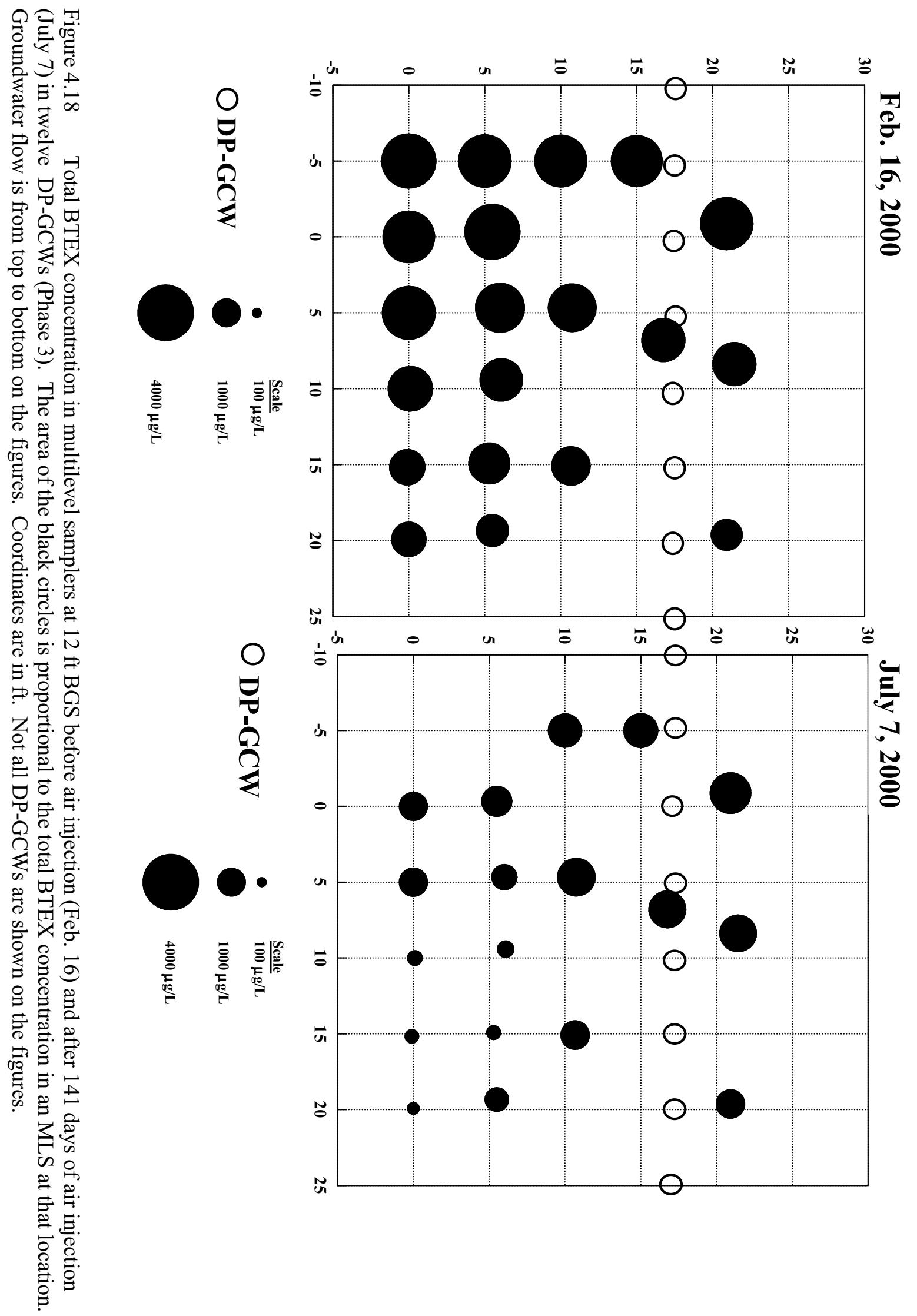




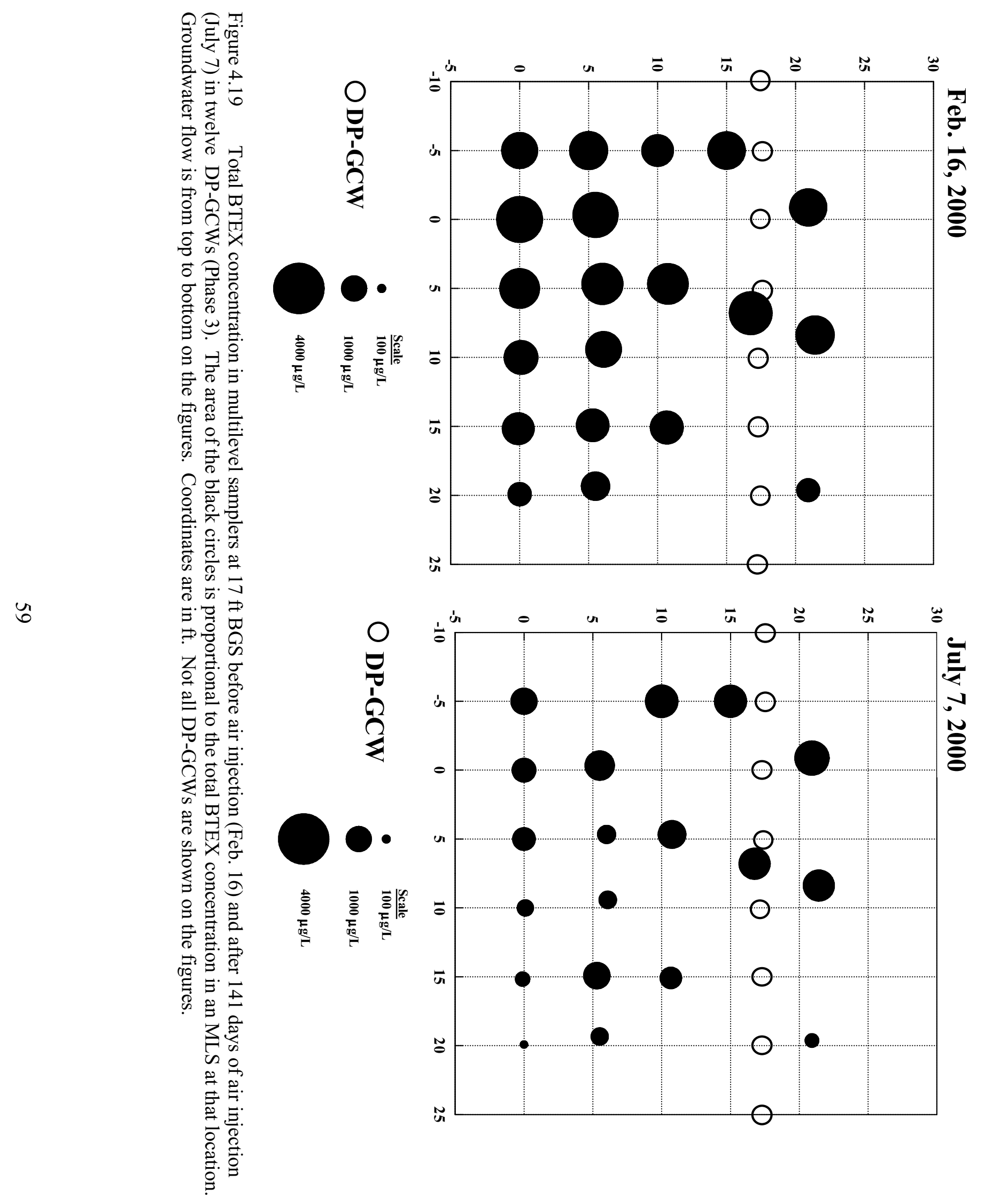




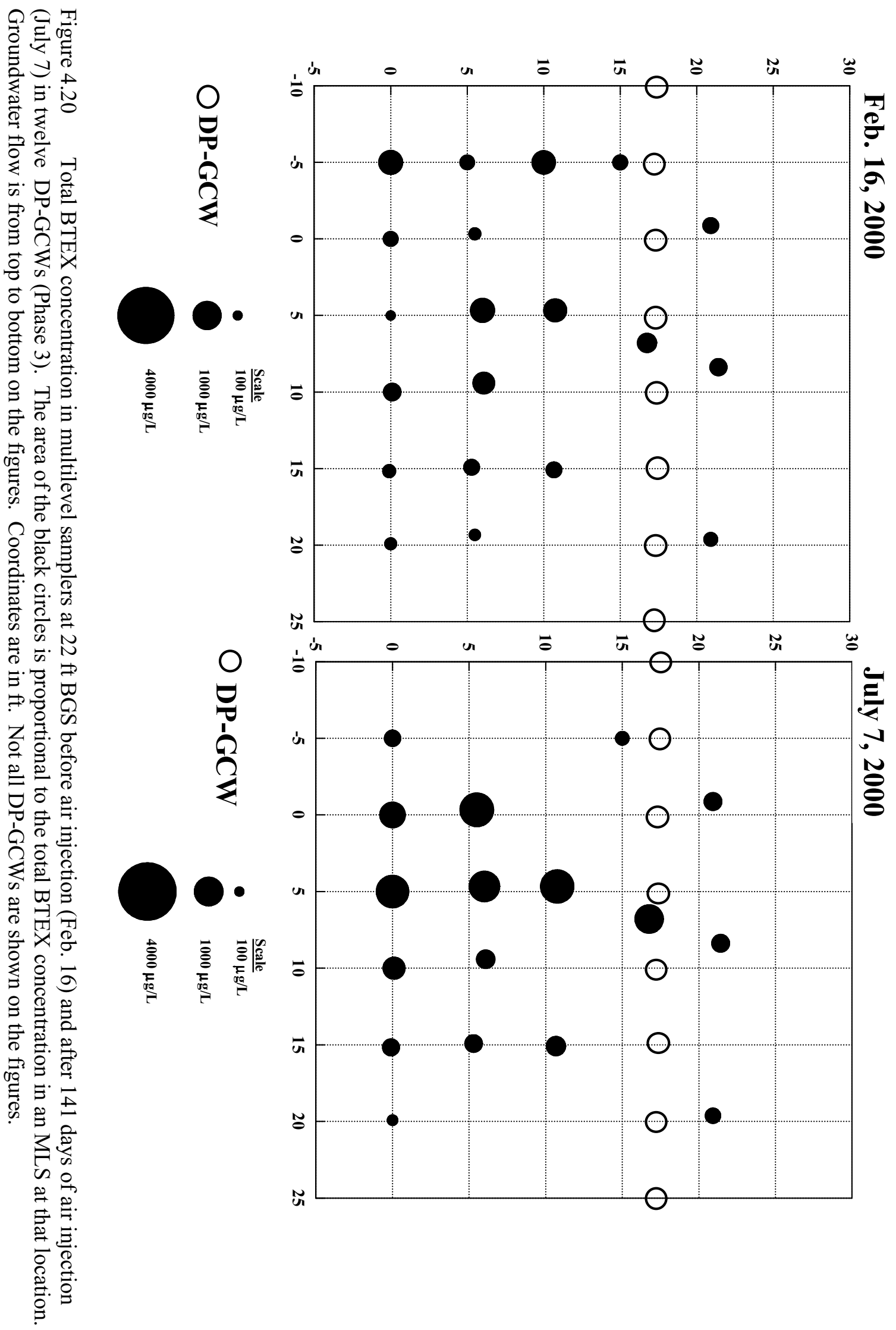




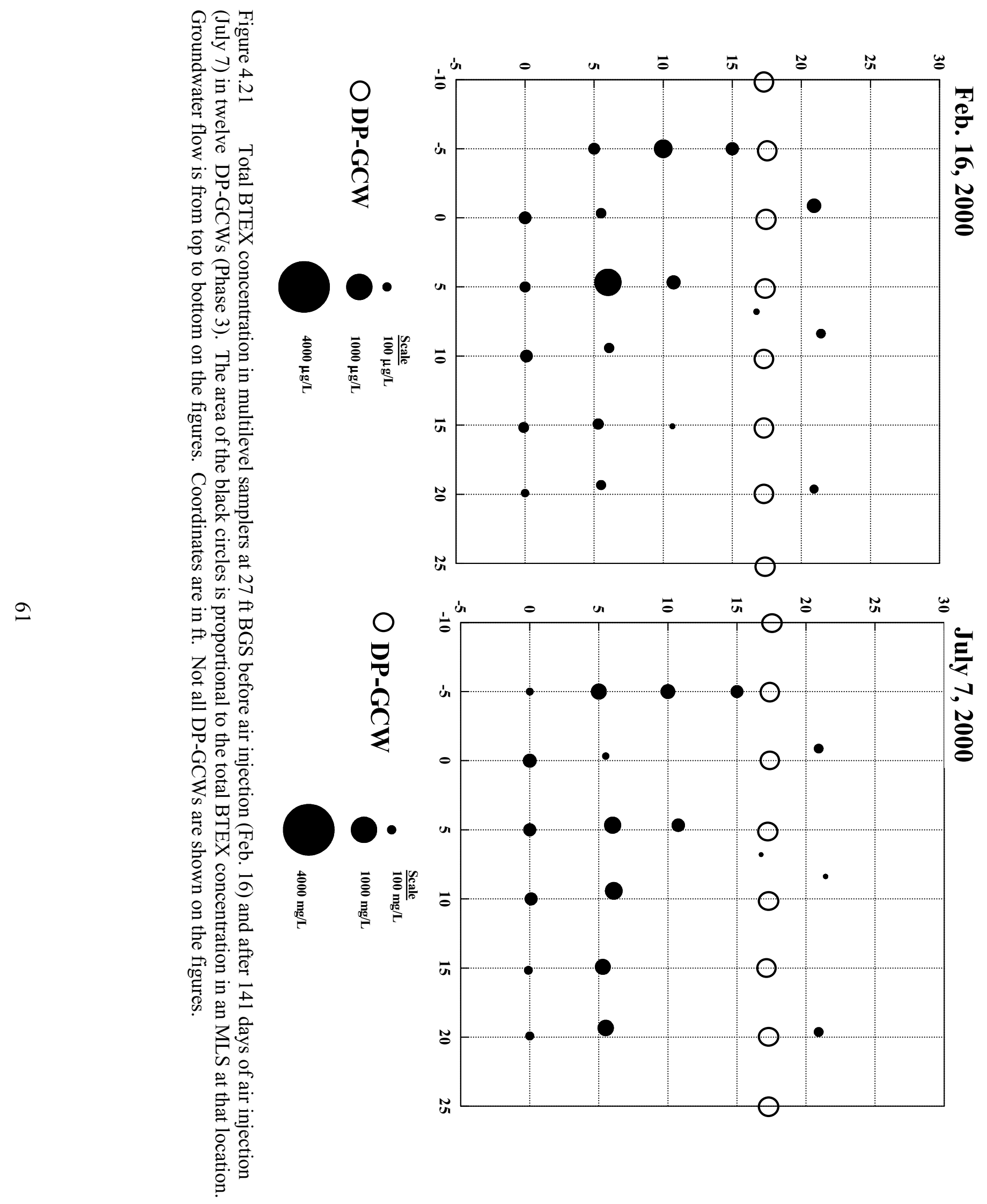




\section{CONCLUSIONS AND RECOMMENDATIONS}

\subsection{Summary conclusions}

In this work, a series of direct-push groundwater circulation wells (DP-GCW) arranged across the width of a BTEX plume was able to substantially remediate the plume. While a variety of types of groundwater circulation wells are available, the use of direct-push technology to install these wells enables a substantial reduction in the cost and complexity compared to other types presently available. This advantage comes with the limitations of direct-push technology, including poor utility in soils containing large amounts of rock or basalt. Direct push technology also has limitations on the depth that can be reached, but because BTEX contamination from motor fuels is typically found in the upper extent of an aquifer the hundred foot depth that direct push technology (in particular, Geoprobe) can reach should be adequate for many sites.

The wells used in this study were made of small diameter ( 0.8 inch inside diameter) slotted PVC well screen. This material is inexpensive and readily available. The use of such small wells achieved two goals: it allowed the use of the direct push technology to install the wells, and it required only a small air flow rate to generate an acceptable liquid pumping rate in each well. For the field test, about $1.2 \mathrm{~L} / \mathrm{min}$ of air was sparged into each well, generating about $1 \mathrm{~L} / \mathrm{min}$ of water circulation. Although this is low compared to the circulation rates of other published GCWs, the low capital and installation costs of direct push technology allow more wells to be installed to do the total amount of water treatment needed.

The number of wells necessary to treat a flowing plume of contaminant is determined by a balance between the volume of water pumped by a well (at a base case air sparging rate) and the volume of contaminated groundwater flowing through a rectangle of area equal to the depth of contamination in the aquifer times the distance between spargers. With the well to well spacing known from this calculation, the total number of wells needed is obtained by dividing the plume width at the treatment location by the well spacing. The hydrodynamics of the flows around these wells is such that, at the proper well spacing, all water from the water table down to the bottom of the contaminant must be captured and treated.

The amount of water pumped by each well at various air flow rates is a function of both the details of sparger construction (such as the actual well diameter, the air supply tube diameter, and the presence of any other internal elements such as sampling lines) as well as the aquifer permeability. Chapter three discussed these calculations in detail. To correct for unanticipated heterogeneities, one can measure the actual well pumping rate in the field using a tracer dilution test. The air flow rate to each sparger can then be individually regulated to assure that it is pumping at least the design amount of water. Excess pumping does not hurt the hydraulic performance although it does incur additional compression costs.

As with other GCWs, this system remediates the plume of BTEX or other volatile contaminants by two mechanisms. For BTEX, the primary mechanism is air stripping of the volatile components from the water which circulates into the well. For the conditions of this test, this mechanism was estimated to account for well over $90 \%$ of the BTEX removal. The second mechanism is biological degradation stimulated by the oxygen added to the water. This biodegradation could occur in the well itself (although we did not see evidence of significant amounts of biomass growth) or externally in the aquifer where bacteria attached to the soil react oxygen in the water flowing from the well with both unstripped BTEX in that water and sorbed BTEX on the soil with the bacteria.

Moreover, we have shown in computational fluid dynamics simulations that the circulation pattern around each well, and therefore well performance, is not strongly affected by unexpected gradients in aquifer permeability. Even assuming the presence of an unknown impermeable clay layer in the middepth of the contaminated zone did not prevent these spargers from treating all the water since two 
recirculation zones formed in that case, one each above and below the clay layer. The part of the GCW in each zone treats only half as much water, but the clay layer means that only half as much water is needed to be treated within each zone. As long as the contaminated water in each part of the aquifer is flowing in response to the same imposed hydraulic gradient so the flow of contaminated water is proportional to the local aquifer permeability, the GCW will automatically balance its flow circulation to match.

\subsection{Potential applications}

This technology developed specifically for remediation of plumes of BTEX. Although the field trial did not remediate the site to drinking water standards in the time available, the spargers appeared to be working as intended and with more time would produce cleaned groundwater. Application to other sites of BTEX contamination caused by spilled fuels appears warranted. Because the primary mechanism of action is stripping of the volatile contaminants and secondarily oxygenation of the water so in situ microorganisms can bioremediate sorbed or trace soluble organics, this system would also be useful to treat other compounds which are volatile and not particularly soluble in water. Examples might include ethylene dibromide or styrene. Unfortunately, methyl tert-butyl ether - another common water contaminant derived from gasoline - is soluble in water and can not be effectively stripped using this type of system. However, if aerobic bacteria capable of rapidly degrading MTBE are developed, these spargers might be useful to add oxygen to the water for MTBE biodegradation while simultaneously stripping BTEX.

The use of direct push technology to install these spargers also makes them most applicable to shallow plumes preferably in soils lacking buried large rocks, boulders, or lava flows. One way to extend the utility of this sparger technology in such soils, although it is more expensive, is to drill larger diameter holes (say, four inch diameter) to the desired depth then to install a small diameter sparger in them and backfill the hole with sand. As long as the sand fill is equally or less permeable than the aquifer, the sparger will still capture, air strip, oxygenate, and circulate water as described in this report.

Because the wells described in this report are small, easily installed, and require little in the way of surface facilities except a small air supply line, they can potentially be installed through a basement floor to treat a plume flowing under a building. Of course, the initial hole through a concrete floor would have to be drilled rather than pushed, but Geoprobe installation systems small enough to be used indoors can be obtained. In this type of use, the organic-laden air venting from the top of the well would likely have to be captured and treated in some way to avoid odors or excessive exposure levels in the basement.

The small size of these GCW also recommends them for applications where well cleaning is expected to be necessary because of aggressive growth of biofilm in the wells or the accumulation of ferric precipitates. The small size of the wells means that cleaning them with acids or biofilm removal treatments requires less volume of fluid in each well and less infiltration into the aquifer which must be pulled back into the well to be pumped out for proper disposal. Further, if cleaning should eventually become ineffective, a replacement well can be installed near the plugged one using direct push methods.

\subsection{Recommended other work}

\subsubsection{Pumping relationships}

As with any pumping or injection well, the flow rate through the well is a function of the aquifer permeability, well geometry and pumping head supplied. In this system, the pumping head is supplied by air injection into the bottom of the well with higher air flowrates resulting in a greater pumping head. The relations describing both the head and water flow rate for a given flow of sparged air in a well as well as the amount of flow through the external aquifer for a given well internal performance can be refined. 
The well's performance as a pump (i.e., the pump curve of head generated vs. liquid flow rate generated with air flow rate as a parameter) is affected by the details of well geometry and the air flow regime in the sparger. The design tested in the field used flexible plastic tubing, hanging loosely in the well's center, to carry air to the sparge point at the bottom of the well. Consideration of the effects of that line's diameter, plus the effects of any additional sampling lines also in the same well, on the air and water flow dynamics would be appropriate. These studies might also consider the location of the tubes, for instance whether a central location is preferable to having those tubes held against the inside wall of the well. Similarly, the use of some kind of internal baffles at regular intervals to attempt to break up the rising bubbles may have advantages in increasing the total bubble surface area (hence mass transfer performance for both oxygen and BTEX) and increasing bubble holdup (hence the density driving force which circulates water into and through the well).

This report considered the amount of circulation through the external aquifer that would be obtained with a given amount of head in the well. This was based on an idealized homogeneous aquifer. Development of ways to predict that circulation rate from a known or assumed variability in the aquifer permeability would be valuable. The most direct approach would seem to be the derivation of some form of equivalent length of homogeneous material which could be used in the existing flow formulas.

\subsubsection{Effect of nonvertical wells}

Implicit in the testing of these GCWs has been the idea that they are vertical and that the gas inside them is fairly uniformly distributed across the well cross-section, so that the air-water mixture rises across the entire well. However, if the wells are not vertical, air bubbles will rise to the upward side of the well criss section and then ascend the well clustered against that part of the wall. This situation can then lead to a rapid rise of bubbles and water along the upper wall and a significantly slower, or even downward, flow of water (with no bubbles) along the lower part of the cross-section. Evaluation of the significance of this phenomenon on well performance under the range of conditions likely to encountered in the field may be useful. A deviation from vertical of a few degrees is unlikely to have major effect, but if the well can be intentionally installed at angles of 30 or 45 degrees from vertical it may offer flexibility in installing a row of wells in an area with surface obstructions such as a forest or a gas station. 


\section{REFERENCES}

Allmon, W.E., L.G. Everett, A.T. Lightner, B.A. Alleman, T.J. Boyd, and B.J. Spargo, 1999, Groundwater Circulating Well Technology Assessment, Naval Research Laboratory, NRL/PU/6115-99-384, Washington, DC.

American Wick Drain Corporation. 1997, Company information, Prefabricated Soil Drains.

Bedient, P.B., H.S. Rifai, and C.J. Newell. 1994. Ground Water Contamination. Englewood Cliffs, NJ: Prentice Hall.

Borden, R. C., Natural Bioremediation of Hydrocarbon-Contaminated Ground Water. 1994. Handbook of Bioremediation, Lewis Pub., Boca Raton, FL, pp. 177-199.

Borden, R. C., R. A. Daniel, L. E. LeBrun IV, and C. W. Davis, 1997. Intrinsic Biodegradation of MTBE and BTEX in a Gasoline-Contaminated Aquifer, Water Resources Research,33(5):1105-1115.

Borden, R. C., C. A. Gomez and M. T. Becker. 1995. Geochemical Indicators of Intrinsic Bioremediation, Ground Water, 33(2):180-189.

Chapelle, F.H. 1999. "Bioremediation of petroleum hydrocarbon-contaminated ground water: The perspectives of history and hydrology." Ground Water, 37, no. 1:122-132.

Clayton, C. T., Jr., 2000. Effect of a Modified Groundwater Circulation Wel on a BTEX Contaminated Aquifer, North Carolina State University, MS Thesis in Civil Engineering, Raleigh, NC.

Clement, T.P., 1997. A Modular Computer Code for Simulating Reactive Multispecies Transport in 3Dimensional Groundwater Systems, Pacific Northwest National Laboratory.

Driscoll, Fletcher G., 1986. Groundwater and Wells. St. Paul, Minnesota: Johnson Division.

Fetter, C.W. 1994. Applied Hydrogeology, $3^{\text {rd }}$ Edition. 93-95, 134-137. New York: MacMillan College Publishing Company.

Fidap, version 8.5. 1999. Fluent Inc., Centerra Resource Park, 10 Cavendish Court, Lebanon, NH 03766.

Francois, O., T. Gilmore, M. J. Pinto, and S. M. Gorelick., 1996. "A Physically Based Model for Air-lift Pumping.” Water Resources Research, Vol. 32, no. 8:2383-2399.

Gibbs, Charles W., 1969. Compressed Air and Gas Data. New York, NY: Ingersoll-Rand Company.

Gomez, C. A. 1993. "Characterization of a dissolved hydrocarbon plume.” M.S. Thesis, North Carolina State University, Raleigh, NC. 107 pages.

Gonen, O., and H. Gvirtzman. 1997. "Laboratory-scale analysis of aquifer remediation by in-well vapor stripping: 1. Laboratory results.” Journal of Contaminant Hydrology, 29:23-39.

Govier, G. W., B. A. Radford, and J. S. C. Dunn., 1957. "The Upward Vertical Flow of Air-Water Mixtures." The Canadian Journal of Chemical Engineering. Vol. 35:58-70. 
Griffith, P., 1984., "Multiphase Flow in Pipes.” Journal of Petroleum Technology, March:361-367.

Gvirtzman, H., and S. Gorelick. 1992. "The concept of in situ vapor stripping for removing VOCs from groundwater." Transport in Porous Media, 8:71-92.

Herrling, B., J. Stamm, and W. Buermann. 1991. "Hydraulic circulation system for in situ bioreclamation and/or in situ remediation of strippable contamination." In In Situ Bioreclamation, ed. R.E. Hinchee and R.F. Olfenbuttel, 173-195. Stoneham, MA: Butterworth-Heinemann.

Hinchee, R.E. 1994. "Air sparging state of the art.” In Air Sparging for Site Remediation, ed. R.E. Hinchee, 1-13. Columbus, Ohio: CRC Press.

Johnson, R.L., and P.C. Johnson, D.B. McWhorter, R.E. Hinchee, and I. Goodman. 1993. “An Overview of in situ air sparging." Ground Water Monitoring and Remediation, 13, no. 4: 127-135.

Lee, M. D., R. C. Borden, J. T. Wilson, M. Thomas, P. B. Bedient, and C. H. Ward, Biorestoration of Organic Contaminated Aquifers, CRC Critical Reviews in Environmental Control, 18(1):29-89, 1988.

McDonald, M.G., A.W. Harbaugh, 1983. A Modular Three-Dimensional Finite-Difference Ground-Water Flow Model, US Geological Survey, Techniques of Water-Resources Investigations, Chapter A1Book 6.

Miller, R.R, and D.S. Roote, 1997. In-Well Vapor Stripping, Ground-Water Remediation Technologies Analysis Center, Pittsburg, PA.

Philip, R.D., and G. R. Walter. 1992. "Prediction of flow and hydraulic head fields for vertical circulation wells." Ground Water, 30, no. 5:765-773.

Reisinger, H.L. 1995. "Hydrocarbon bioremediation-An overview." In Applied Bioremediation of Petroleum Hydrocarbons, ed. R.E. Hinchee, J.A. Kittel, and H.J. Reisenger, 1-9. Columbus, Ohio: Batelle Press.

Reynolds, T.D., and P.A. Richards. 1996. Unit Operations and Processes in Environmental Engineering, $2^{\text {nd }}$ Edition. 38-63. Boston: PWS Publishing Company.

Rifai, H., R. C. Borden, J. T. Wilson, and C. H. Ward, 1995, Intrinsic Bioattenuation for Subsurface Restoration, Intrinsic Bioremediation, Battelle Press, Columbus, OH, pp. 1-30.

Roberson, J.A. and Crowe, C.T., 1985, Engineering Fluid Mechanics, 3rd ed., Houghton Mifflin Company, Boston, p. 358.

Rutherford, K.W. and P.C. Johnson. 1996. "Effects of process control changes on aquifer oxygenation rates during in situ air sparging in homogeneous aquifers." Ground Water Monitoring and Remediation, Fall: 132-141.

Schrauf, T. W. and L. H. Pennington, 1995. Design and Application of Alternative Groundwater Sparging Technology. In Situ Aeration: Air Sparging, Bioventing, and Related Remediation Processes, ed. R. E. Hinchee, R. N. Miller, and P. C. Johnson, 145-158. Columbus, Ohio: Battelle Press.

Snoeyink, V.L., and D. Jenkins. 1980. Water Chemistry. 378-386. New York: John Wiley \& Sons. 
Stewart, E.R., 2000. Field Evaluation and Mathematical Modeling of a Direct Push Groundwater Circulation Well System, North Carolina State University, MS Thesis in Marine, Earth and Atmospheric Sciences, Raleigh, NC.

USEPA, 1998, Field Applications of In Situ Remediation Technologies: Ground-Water Circulation Wells, EPA 542-R-98-009, US Environmental Protection Agency, Washington, DC.

Vergonio, M. A. B., 1999. Design of Geotextile Sparging Well for Remediation of a Gasoline Contaminated Aquifer., North Carolina State Univ., MS Thesis in Civil Engineering, Raleigh, NC. 